NBSIR 81-2366

\title{
Method for Assessing Costs of Noise Control Requirements in Multifamily Residential and Educational Buildings
}

U.S. DEPARTMENT OF COMMERCE

National Bureau of Standards

National Engineering Laboratory

Center for Building Technology

Building Economics and Regulatory Technology Division

and Environmental Design Research Division

Washington, DC 20234

December 1981

Prepared for

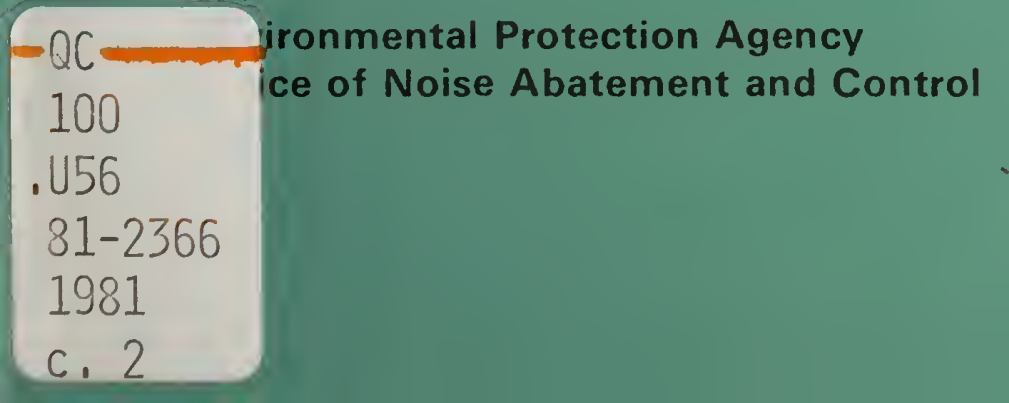



U.S. DEPARTMENT OF COMMERCE

National Bureau of Standards

National Engineering Laboratory

Center for Building Technology

Building Economics and Regulatory Technology Division and Environmental Design Research Division

Washington, DC 20234

December 1981

Prepared for

Environmental Protection Agency

Office of Noise Abatement and Control

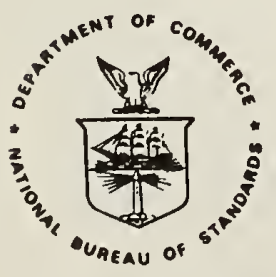

U.S. DEPARTMENT OF COMMERCE, Malcolm Baldrige, Secretary NATIONAL BUREAU OF STANDARDS, Ernest Ambler, Director 



\begin{abstract}
This report presents a methodology developed to measure the cost impacts of acoustical performance requirements for new buildings. The methodology can be applied to a wide range of noise control requirements. The cost items addressed by this methodology are expected changes in construction costs, the cost of acoustical cesting to certify levels cf performance, code administration costs, and energy savings due to modifications of the building envelope. The building components considered, which are those most commonly affected by noise control requirements, are doors, windows, interior walls, exterior walls, and floor/ceiling assemblies. The basic cost assessment methor consists of linear cost estimation equations for most component designs commonly used in educational and multifamily residential buildings. Each equation relates the acoustical performance of the design to its construction cost so that construction costs associated with alternate levels of acoustical performance can be compared. The methodology also includes a cost minimization model useful for selecting the least-cost design for a particular level of acoustical performance.
\end{abstract}

Keywords: acoustical design; acoustics; architectural design; building codes; building economics; construction costs; cost minimization; economic impact; economics; energy; model code; noise control. 


\section{PREFACE}

The research leading to this report was conducted by the Applied Economics Group and the Building and Community Acoustics Group in the Center for Building Technology, National Engineering Laboratory, at the National Bureau of Standards. The effor: was sponsored by the V.S. Environmental Protection Agency, Office of Noise Abatement and Control (ONAC) under the Interagency Agreement, "Method for Assessing Impacts of a Model Noise Control Code," dated August 9, 1979.

The authors are grateful to Casey Caccavari, Joseph Montgomery, and Frank Pesce of ONAC for the encouragement and suggestions they provided throughout the research effort. The authors have benefited also from the many helpful comments made by the NBS reviewers of the report: William Danner, James Gross, Harold Marshall, Heinz Trechsel, and Simone Yaniv. Special credit is due to Anne Hillstrom for verifying the numerical examples and editing several drafts of the report. The authors are also grateful to the staff of the Word Processing Center for the many hours of typing needed to bring the report to camera-ready form. 
1. INTRODUCTION $\ldots \ldots \ldots \ldots \ldots \ldots \ldots \ldots \ldots \ldots \ldots \ldots \ldots \ldots \ldots \ldots \ldots \ldots \ldots \ldots$

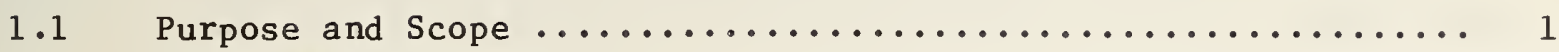

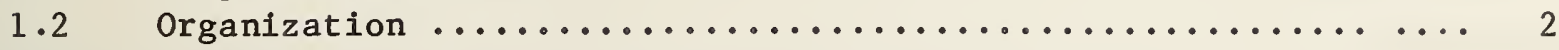

2. MODEL NOISE CONTROL CODE PROVISIONS $\ldots \ldots \ldots \ldots \ldots \ldots \ldots \ldots \ldots \ldots \ldots \ldots \ldots$

2.1 Outdoor Noise Isolation and Acoustical Privacy ........... 4

2.2 Impact Noise Isolation and Mechanical Equipment Noise ....... 6

3. ANALYTICAL APPROACH $\ldots \ldots \ldots \ldots \ldots \ldots \ldots \ldots \ldots \ldots \ldots \ldots \ldots \ldots \ldots \ldots \ldots \ldots$

3.1 Relationship between Construction Cost and Sound

Transmission Class ............................. 8

3.1.1 Establishing Component Design Categories ........... 8

3.1 .2 Architectural Design Variations ................. 9

3.1 .3 Derivation of Cost Estimating Equations ............ 10

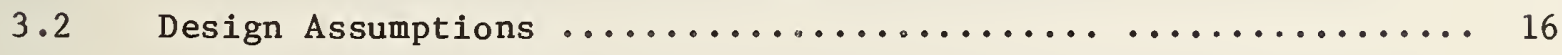

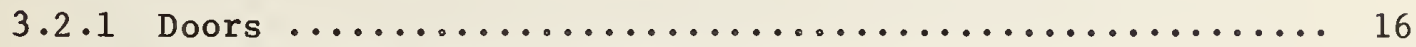

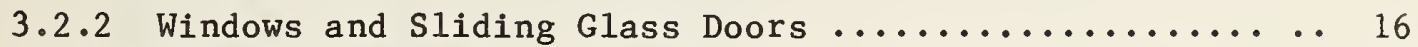

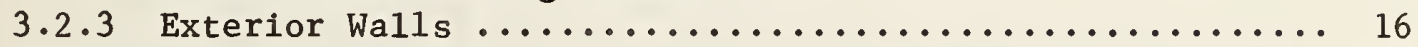

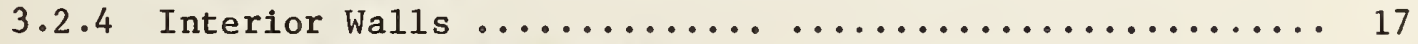

3.2 .5 Floor/Ceiling Assemblies ..................... 17

4. APPLICATION OF COST EQUATIONS TO BUILDING COMPONENTS ............ 18

4.1 Single Component Applications $\ldots \ldots \ldots \ldots \ldots \ldots \ldots \ldots \ldots \ldots \ldots \ldots \ldots$

4.2 Multi-Component Applications ..................... 20

4.2.1 Data Required to Determine the Minimum Constructon Cost

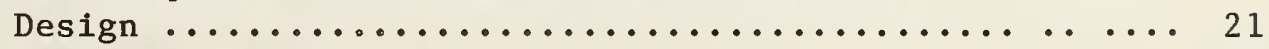

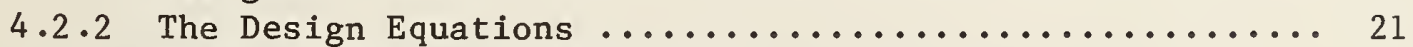

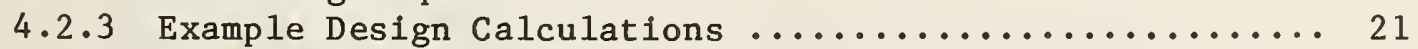

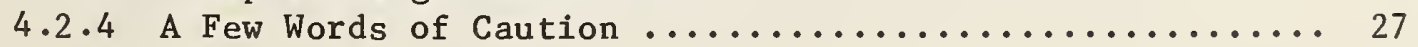

5. ENERGY SAVINGS AND NON-CONSTRUCTION $\operatorname{cosTS} \ldots \ldots \ldots \ldots \ldots \ldots \ldots \ldots$

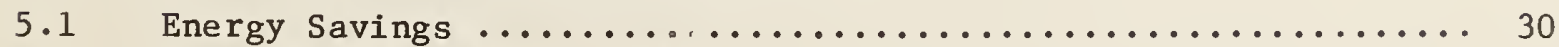

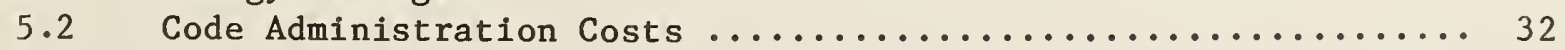

5.2 .1 Overview of Administrative Requirements .......... 32

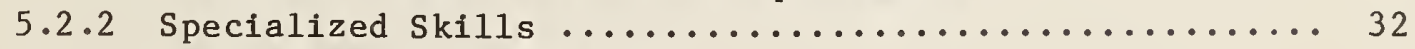

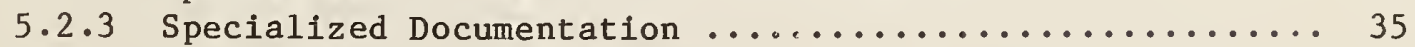

5.2 .4 The Experience of San Diego ................... 36 
TABLE OF CONTENTS (Continued)

Page

5.3 Acoustical Testing Costs for Acceptance .............. 37

6. CONCLUSION ...................................... 41

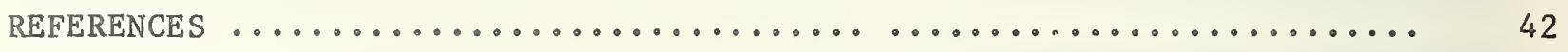

Appendix A: COST ESTIMATING EQUATIONS FOR BUILDING COMPONENTS ...... A-1

Appendix B: ADJUSTING FOR REgIONAL CONSTRUCTION COST DIFFERENCES ..... B-1

Appendix C: DESIGN OF MINIMUM COST MULTI-GOMPONENT WALLS TO ACHIEVE A

SPECIFIED LEVEL OF NOISE INSULATION ............... C-1 
Table 2.1 Model Noise Control Provisions Developed by Bolt,

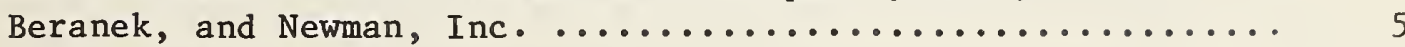

Table 2.2 Model Noise Control Code Specifications (Decibels) for Outdoor Noise Isolation and Acoustical Privacy ........... 5

Table 2.3 Major Building Components Affected by the Outdoor Noise Isolation and Acoustical Privacy Provisions of the MNCC ..... 7

Table 3.1 Acoustical Performance and Cost Data Used in the Regression

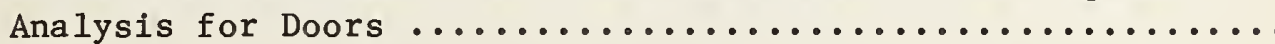

Table 3.2 Estimated Regression Coefficients and Relevant Cost and STC Ranges for each Component Design Category ............ 14

Table 4.1 Minimum Cost Equations for a Two Component Wall Design ..... 22

Table 4.2 Minimum Cost Equations for a Three Component Wall Design .... 22

Table 5.1 Code Administration Functions Required for Analysis, Plan Review, and Acceptance According to the Model Noise Control Code ..................................

Table 5.2 Model Noise Control Code Acceptance Testing Requirements for

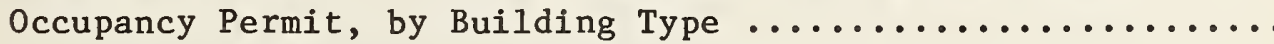

Table B.1 Regional Cost Adjustment Factors (RCAF) for Major U.S. Cities ............................... B -2

Table C.1 Detailed Calculation Results for Design No. 1........... C-19

Table C.2 Calculations for Example Problem for Minimum Cost STC Design Range ..................................... -25

Table C.3 Calculations for Example Problem for Varying Door STC

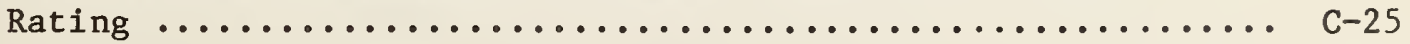


Figure 3.1 Scatter Plot of Data Points and Least Squares Linear

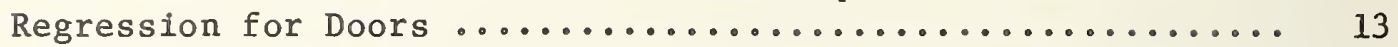

Figure 4.1 Selection of Specific Designs Relative to the Optimum

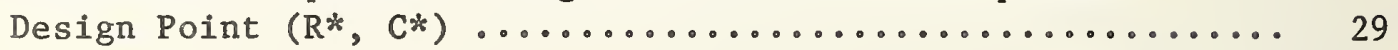

Figure C.1 Example Calculation Using Equation (C.25) to Illustrate the Effect of Varying Glazing Area ..........................

Figure C.2 Example Calculation Using Equation (C.29) to Illustrate Minimum Cost Design with a Single Fixed Component ........... C-26 
CONVERSION FACTORS FROM CUSTOMARY TO METRIC (SI) UNITS

\begin{tabular}{llll}
\hline Quantity & To Convert From & To & Multiply By \\
\hline $\begin{array}{l}\text { length } \\
\text { area }\end{array}$ & linear foot $(\mathrm{f})$ & meter & $3.048 \times 10^{-1}$ \\
energy & square foot $(\mathrm{sf})$ & square meter & $9.290 \times 10^{-2}$ \\
U-value & Btu $/ \mathrm{hr} / \mathrm{sf} / \Delta^{\circ} \mathrm{F}$ & joule & $1.055 \times 10^{8}$ \\
price & dollars $/$ square foot & watt $/ \mathrm{m}^{2} / \Delta^{\circ} \mathrm{C}$ & 5.678 \\
& $\begin{array}{l}\text { dollars } / \text { square } \\
\text { meter }\end{array}$ & $1.076 \times 10^{1}$ \\
\hline
\end{tabular}





\section{INTRODUCTION}

\subsection{PURPOSE AND SCOPE}

The purpose of this report is to present a standard methodology for measuring selected economic impacts of acoustical performance requirements for new educational and multifamily residential buildings. The primary economic impacts address-d by this assessment method are those related to costs. The most important costs are the additional construction costs estimated to result from complying with new acoustical performance requirements of proposed code provisions. Two other cost items are discussed in general terms: the costs for acoustical testing to certify compliance, and the administrative costs attributable to acoustical performance provisions.

The major benefit expected from acoustical performance provisions, namely an improved acoustical environment in multifamily residences and educational facilities, is not addressed by the assessment method presented in this report. Efforts to relate changes in property values or rental rates to improved acoustical performance in residences are recommended for future research. There is some discussion of one important benefit that under certain circumstances could result from new acoustical performance provisions: the value of energy savings due to modifications in the exterior envelope of the building.

In order to illustrate the cost assessment method, a particular sound transmission control code, called the Model Noise Control Code (MNCC), 1 is used. This proposed model code was developed by the acoustical consulting firm of Bolt, Beranek, and Newman, Inc. (BBN) under the sponsorship of the Environmental Protection Agency. 2 Unique to the MNCC are variable performance requirements based on expected noise levels surrounding the buildings in question. In contrast, current building noise control provisions in the Appendix of the Uniform Building Code, ${ }^{3}$ have fixed performance requirements regardless of the amount of noise in the building's environment. As described in the BBN reports, the MNCC could be substituted for the current building noise control provisions contained in the Appendix, Chapter 35, "Sound Transmission Control," of the Uniform Building Code. The performance requirements

1 The selection of the MNCC to illustrate the impact assessment method should not be construed as an endorsement by NBS or the authors. One code was needed for an example code in order to show how the methodology works. The MNCC is general enough for all aspects of the methodology to apply to it, and specific enough to show how the methodology can be applied to a particular code.

2 The Model Noise Control Code (MNCC) developed by Bolt, Beranek, and Newman Inc. $(B B N)$ is presented in two reports: Noise Control for Building Codes: Model Noise Control Provisions (No. 3759), and Implementation Manual (No. 3837) (Cambridge, Mass., Bolt, Beranek, and Newman, Inc., 1978).

3 International Conference of Building Officials, Uniform Building Code (Whittier, CA: International Conference of Building Officials, 1979), Appendix, Chapter 35, "Sound Transmission Control," pp. 668-669. 
of the MNCC are restricted to residential multifamily and educational building applications.

The methodology presented here consists of the application of linear cost functions which were estimated for the designs most commonly used for the door, window, wall, and deck assemblies of residential and educational buildings. Each cost function relates the acoustical performance of each assembly design to its corresponding construction cost. Moreover, each function explicitly presents an estimate of the extra construction cost required for a unit increase in the acoustical performance of a design. Thus these cost functions provide a method to estimate and compare the construction costs of a design under two alternative levels of acoustical performance: (1) that called for by existing requirements or current construction practice; and (2) whatever alternative acoustical performance level is being proposed. The linear cost functions that are presented in this report cover only the most commonly used designs and materials for which reliable acoustical performance and cost data were available at the time the analysis was conducted. To apply the methodology to other designs, specific cost estimating functions need to be developed.

In addition to the analysis of the building code provisions governing sound transmission control, the methodology presented here has two other useful applications. First, the methodology is general enough to assess the costs of changing the acoustical performance levels of building components regardless of whether the specifications being analyzed are contained in a building code. This is because a wide range of acoustical performance values and their corresponding construction costs were obtained and used as the data base in estimating the cost functions for those designs analyzed here. The ranges of acoustical performance values used for the designs are sufficiently broad to cover both current construction practice as well as most increases in recommended acoustical performance levels likely to occur in the near term. Moreover, for designs not covered by the cost functions presented here, the basic methodology can be used to derive the appropriate cost functions.

The other useful application of the methodology is that it can provide architects and builders with valuable information about the cost consequences of designing buildings to alternative levels of acoustical performance. Indeed, a special cost minimization model is presented which guides architects to select the least-cost combination of levels of component acoustical performance when a single performance criterion addresses more than one building component. This least-cost solution can be found for any specific acoustical performance criterion using a hand calculator.

\subsection{ORGANIZATION}

Section 2 of this report begins with an overview of the specific provisions of the acoustical performance code used to illustrate this methodology, the MNCC, and identifies the types of buildings affected by each provision. The detailed acoustical performance requirements specified in the MNCC provisions are presented in tabular form and interpreted. Then the major building envelope components affected by the MNCC provisions are identified. 
Section 3 contains a description of the analytical procedure used to develop the cost assessment methodology. First, the underlying assumptions are explained for categorizing the component designs used in developing the cost functions. Next, the procedure used to derive the cost functions is presented in detail along with a discussion of the statistical measures used to describe the underlying regression results. The assumptions needed to assure appropriate usage of the cost functions are also explained. The section concludes with a detailed description of each of the five major building components addressed by this methodology.

Section 4 describes how the cost equations are to be applied in estimating the additional construction costs due to increases in the acoustical performance requirements of a building. The first subsection deals with the simple case of an acoustical performance requirement which affects the design and construction of a single homogentous building component. The second subsection treats the complex case of a performance requirement simultaneously affecting more than one building component.

Section 5 discusses non-construction related costs and the value of energy savings that may result from certain acoustical performance provisions. A technique is presented for estimating the possible energy saving benefits from acoustical improvements in window designs. The non-construction related costs are of two categories: one for the costs of acoustical testing of a completed building, and the other for the costs of administering the code. These cost items are treated separately to allow the measures to be applied only when appropriate to the particular noise control code being evaluated.

There are three appendixes to this report, the first two of which provide data needed to apply the methodology. Appendix A contains the technical specifications for each assemly design, the estimated linear cost equations, and statistical measures of how well the equations represent the relationship between cost and acoustical performance. Appendix B presents a table of regional cost adjustment factors and illustrates how to apply these factors to account for regional construction cost differences. Appendix C provides a detailed derivation and formulation of the cost-minimizing model for multi-component designs. 


\section{MODEL NOISE CONTROL CODE PROVISIONS}

This section reviews the provisions of the MNCC used to illustrate the cost assessment method and identifies the building types and major building envelope components affected by those provisions. Our purpose here is to provide the reader with a brief description of the MNCC sections which are specifically addressed by the methodology. For more elaborate details on these MNCC provisions, the $B B N$ reports prepared for the Environmental Protection Agency should be consulted.1

\subsection{OUTDOOR NOISE ISOLATION AND ACOUSTICAL PRIVACY}

Table 2.1 presents the titles of the four MNCC provisions and indicates the building types affected by each. The first two provisions, Outdoor Noise Isolation and Acoustical Privacy, both govern the transmission of airborne noise into and within buildings. It is expected that these provisions would account for most of the increased cost resulting from widespread adoption of the MNCC. The acoustical provisions contained in building codes today are generally presented in terms of a fixed acoustical performance requirement. 2 In contrast, the airborne noise requirements of the MNCC vary as a function of the outdoor acoustical environment. This acoustical environment is measured in decibels of outdoor Day-Night Sound Level (DNL) which is defined as "...the equivalent A-weighted sound level during a 24-hour period with 10 decibels added to the equivalent A-weighted sound level during the nighttime hours (10:00 p.m. to $7: 00 \mathrm{a} \cdot \mathrm{m} \cdot) \cdot " 3$

The Outdoor Noise Isolation provision (section 3507) imposes outdoor noise isolation requirements on the exterior shell of the building. It affects both multifamily residential and educational buildings exposed to outdoor DNL values greater than $60 \mathrm{~dB}$. As indicated in table 2.2, the outdoor noise isolation requirements vary directly with changes in the DNL ranges.

The Acoustical Privacy provision (section 3504) imposes performance requirements for airborne noise transmission reductions for multifamily residential and educational buildings. These noise transmission reduction requirements distinguish two types of acoustical privacy provided by building separations (e.g•, floors/ceilings or interior walls): (1) Interior Private to Private dwelling

1 Bolt, Beranek, and Newman, Inc., Reports 3759 and 3837.

2 For an overview of various noise control codes currently in effect, see Bolt, Beranek, and Newman, Inc. Interim Report 3547, task 1: Development of Noise Control Requirements for Model Building Code (Cambridge: Bolt, Beranek, and Newman, Inc., 1977), pp. 15-20.

3 Bolt, Beranek, and Newman, Inc., Report No. 3759, p. 27. A-weighting is a system of weights which gives relative importance to each frequency range in accordance with human hearing. 
Table 2.1 Model Noise Control Provisions Developed by Bolt, Beranek, and Newman, Inc.

\section{Provision}

Outdoor Noise Isolation (sec. 3507)

Acoustical Privacy (sec. 3504)

Impact Noise Isolation (sec. 3505)

Mechanical Equipment Noise (sec. 3506)
Buildings Affecteda

R E

R E

R

R E

a Key: $\mathrm{R}=$ Multifamily high-rise, low-rise, and townhouse buildings.

$\mathrm{E}=\mathrm{All}$ educational buildings.

Table 2.2 Model Noise Control Code Specifications (Decibels) for Outdoor Noise Isolation and Acoustical Privacy

If Outdoor

Day-Night

Sound Level
Outdoor Noise

Isolation

(sec. 3507)

Outside to Insidea
Acoustical Privacy

(sec. 3504)

$>\quad$ Outside to Inside ${ }^{a}$

50

$50 \quad 55$

5560

$60 \quad 65$

$65 \quad 70$

$70 \quad 75$

$75 \quad 80$

80
$-$

$-$

$-$

20

25

30

35
Public To

Private ${ }^{\mathrm{b}}$

55

50

45

40

40

40

40
Private To Private ${ }^{b}$

60

55

50

45

45

45

45

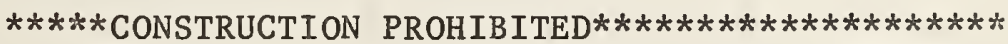

a The difference, in decibels, between the outdoor equivalent A-weighted sound level and the corresponding equivalent A-weighted sound level in the receiving space.

b The Normalized Sound Level Difference as defined in Bolt, Beranek, and Newman, Inc., Report No. 3759, p. 29. The MNCC recommends that these values be increased $5 \mathrm{~dB}$ when using $\mathrm{STC}$ as the design requirement. 
unit separations (party walls); and (2) Interior Public to private dwelling unit separations.

These requirements vary inversely with changes in the outdoor DNL within a range from $60 \mathrm{~dB}$ and lower. These requirements, however, become constant above $60 \mathrm{~dB}$.

The predominant construction cost impacts of the performance requirements for Outdoor Noise Isolation and Acoustical Privacy given in table 2.2 affect five different building components. 1 Table 2.3 lists these components and indicates which provisions affect each component. The exterior walls are affected by the Outdoor Noise Isolation provision. Windows and doors are affected by both provisions. Interior walls and floor/ceiling assemblies are affected only by the Acoustical Privacy provision.

\subsection{IMPACT NOISE ISOLATION AND MECHANICAL EQUIPMENT NOISE}

The other two provisions listed on table 2.1 are Impact Noise Isolation and Mechanical Equipment Noise. The Impact Noise Isolation provision (section 3505) calls for prescriptive compliance with a Construction Handbook of approved designs for impact noise reduction. 2 This provision could not be addressed by the methodology presented in this report because the proposed Construction Handbook of acceptable designs has not yet been prepared. If this provision were implemented it would primarily affect multifamily residential buildings.

The fourth provision addresses Mechanical Equipment Noise (section 3506). This provision requires that both multifamily residential and educational buildings control the noise transmission of various building machinery and appliances.

The Mechanical Equipment Noise provision specifies that the A-weighted sound levels produced by the operation of mechanical equipment be no greater than $45 \mathrm{~dB}$ in any dwelling unit of guest room. It also specifies that operation of appliances produce an A-weighted sound level no more than $70 \mathrm{~dB}$ and food waste disposals no more than $88 \mathrm{~dB}$.

1 The Outdoor Noise Isolation requirement may also affect the construction cost of roofs. This component is not included in the analysis since its impact on the entire cost of a high-rise building is likely to be minimal.

2 For justification of the use of prescriptive rather than performance requirements for Impact Noise Isolation see Bolt, Beranek, and Newman Inc., Report 3759 , p.45. 
Table 2.3 Major Building Components Affected by the Outdoor Noise Isolation and Acoustical Privacy Provisions of the MNCC.

\begin{tabular}{lcc} 
Building Component & $\begin{array}{c}\text { Outdoor Noise } \\
\text { Isolation Provision }\end{array}$ & $\begin{array}{c}\text { Acoustical } \\
\text { Exteriogacy Provision }\end{array}$ \\
\cline { 2 - 3 } Windows & $\mathrm{X}$ & $\mathrm{X}$ \\
Doors & $\mathrm{X}$ & $\mathrm{X}$ \\
Interior Walls (Partitions) & $\mathrm{X}$ & $\mathrm{X}$ \\
Floor/Ceiling Assemblies & & $\mathrm{X}$ \\
\hline
\end{tabular}


This section describes the approach used to determine the functional relationship between construction cost and acoustical performance and presents the limitations that should be noted when these equations are applied to assess economic impacts. The first subsection covers the basic approach and data sources used in estimating construction costs and acoustical performance levels of building component designs. The approach includes a procedure for categorizing designs and regressing construction cost on acoustical performance for each design assembly. The second part of this section discusses how to use the derived cost equations to assess impacts of noise control provisions on the affected building components.

\subsection{RELATIONSHIP BETWEEN CONSTRUCTION COST AND SOUND TRANSMISSION CLASS}

This subsection is based on the premise that a direct relationship exists between the construction cost and acoustical performance levels of the building components affected by noise requirements. It explains how the categories for design assemblies were established, how individual designs were varied within each category, and how the cost equations were derived for each category.

The measure of acoustical performance for building components used in this methodology is the Sound Transmission Class (STC). This measure is defined as "... a single-number rating of the airborne sound insulation of a specific partition (party wall or floor/ceiling construction), derived from sound transmission loss values in accordance with procedures of ASTM E413-73, 'Determination of Sound Transmission Class."I STC is a laboratory measurement taken under ideal conditions. The application of these measured values to field conditions requires the assumption that the quality of workmanship is controlled at the construction site.

\subsubsection{Establishing Component Design Categories}

When the cost and STC values of all documentable architectural designs for a given component are displayed in a single scatter diagram, the reiationship between the two variables remains unclear. When the diverse designs are grouped into more closely defined homogeneous categories, however, the direct effect of acoustical performance on cost becomes quite apparent. These groups of homogeneous designs are called Component Design Categories (CDC) and are formed by limiting the range of variation of key design characterstics such as general aesthetic appearance, and structural loading performance. In this way the statistical analysis within each CDC is allowed to focus on the central question addressed by the cost assessment methodology: the effect of varying STC on construction cost. Because of the grouping procedure, the cost assessment method cannot be used to make acoustical performance/cost trade-offs between two different $\mathrm{CDC}^{\prime} \mathrm{s}$, but rather is limited to analyzing such trade-offs only within a single CDC.

1 Bolt, Beranek, and Newman, Inc。, Report 3759, p. 30. 


\subsubsection{Architectural Design Variations}

Within each established CDC, specific currently available designs were selected to represent a broad range of STC values. For each of these architectural designs, data on construction cost per unit area and STC were gathered from a number of published sources. The cost data for floor/ceiling assemblies and exterior and interior walls were taken from the Design Cost File. 1 The cost data for doors and windows were taken from the Eastern Edition of both of these sources, which means they are based on construction costs in Philadelphia. To find costs in other cities, the regional cost indexing system provided by the Building Cost File is presented in Appendix $C$ of this report. This cost indexing can be used to adjust the Philadelphia-based costs of acoustical performance reported in Appendix A to the equivalent cost in any one of $122 \mathrm{U} . \mathrm{S}$. cities.

The STC data were collected from various sources. Exterior and Interior wall data are from the Design Cost File. The STC data on doors are from three sources: a National Bureau of Standards publication entitled, Acoustical and Thermal Performance of Exterior Residential Walls, Doors, and Windows; the Building Cost File; and a National Institute for Occupational Safety and Health Report entitled Compendium of Materials for Noise Control. 3 STC values for windows are based on an estimating procedure using separate equations for single pane and for double pane glazing.

$$
\begin{array}{ll}
\text { Single pane: } & \text { STC }=38.3+10.5 \log _{10}(\mathrm{~h}) \text {, for } 3 / 32 \leq \mathrm{h} \leq 1.0 \\
\text { Double pane: }{ }^{4} & \text { STC }=42.4+10.93 \log _{10}(\mathrm{H})+10.77 \log _{10}(\mathrm{~d}), \\
& \text { for } 9 / 32 \leq \mathrm{H} \leq 1 / 2 \text { and } 3 / 4 \leq \mathrm{d} \leq 6.0
\end{array}
$$

1 McKee-Berger-Mansueto, Inc., Design Cost File (New York: Von Nostrand Reinhold Company, 1979), pp. 129-218.

2 McKee-Berger-Mansueto, Inc., Building Cost File (New York: Von Nostrand Reinhold Company 1978), pp. 5-186. The cost per unit area of each building component is derived on the basjs of the published unit costs for the elements of each component. To assure comparability, these 1978 data were adjusted to 1979 dollars using the method of adjusting for construction cost changes that is discussed and illustrated in subsection 4.1, below.

$3 \mathrm{H}$. J. Sabine et al., Acoustical and Thermal Performance of Exterior Residential Walls, Doors, and Windows, Building Science Series 77 (Washington, D.C.: National Bureau of Standards, 1975), pp. 122-147; and Robert A. Hedeen, Compendium of Materials for Noise Control, DHEW (NIOSH) Report 80-116 (Washington, D.C.: Department of Health, Education, and Welfare, National Institute of Occupational Safety and Health, May 1980), p. 81 .

4 The data on which this estimating procedure for double glazing is based was taken from J. D. Quirt, Measurement of Sound Transmission Loss of Windows, Building Research Note No. 172 (Ottawa, Canada: National Research Council of Canada, 1981). 
where

$\mathrm{h}=$ pane thickness (inches);

$\mathrm{H}=$ total pane thickness of the two panes (inches); and

$\mathrm{d}=$ air space thickness (inches).

STC data for floor/ceiling assemblies were estimated with the use of an itemized list of basic design materials found in the Design Cost File and some basic architectural designs found in A Guide to Airborne, Impact, and Structure Borne Noise-Control in Multifamily Dwellings. 1 The basic deck designs are varied slightly with different materials in order to achieve sufficient variation in STC levels to establish a relationship between cost and acoustical performance.

\subsubsection{Derivation of Cost Estimating Equations}

This subsection presents the analysis of the relationship between construction cost and STC for the five major building components expected to be affected by noise control requirements. The components analyzed are: (1) doors; (2) windows and sliding glass doors; (3) exterior walls; (4) interior walls; and (5) floor/ceiling assemblies. The relationships presented here are expressed as linear equations; with construction cost being a linear function of the STC level. These equations are to be used to develop an estimate of the cost impact of a given change in the STC level required for a particular building component. Each equation represents one particular CDC.

For each individual design within a particular $C D C$, the construction costs and the STC values were established based on the data sources discussed above in subsection 3.1.2. Using this data on cost and STC, a least squares regression line was calculated for each CDC according to the following format:

$$
\operatorname{Cos} t=A+B \cdot S T C \text {, }
$$

where $\mathbf{A}=$ the intercept of the equation; and

$B=$ the slope of the equation.

To illustrate how this was done, consider the regression for doors. Table 3.1 shows the acoustical performance levels and construction costs for the nine doors used in the regression. Both wood and metal doors were used, either hollow or solid, all with steel frames and weatherstripping, all with the same $3 \times 7$ foot dimensions and some with added soundproofing. When the least squares regression was calculated, the following equation for the regression line resulted:

$$
\text { Cost }=0.77+0.462 \cdot \operatorname{STC}
$$

1 R. D. Berendt, G. E. Hinzer and C. B. Burroughs, A Guide to Airborne, Impact, and Structure Borne Noise-Control in Multifamily Dwellings (Washington, D.C.: National Bureau of Standards, 1967), ch. 6., p.7. 
Table 3.1 Acoustical Performance and Cost Data Used in the Regression Analysis for Doors

(1) Interior, hollow core wood door with rotary natural birch veneer

(2) Interior, solid core wood door with rotary natural birch veneer

(3) Hollow, 18 gauge metal door

(5) Interior, solid core door rotary natural birch veneer and soundproofing

(6) Hollow, 14 gauge metal door

(7) Hollow, 12 gauge metal door

(8) Interior, solid core door with rotary natural birch veneer and soundproofing

(9) Interior, solid core door with rotary natural birch veneer and soundproofing
20

27

33

35

36

0

11.47

13.56

15.29

15.79

18.97

37

16.62

41

17.14

42

19.79

51

26.94

a Each door is $3^{\prime} \times 7^{\prime}$ or 21 sf with a hollow metal door frame, an aluminum threshold with interlocking weatherstripping, and $17 \mathrm{ft}$ of zinc weatherstripping. Doors (1) through (8) are all $13 / 4$ inches thick, while door (9) is $21 / 4$ inches thick. The density of the core material in doors (5) and (8) is the only factor that distinguishes the two from each other.

b The STC values for doors (1) and (2) are from H. J. Sabine, et al., pp. 127-147. The STC values for doors (3), (4), (6) and (7) are from equation 49.A in Robert A. Hedeen, p. 81. The STC values for the remaining doors are from Building Cost File, p. 91.

c All cost data are estimated from Building Cost File, pp. 88-101. 
Figure 3.1 shows graphically the data points and resulting regression line. Each point represents the construction cost and STC level of a particular door. The slope of the line, $B=0.462$, measures the rate of change in cost per unit change in STC and is interpreted as the marginal construction cost of a oneunit increase in the STC level. This equation ( 3.4$)$ would be used to determine cost increases resulting from a noise control code provision by multiplying a provision's required STC improvement by B. Thus, for example, if an MNCC provision required an STC improvement for doors of 5 , then the additional construction cost would be $5 \times 0.462$ or $\$ 2.31$ per square foot of door.

The results of the regression analyses for all of the CDCs are summarized in table 3.2. For each CDC name, the intercept, the slope, and the ranges of relevant values covered by each regression in terms of STC and Cost are given. For example, CDC 3.2 (Stud Frame Walls with Stucco Exterior) would be estimated to cost $\$ 4.08 /$ sf if STC of 40 were required.1 Moreover, if a new noise control code called for improving the acoustical performance of the same wall from an STC of 40 to an STC of 45, the additional construction cost would be estimated to be about $\$ 0.26 /$ sf. 2

In Appendix A, results of the regression analysis are presented in detail. For each CDC a description is provided of all the variations in materials specifications and construction techniques used to establish a range of STC values. The number of distinct STC design values analyzed and the range of STC values covered by those designs are also reported for each CDC. In addition to the estimated coefficients of the least squares regression line, two other statistics are reported which indicate the validity and reliability of the relationship. The t-statistic for the slope of each regression equation is presented in parentheses directly below the slope coefficient. This statistic is the ratio of the slope to its own standard error and provides a measure of whether the estimated slope value is significantly different from zero.

[Note that a zero slope would imply that there is no relationship between construction cost and STC values.] The degree of confidence to be placed on the significance of the slope coefficient is indicated by the asterisk(s) following the parentheses. A single asterisk means 95 percent level while a double asterisk means a 99 percent level of confidence. Of all the equations presented in this report 84 percent have 99 percent confidence levels and the rest have 95 percent levels.

In addition to the test for significance on the slope coefficient, the adjusted $\mathrm{R}^{2}$ (multiple correlation coefficient) is also presented for each CDC. This statistic is a measure of the goodness of fit of the regression line to the data, adjusted for the number of specific designs analyzed in the regression. The direct interpretation of $\mathrm{R}^{2}$ is the proportion of variation in construction cost explained by the STC values. Thus an $R^{2}$ of 0.9 would indicate that 90 percent of the variation in cost among these designs is accounted for by STC values. All but one of the equations reported in Appendix A have

\footnotetext{
$12.00+0.052(40)=4.08$.

$20.052(5)=0.26$.
} 


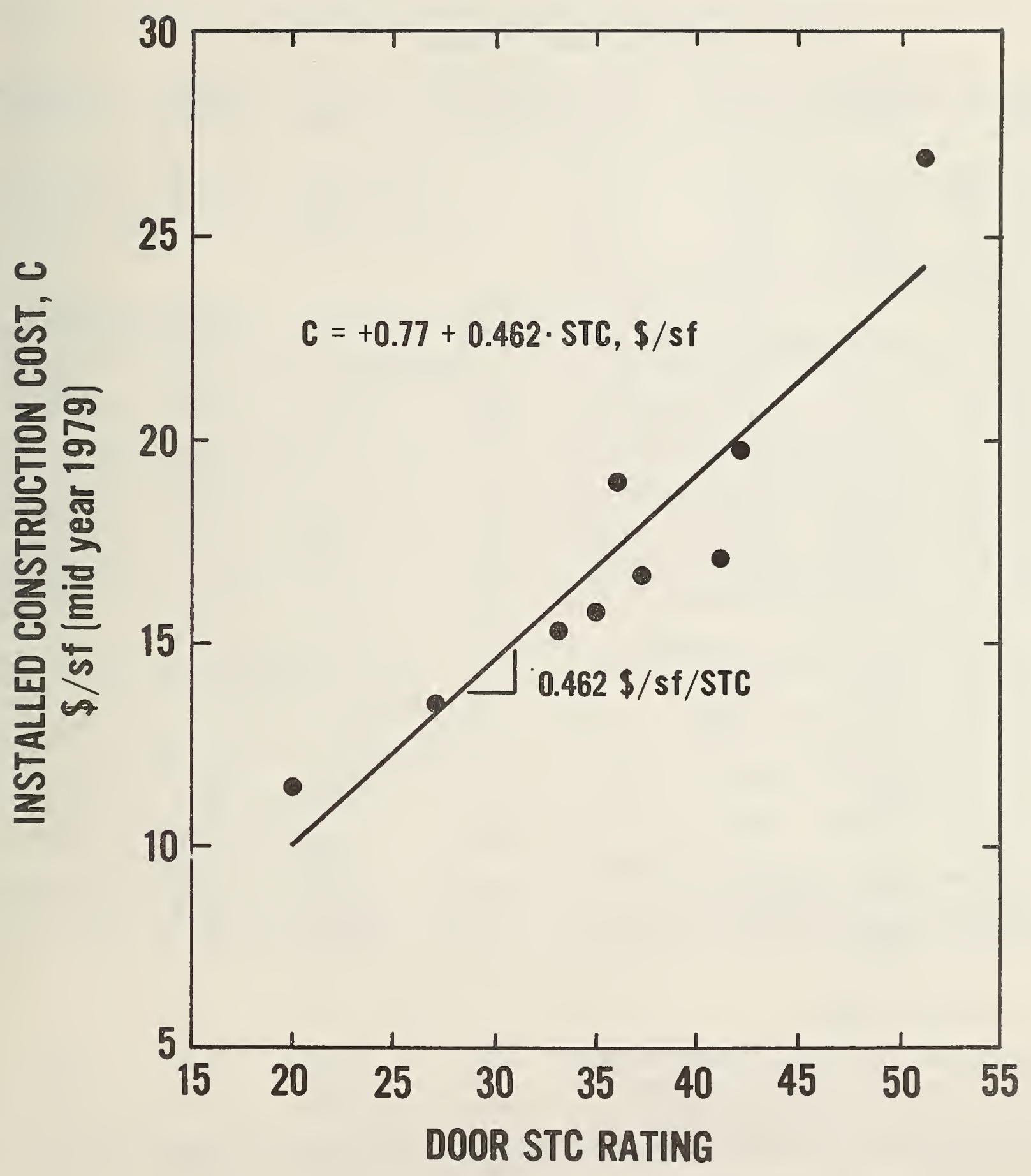

Figure 3.1 Scatter Plot of Data Points and Least Squares Linear Regression for Doors. 
Table 3.2 Estimating Regression Coefficients and Relevant Cost and STC Ranges for each Component Design Category. (Continued)

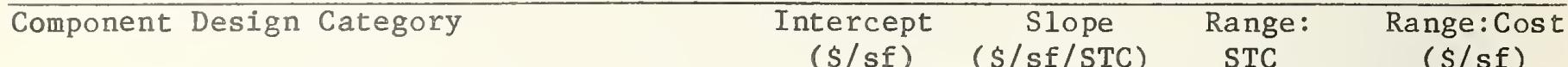

\section{Doors}

1.1 Wood or Metal Doors

Windows

2.1 Aluminum Frame Fixed Sheet or Plate Glass

2.2 Aluminum Frame Fixed Tempered Glass

2.3 Steel Frame Fixed sheet or Plate Glass

2.4 Steel Frame Fixed Tempered Glass

2.5 Aluminum Frame Pivoting Casement Sheet or Plate Glass

2.6 Aluminum Frame Pivoting Casement Tempered Glass

2.7 Steel Frame Pivoting Casement Sheet or Plate Glass

2.8 Steel Frame Pivoting Casement Tempered Glass

2.9 Aluminum Frame Double Hung Sheet or Plate Glass

2.10 Aluminum Frame Double Hung Tempered Glass

2.11 Steel Frame Double Hung Sheet or Plate Glass

2.12 Steel Frame Double Hung Tempered Glass

2.13 Aluminum Frame Horizontal Sliding Sheet or Plate Glass

2.14 Aluminum Frame Horizontal Sliding Tempered Glass

\section{Exterior Walls}

3.1 Stud Frame with Wood Siding Exterior

3.2 Stud Frame with Stucco Exterior

3.3 Stud Frame with Aluminum Siding

3.4 Stud Frame with 22 Gauge Metal Siding Exterior

3.5 Stud Frame with Brick Veneer

3.6 Cast in Place Concrete

3.7 Concrete Wall with Brick Veneer

3.8 Concrete Block

3.9 Concrete Block without large Coat, with Brick Veneer

3.10 Concrete Block with Parge Coat \& Brick Veneer
0.77

0.462

$20-51$

$10.01-24.33$

$\begin{array}{rlrr}-13.10 & 0.940 & 29-47 & 14.16-31.08 \\ -6.44 & 0.811 & 31-47 & 18.70-31.68 \\ -13.48 & 0.788 & 29-47 & 9.37-23.56 \\ -8.13 & 0.717 & 31-47 & 14.10-25.57 \\ -12.74 & 0.945 & 29-47 & 14.67-31.68 \\ -7.97 & 0.881 & 31-47 & 19.34-33.44 \\ -13.51 & 0.787 & 29-47 & 9.31-23.48 \\ -12.34 & 0.848 & 31-47 & 13.95-27.52 \\ -12.66 & 0.938 & 29-47 & 14.54-31.43 \\ -7.85 & 0.874 & 31-47 & 19.24-33.23 \\ -13.74 & 0.804 & 29-47 & 9.58-24.05 \\ -8.18 & 0.724 & 31-47 & 14.26-25.85 \\ -12.46 & 0.878 & 29-47 & 13.00-28.81 \\ -7.09 & 0.802 & 31-47 & 17.77-30.60\end{array}$

$\begin{array}{rrrr}1.14 & 0.072 & 37-48 & 3.80-4.57 \\ 2.00 & 0.052 & 37-47 & 3.92-4.44 \\ -0.63 & 0.110 & 37-50 & 3.44-4.87 \\ & & & \\ 4.45 & 0.072 & 37-48 & 7.11-7.91 \\ 2.07 & 0.079 & 48-65 & 5.86-7.21 \\ 0.22 & 0.171 & 47-60 & 8.26-10.48 \\ -44.46 & 1.094 & 53-56 & 13.52-16.80 \\ -6.13 & 0.245 & 44-80^{a} & 4.65-13.48 \\ -23.25 & 0.609 & 50-55 & 7.20-10.25 \\ -8.50 & 0.273 & 58-63 & 7.33-8.70\end{array}$


Table 3.2 (Concluded)

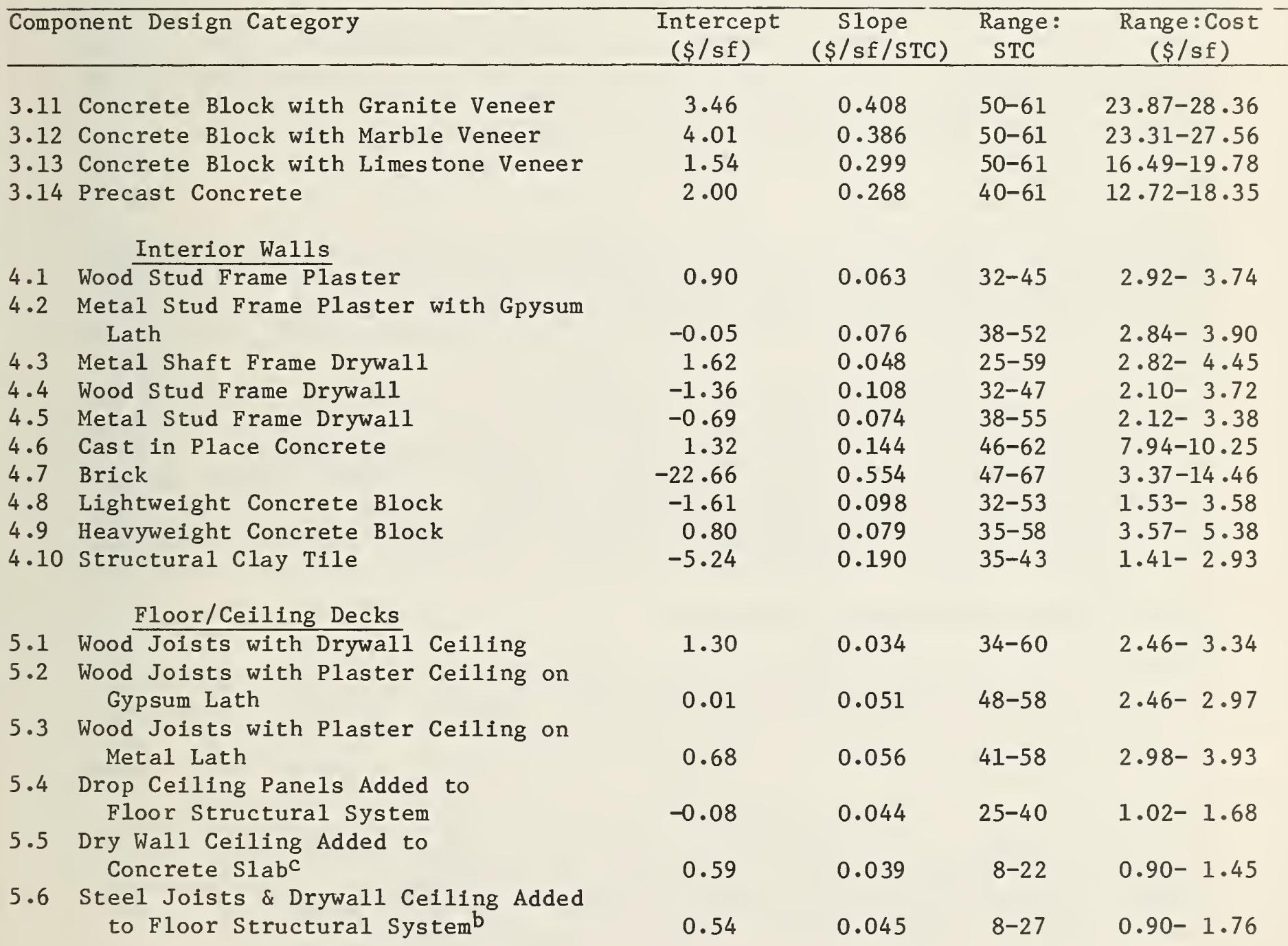

a The upper STC extreme for this concrete block CDC is estimated for a double wall of solid block construction of high quality construction.

b Values of cost and STC for the floor structural system are not included in these estimating equations.

c A concrete slab is the only floor structural system compatible with the design specifications used to develop this CDC estimating equation. The values of cost and STC for the concrete slab, however, are not included in this estimating equation. 
adjusted $R^{2}$ values greater than 0.5 ; indeed 49 percent have $R^{2}$ statistics in excess of 0.9 and 69 percent exceed 0.8 .

\subsection{DESIGN ASSUMPTIONS}

This subsection describes in some detail the design assumptions underlying the CDC cost equations. These assumptions must be taken into account whenever the methodology is applied to assess economic impacts. Each of the five major envelope components of dwelling units and classrooms is discussed in turn.

\section{2 .1 Doors}

Doors typically found in educational bulldings and residential dwelling unit main entrances were considered similar enough to be grouped into a single CDC. The corresponding cost estimating equation for docrs in Appendix A.1 and illustrated in the example above represents both wood and metal doors. The cost data were calculated in terms of a $3 \times 7$ foot door and converted to a square foot basis by dividing the entire cost of the door by 21 . This particular door size was assumed to be reasonable in light of current building firecode exit requirements and current standard practice. 1 It is also assumed that the doors are weatherstripped since this is standard practice. Moreover, acoustical test results on doors without weatherstripping tend to be inconsistent. 2 This is because test results are dominated by varying crack widths around the perimeter of doors as a result of different installation procedures.

\subsubsection{Windows and Sliding Glass Doors}

The cost equations for windows and sliding glass doors in Appendix A.2 are categorized by window glazing and frame type. Aluminum and steel are the only frame types analyzed because together they accounted for 93 percent of the windows installed in new multifamily residential buildings in 1980, the most recent year for which statistics are available.3 Each of the seven metal frame types is assumed to have weatherstripping. Four glazing types are presented for each each frame type: (1) sheet and plate glass; (2) tempered glass; (3) insulating glass; and (4) laminated glass. The first two are presented as least squares linear equations, and the last two are handled as discrete points due to the lack of sufficient data points to conduct regression analysis.

\subsubsection{Exterior Walls}

The exterior wall cost equations presented in Appendix A.3 permit one to calculate cost per square foot of exterior wall surface area at any specific

The firecode exit requirements assumed here are those given by International Conference of Building Officials, Uniform Building Code (Whittier, CA: International Conference of Building Officials, 1979), pp.501-502.

2 H. J. Sabine, et al.

3 Architectural Aluminum Manufacturers Association, Architectural Aluminum Industry Statistical Review: 198C (Chicago: Architectural Aluminum Manufacturers Association, 1981), table 14, p. 20. 
STC level within the stated range. Extrapolations of these cost equations beyond the stated range would require further cost estimating and acoustical testing of alternative interior finishes for each exterior wall CDC. Throughout the entire range of CDCs listed, it is assumed that quality construction methods and materials are employed.

\subsubsection{Interior Walls}

The cost equations for the Interior Wall CDCs presented in Appendix A.4 are to be used to establish the cost per square foot of wall area. Special care must be taken in using these costs, because the entire cost per square foot of wall area is not attributable to each dwelling unit. For party walls between dwelling units, each should be charged half the cost of common partitions. This is not the case, however, for walls classified as public-to-private separations. The total cost of each unit's public-to-private wall surface area is to be charged to that unit in the cost assessment.

One frequently used method of increasing STC is to design partitions with greater density. One drawback to this approach is the consequent increase in dead load on the building elements with the added cost of increasing the structural strength. The cost equations reported in Appendix A.4 do not include these possible increased structural costs because the CDCs employed here do not have greatly varied densities. Instead, an alternative method of greatly increasing the STC of a wall, double-wall construction, was used. However, the possible economic impact of lost floor area is not included in this methodology. As indicated by Berendt, Winzer, and Burroughs, "Double walls have substantially greater sound insulation than a single wall of the same weight." 1 It is also assumed that acoustical flanking paths around walls have been sealed in conformity with code requirements. 2

\subsubsection{Floor/Ceiling Assemblies}

The cost estimating equations for floor/ceiling assemblies are presented in Appendix A.5. These equations are to be used to estimate construction cost per square foot as a function of STC level. Note that exterior roofs are not included among these equations. For three of the six CDC designs, the cost and STC values of the floor structural system are meant to be combined with these estimating equations. That is, values for cost and STC of the floor structural system should be combined with the total cost and STC values derived form using equations $(5.4),(5.5)$, and $(5.6)$ of table 3.2 .

1 Raymond D. Berendt, George E. Winzer, and Courtney B. Burroughs, A Guide to Airborne, Impact, and Structure Borne Noise-Control in Multifamily Dwellings Federal Housing Administration Publication 750 (Washington, D.C.: U. S. Department of Housing and Urban Devolopment, September 1967), ch. 6, p. 7.

2 For a detailed description of the design requirements of a firewall, see the International Conference of Building Officials, Uniform Building Code (Whittier, CA: International Conference of Building Officials, 1979), pp. 102-119. 


\section{APPLICATION OF COST EQUATIONS TO BUILDING COMPONENTS}

This section illustrates how the cost estimating equations presented in Appendix $A$ are to be applied to determine how rauch additional cost is expected to result from noise control provisions. Subsection 4.1 deals with the case of a single homogeneous building component governed by a particular provision. The example used is that of a party wall separating two apartment units. Such party walls are governed by the private-to-private acoustical privacy provision of the MNCC. Subsection 4.2 deals with the more complex case of two or more building components that are simultaneously governed by the same provision. Two examples are used to illustrate this multi-component case. The first deals with two components governed by the MNCC public-to-private acoustical privacy provision: a basic interior wall structure, and a door leading to the main hallway. The second example concerns three distinct building components governed by the MNCC outdoor noise provision: a basic exterior wall structure, a window, and a door.

\subsection{SINGLE COMPONENT APPLICATIONS}

The application of the cost assessmant methodology to a single building component is relatively straightforward. The basic construction cost estimating equation is found on table 3.2 above for the particular CDC being estimated. This equation is used to calculate the basic construction cost under both current acoustical practice and the new noise control provisions. The difference between these two cost figures represents the expected increase in the basic construction cost. Then this basic construction cost figure is adjusted to account for the general contractor's mark-up and the architectural and engineering design fees. Finally, adjustments are made to account for regional construction cost differences and the effects of inflation over time. These adjustments are accomplished by applying a multiplication factor to the basic construction cost.

The building component used to 1 llustrate this single component application of the methodology is that of a metal stud frame drywall partition. The CDC construction cost estimating equation for such a partition is: 1

$$
\text { Cost } / \text { sf }=-0.69+0.074(\text { STC }) \text {. }
$$

A current design STC level of 50 is assumed in this case based on the Sound Transmission Control provision found in the Appendix of the Uniform Building Code.2 Assuming an outdoor day-night sound level of between 55 and $60 \mathrm{~dB}$ and assuming the partition is a private-to-private separation, the MNCC design

1 The intercept and slope values of this cost estimating equation are taken from CDC 4.5 of table 3.2 .

2 International Conference of Building Officials, Uniform Building Code, Appendix, p. 668。 
requirement is an STC rating of 55.1 Using the above equation and the current and expected STC requirements, current and expected cost estimates can be calculated:

$$
\begin{aligned}
\text { Current Cost/sf } & =-0.69+0.074(\text { STC) } \\
& =-0.69+0.074(50) \\
& =\$ 3.01
\end{aligned}
$$

Expected Cost $/ \mathrm{sf}=-0.69+0.074(55)$

$$
=\$ 3.38 \text {. }
$$

The change in cost/sf is calculated by subtracting the Current Cost/sf from the Expected Cost/sf:

$$
\begin{aligned}
\text { Cost Change/sf } & =\$ 3.38-\$ 3.01 \\
& =\$ 0.37 .
\end{aligned}
$$

It should be noted that the Cost Change/sf can also be calculated by multiplying the marginal cost factor (i.e., the slope of the cost estimating equation) by the change in required STC:

$$
\begin{aligned}
\text { Cost Change/sf } & =0.074\left(\mathrm{STC}_{2}-\mathrm{STC}_{1}\right) \\
& =0.074(55-50) \\
& =\$ 0.37 .
\end{aligned}
$$

These cost estimates are for basic construction costs. There are, however, other cost components which must still be accounted for by multiplying the change in cost/sf by certain factors. Two such factors are the general contractor's mark-up percentage (CMP) and the architectural and engineering design fee percentages (DFP). Median values for these percentages have been estimated to be 5.5 percent for $C_{M P}^{2}$ and 6.4 percent for DFP. 3 These two percentages are additive because they are both applied to the same basic construction cost estimates derived from the CDC equations. Thus, the proper calculation procedure to account for these adjustments is as follows:

1 See table 2.2 of this report.

2 Building Cost File: Eastern Edition, p. 1.

3 Boeckh, Inc., "Architectural Fees," in Boeckh Building Valuation Manual, 2nd Edition (Milwaukee: Boeckh Publications - A Division of American Appraisal Associates, Inc., 1979), pp. C37-38. 
Adjusted Cost Change $=$ Basic Construction Cost Change $x\left[1+\frac{\text { CMP }+ \text { DFP }}{100}\right]$,

$$
\begin{aligned}
& =0.37 \mathrm{zs}\left[\frac{1+5.5+6.4}{100}\right], \\
& =0.41(\mathrm{~s} / \mathrm{sf}) .
\end{aligned}
$$

Additional adjustments must be made to this figure in order to account for regional construction cost differences and for inflation over time. The cost data used to develop the cost estimating equations are relevant for the base city of the Eastern Edition of the Building Cost File, namely Philadelphia.

If the construction project being evaluated were in Sacramento, for example, one would find the Regional Cost Adjustment Factor (RCAF) for Sacramento in Appendix $C$ and multiply it times the construction cost figure adjusted for mark-up and design fee. For the case example above, the calculation would be as follows:

Cost Change in Sacramento = Cost Change in Philadelphia $\times$ RCAF

$$
\begin{aligned}
& =\$ 0.41 / \mathrm{sf} \times \$ 1.106 \\
& =\$ 0.45 / \mathrm{sf} .
\end{aligned}
$$

To adjust the cost figure for inflation, one must note that the cost data on which the cost estimating equations were based refer to construction costs in Midyear 1979. One of the Boeckh Indexes for construction costs published by the American Appraisal Companyl is designed for apartments, hotels, and office buildings and should serve fairly well for both educational and multifamily residential buildings. This index gives 169.3 for May-June 1979 and 197.1 for March-April 1981. Thus, to update the above cost figure for Sacramento from its midyear 1979 basis to March-April 1981 dollars one would multiply by the ratio $197.1 / 169.3$ as follows:

$$
\$ 0.45 / \text { sf } \times\left(\frac{197.1}{169.3}\right)=\$ 0.52 / \text { sf. }
$$

\subsection{MULTI-COMPONENT APPLICATIONS}

The model noise control provisions discussed in section 2 specify noise isolation performance requirements for both interior building partitions and exterior walls. In either case, the construction cost of a single component continuous partition or exterior wall may be directly estimated using the CDC cost equation for the particular construction. If the construction comprises two or more components, however, the possibility arises of trading off noise

1 This construction cost index series is published bimonthly in the U.S. Department of Commerce, Construction Review. 
insulation in one component for that in another component to find the leastcost combined solution. This section describes a method for conducting such trade off studies. In particular, the method utilizes the CDC cost equations discussed in section 3.2 and allows the user to determine the noise insulation specification for each component that will minimize the total construction cost of the combined design while still satisfying the given noise control provision. Details concerning the assumptions and the derivation of the design selection method a presented in Appendix C. The methor is mathematically exact and is easily used to obtain design results. However, the user must always remember that the linear relationship assumed to exist between construction cost and component noise isolation is only an approximation.

\subsubsection{Data Required to Determine the Minimum Construction Cost Design}

To determine the minimum cost design for a rulti-component wall, it is necessary to know details concerning the design. Specifically, the required data are the percentages of total surface area of each component and the component construction. Hence, the basic parameters defining the noise insulation of a composite or multi-component wall are the component surface areas and the component construction or noise insulation characteristics. The Component Design Categories or CDCs are used to define the cost/noise insulation characteristics of the component construction for this design method.

\subsubsection{The Design Equations}

The method allows the user to calculate the noise insulation requirements for each component of a multi-component wall using a pocket calculator. The construction cost of the design is minimized for all designs meeting the noise insulation specification. The user must always remember that a "design," as used here, is a combination of component areas and component materials (CDC cost equations). Changing either the distribution of surface areas among the components or changing the component materials defines a new design and will result in a different minimum cost solution.

Appendix C presents the general equation for calculating the noise insulation required of each component to define the minimum cost design. In this section, specialized equations are presented for two and three component designs. These two cases encompass almost all building noise insulation situations of practical interest. Table 4.1 presents the design equations and nomenclature for a two component wall design, while table 4.2 does the same for a three component wall design. Example calculations illustrate the use of the design equations to estimate both the component noise insulation requirements and the minimum construction cost for achieving a specified noise control provision.

\subsubsection{Example Design Calculations}

Two example design calculations are presented. The first example problem is an partition with a door separating a public space from a private space. The second example calculation is for an exterior wall design. 
Table 4.1 - Minimum Cost Equations for a Two Component Wall Design

The Two Component Wall Must provide a Design Noise Insulation of $\mathbf{R}_{\mathbf{c}}$.

-The Noise Insulation Required for Each of the Two Components is:

$$
\begin{array}{ll}
\text { Component 1: } & R_{1}=R_{c}-10 \log _{10}\left[B_{1} /\left(k_{1} B_{1}+k_{2} B_{2}\right)\right] \text {, and } \\
\text { Component 2: } & R_{2}=R_{c}-10 \log _{10}\left[B_{2} /\left(k_{1} B_{1}+k_{2} B_{2}\right)\right] .
\end{array}
$$

-The Minimum Construction Cost per Unit Area of the Two Component Wa11 is Calculated Using:

Cost per unit area $=k_{1}\left[A_{1}+B_{1} R_{1}\right]+k_{2}\left[A_{2}+B_{2} R_{2}\right]$.

-The Definitions of the Above Terms are as Follows:

Component Cost: $C_{i}=A_{i}+B_{i} R_{i} ; i=1,2$ (See table 3.2 or Appendix A)

Fraction of Total Area: $k_{i} ; i=1,2$ (Note: $k_{1}+k_{2}=1$ )

Design Noise Insulation: $\mathrm{R}_{\mathrm{C}}$.

See Appendix C, equation (C.28) for limitations on $R_{C}$

\section{Table 4.2 - Minimum Cost Equations for a Three Component Wall Design}

-The Three Component Partition Must Provide a Design Noise Insulation of $\mathrm{R}_{\mathrm{c}}$.

-The Noise Insulation Required For Each of the Three Components is:

Component 1: $R_{1}=R_{c}-10 \log _{10}\left[B_{1} /\left(k_{1} B_{1}+k_{2} B_{2}+k_{3} B_{3}\right)\right]$,

Component 2: $\quad R_{2}=R_{c}-10 \log _{10}\left[B_{2} /\left(k_{1} B_{1}+k_{2} B_{2}+k_{3} B_{3}\right)\right]$, and

Component 3: $R_{3}=R_{C}-10 \log _{10}\left[B_{3} /\left(k_{1} B_{1}+k_{2} B_{2}+k_{3} B_{3}\right)\right]$.

-The Minimum Construction Cost per Unit Area of the Three Component Wall

is Calculated Using:

Cost per unit area $=k_{1}\left[A_{1}+B_{1} R_{1}\right]+k_{2}\left[A_{2}+B_{2} R_{2}\right]+k_{3}\left[A_{3}+B_{3} R_{3}\right]$.

-The Definitions of the Above Terms are as Follows:

Component Cost : $C_{i}=A_{i}+B_{i} R_{i} ; i=1,2,3$

(See table 3.2 or Appendix A)

Fraction of Total Area: $k_{i} ; i=1,2,3$ (Note: $k_{1}+k_{2}+k_{3}=1$ )

Design Noise Insulation: $R_{C}$.

See Appendix C, equation (C.30) for limitations on $R_{C}$ 
Example No. 1, Two Component Interior Wall ${ }^{1}$

For this example, the partition separating a public space from a private space is comprised of a basic wall and a door. The total surface area is 96 square feet. The wall is metal stud frame drywall partition. The door dimensions are $3 \times 7$ feet. The outdoor day-night sound level is estimated to be $58 \mathrm{~dB}$. It is required to calculate the noise insulation requirements for the wall and the door and to estimat the construction cost for this interior partition in order to meet the MNCC provisions.

Since this is a two component partition, the minimization equations are listed in table 4.1. First, we denote the wall as component 1 and use a subscript " 1 " on all data related to the wall. The door data are then denoted by the subscript 2 .

The fractional area of each component is:

$$
\begin{array}{ll}
\text { wa11, } & k_{1}=(75 / 96)=0.781 \\
\text { door, } & k_{2}=(21 / 96)=0.219
\end{array}
$$

check: $k_{1}+k_{2}=1.000$

From table 3.2 , the CDC cost equation for a metal stud frame drywall partition is:

$$
\begin{aligned}
& C_{1}=-0.69+0.074 \quad R_{1} \\
& 38 \leq R_{1} \leq 55 \quad \text { (STC units). }
\end{aligned}
$$

From table 3.2 , the CDC cost equation for wood or metal doors is:

$$
\begin{aligned}
C_{2}= & 0.77+0.462 R_{2} \\
& 20 \leq R_{2} \leq 51 \quad \text { (STC units). }
\end{aligned}
$$

Then, in terms of the parameters required for the design equations in table 4.1 , the constants describing the component costs are:

Component 1 (Wa11) $A_{1}=-0.65 ; B_{1}=0.074$

Component 2 (Door) $\quad A_{2}=0.77 ; B_{2}=0.462$

Then, from table 4.1 , the noise insulation rating for the wall (component 1 ) required to meet the MNCC provisions, $R_{c}$, is:

1 In these example problems, numerical results are presented to several decimal places so that the reader can closely follow the calculations. Costs should be rounded to the nearest cent and $\mathrm{dB}$ to the nearest whole number in practice. 


$$
\begin{aligned}
R_{1} & =R_{c}-10 \log _{10}[0.074 /((0.781)(0.074)+(0.219)(0.462))] \\
& =R_{c}-10 \log _{10}[0.074 / 0.159] \\
& =R_{c}+3.3 ; \text { STC units. }
\end{aligned}
$$

For the door, the noise insulation rating required to meet the MNCC Provision, $\mathrm{R}_{\mathrm{C}}$, is:

$$
\begin{aligned}
R_{2} & =R_{c}-10 \log _{10}[0.462 / 0.159] \\
& =R_{c}-4.6 ; \text { STC units. }
\end{aligned}
$$

From table 35-A of the MNCC, the noise isolation requirements are a normalized level difference of $40 \mathrm{~dB}$ corresponding to a noise insulation requirement of STC 45 at the building design stage. From table no. 35-B of the MNCC, these requirements must be increased $5 \mathrm{~dB}$ for an outdoor environmental day-night sound level between 55 and $60 \mathrm{~dB} .1$ That is, for our example problem, the MNCC requirements are a normalized level difference of $45 \mathrm{~dB}$ or an STC rating of 50 for the composite wall. Since of the CDC cost equations are expressed in terms of the STC rating of the components, we select $R_{c}=50$ for use in the minimization equations.

Hence, for our example problem, the minimum construction cost design (utilizing a door with metal stud frame drywall corstruction and the door comprising 21.9 percent of the total partition area) is:

$\mathrm{R}_{1}=50+3.3=53.3$ Wall STC Rating

$R_{2}=50-4.6=45.4$ Door STC Rating.

We compare these values with the limits of the cost equations to check that the component STC ratings are physically possible. (See Appendix C.3.3).

From table 4.1 and the data for the example problem, the estimated minimum construction cost per unit area is:

$$
\begin{aligned}
& \underset{\min }{C}=(0.781)[-0.69+0.074(53.3)]+(0.219)[0.77+0.462(45.4)] \\
& \quad=(0.781)(3.25)+(0.219)(21.74)=\$ 7.30 / \mathrm{sf} .
\end{aligned}
$$

The above results provide the minimum cost design. That is, a metal stud frame drywall partition with an STC rating of 53 costing $\$ 3.25 /$ sf and a door with an STC rating of 45 costing $\$ 21.74 /$ sf will provide a composite STC rating of 50 at an average cost of $\$ 7.30 / \mathrm{sf}$. We note that in absolute costs, the estimated construction cost for the wall is $\$ 243.75$ and the door cost is $\$ 456.54$.

${ }^{1}$ Table 2.2 of this report summarizes tables $35-\mathrm{A}$ and $35-\mathrm{B}$ of the MNCC provisions. 
To illustrate that the above result is a minimum cost, we note that if both the wall and the door have STC ratings of 50 then the total structure will have an STC rating of 50. Substituting these values into the above cost equation, the average cost per unit area is estimated to be $\$ 7.58 /$ sf for this "obvious" design requiring an STC 50 wall and door.

The comparison between the cost of the "obvious" design and the estimated minimum cost design does not prove that the estimated minimum cost is an absolute minimum. One should read Appendix $C$ to understand that the method does guarantee a minimum total cost assuming that the component cost is a linear function of the component STC rating. Section 4.2.4, below, discusses practical limitations of this design method.

\section{Example No. 2: Three Component Exterior Wall}

This example problem illustrates the use of the minimum cost design method to determine the noise insulation performance of exterior wall components in order to meet the MNCC provisions. The basic steps required to conduct the calculations are identical to the first example problem. However, for the exterior wall problem, it is necessary to adjust the A-welghted outdoor-to-indoor sound isolation requirements of the MNCC provisions so that the design criteria for the calculation schene is expressed in the STC units of the CDC cost equations.

For this example problem, the total surface area of the exterior wall between the outside and the interior living space is $240 \mathrm{sf}$. The exterior wall components are $60 \mathrm{sf}$ of glazing, one door ( $3 \times 7 \mathrm{feet}$ ), and the basic wall.

The construction utilizes a frame utructure with a stucco exterior finish and aluminum frame double hung windows with either sheet or plate glass. The outdoor day-night sound level to which this construction will be exposed is estimated to be in the range of 75 to $80 \mathrm{~dB}$. The problem is to determine the component noise insulation requirements to achieve the A-weighted sound level reduction of $35 \mathrm{~dB}$ requi.red by table 35-C of the MNCC. (See table 2.2 of this report.)

First, to use the minimum cost design method for an exterior wall it is necessary to adjust the A-weighted sound level reduction of the MNCC provisions to obtain the design criterion in STC units. 1 The required adjustments (See Appendix C.2) are of the form:

$$
\text { STC }=\Delta \mathrm{L}_{\mathrm{A}}+\text { adjustment }
$$

where $\Delta \mathrm{L}_{\mathrm{A}}$ is the $\mathrm{A}$-weighted sound level reduction in table $35-\mathrm{C}$ of the MNCC. The adjustment required depends upon the predominant environmental. noise source outside the bullding (i.e., highway traffic, aircraft, or railway noise) and the interior room furnishings. For a typically furnished rom, an average

1 The reader will note that for partitions (table 35-A of the MNCC), the noise isolation criterion is specified as a normalized A-weighted sound level difference with the design requirement specified in STC units. For the interior partitions, the MNCC applies a $5 \mathrm{~dB}$ adjustment. 
adjustment of $+3 \mathrm{~dB}$ appears appropriate for any of the above listed noise sources. For sites exposed predominately to highway and/or railway noise, a $+2 \mathrm{~dB}$ adjustment may be used. For sites exposed predominately to aircraft noise, $a+4 \mathrm{~dB}$ adjustment may be used. The explicit adjustment selected is a judgment best determined by the architect or acoustical consultant.

For our example problem, the $+3 \mathrm{~dB}$ correction is selected so that the STC design criterion as determined by the outdoor day-night sound level and the MNCC provision is:

$$
R_{c}=35+3=38 \text {. }
$$

From table 3.2 or Appendix A, the cost equations for the particular Component Design Categories of this example are:

Component 1; Stud Frame Wall with Stucco Exterior:

$$
C_{1}=2.00+0.052 \cdot R_{1}, 37 \leq R_{1} \leq 47
$$

Component 2; Doors:

$$
\mathrm{C}_{2}=0.77+0.462 \cdot \mathrm{R}_{2}, 20 \leq \mathrm{R}_{2} \leq 51
$$

Component 3; Double Hung Aluminum Frame Sheet and Plate Glass:

$$
C_{3}=-12.66+0.938 . R_{3}, 29 \leq R_{3} \leq 47 .
$$

The ratios of component surface areas to total surface area for this example are:

$$
\begin{aligned}
& \mathrm{k}_{1}=159 / 240=0.6625 \\
& \mathrm{k}_{2}=21 / 240=0.0875 \\
& \mathrm{k}_{3}=60 / 240=0.2500 .
\end{aligned}
$$

The design equations for the three component partition are listed in table 4.2. To best use these equations, one first calculates the weighted marginal cost of the total construction as follows:

$$
\begin{aligned}
k_{1} B_{1}+k_{2} B_{2}+k_{3} B_{3} & =(0.6625)(0.052) \\
& +(0.0875)(0.462) \\
& +(0.2500)(0.938)=0.3094 .
\end{aligned}
$$

From table 4.2, the STC design values for each component are calculated as follows: 
Exterior Wall: $\quad R_{1}=R_{c}-10 \log _{10}[0.052 / 0.3094]$

$=R_{c}+7.8$

Door:

$$
\begin{aligned}
R_{2} & =R_{c}-10 \log _{10}[0.462 / 0.3094] \\
& =R_{c}-1.7
\end{aligned}
$$

Windows:

$$
\begin{aligned}
R_{3} & =R_{C}-10 \log _{10}[0.938 / 0.3094] \\
& =R_{c}-4.8
\end{aligned}
$$

For the composite wall STC design value of $R_{C}=38$, the following component STC design values are determined:

Exterior Wall STC $=R_{1}=38+7.8=45.8$ or 46

Door STC $\quad=R_{2}=38-1.7=36.3$ or 36

Window STC $\quad=R_{3}=38-4.8=33.2$ or 33

which are physically possible values (See Appendix C.3.3). Hence, the estimated minimum construction cost per square foot for the exterior wall of this example problem is:

$$
\begin{aligned}
\mathrm{C}_{\text {min }} & =(0.6625)[2.00+0.052(45.8)] \\
& +(0.0875)[0.77+0.462(36.3)] \\
& +(0.2500)[-12.66+0.938(33.2)] \\
& =\$ 9.06 / \mathrm{sf} .
\end{aligned}
$$

Another possible design satisfying the MNCC provisions would be the design requiring that each component independently meet the provisions. That is the design specifying $R_{1}=R_{2}=R_{3}=38$, for this example problem. This is the "obvious" design. Using the CDC cost equations for this example, the cost per square foot for the obvious design is $\$ 9.98 / \mathrm{sf}$. Hence, the minimum cost design is estimated to be $\$ 0.92 /$ sf less than the "obvious" design. For the 240 square foot structure of this $\epsilon$ xample, the minimum cost design represents a cost savings of $\$ 220.80$ per living unit over the "obvious" design.

\subsubsection{A Few Words of Caution}

The calculation method described in this section allows judgements to be made -- based on construction cost -- concerning component specifications that achieve a composite performance requirement. The method does not provide absolute answers to a specific problem. However, the method does provide a starting point at which the architect and designer may refine a design to meet the MNCC provisions without incurring excessive construction costs. To place the method in perspective, a few words of caution concerning the use and interpretation of results are provided. 
First, the cost equations for each component design category are only average results. The equations are developed from a tabulation of designs in each category with each design represented as a "point" when plotted as component cost versus the STC rating. Figure 3.1 illustrates the concept using the door CDC. Each point in figure 3.1 represents a specific design within the component design category. As indicated in figure 3.1, few of the specific designs are points on the straight line of the component cost equation.

To illustrate the significance of the lincar cost equations, a small region of the data scatter of cost and STC is illustrated in figure 4.1. The STC value $R^{*}$ represents the component STC rating predicted using the minimum cost design method. The component cost per unit area, $C^{*}$, is calculated using the CDC cost equation and the STC value $\mathrm{R}^{*}$. It is not likely that the predicted design point $\left(R^{*}, C^{*}\right)$ for the minimum cost design will exactly correspond to any specific design used to determine the CDC cost equation. However, one should recognize the advantages of the model rather than emphasize the limitations.

The basic advantage of the method is that the design point ( $\left.R^{*}, C^{*}\right)$ for a component is obtained using simple calculations that require a few minutes and a pocket calculator. Alternatively, a computer program could be developed that sorted through all specific designs of each CDC selected for the structure. The result would then be a listing of specific designs that provided the true minimum cost structure based upon the data files used. It was felt that this approach might prove too cuinbersome in that the user must have access to a computer and must continually use the program for each problem encountered. Further, the computerized approach would not allow for a convenient parameter study afforded by the manual method described here. An example of such a parameter study is presented in Appendix C.4.

Figure 4.1 illustrates the flexibility of the manual method for refining the estimated minimum cost design. In figure 4.1, the specific design selected for each component would be determined relative to the design point ( $R^{*}, C^{*}$ ) depending upon the architectural requirements. For example, the architect would select specific design points $\left(R_{i}, C_{i}\right)$ in a neighborhood of the design point $\left(R^{*}, C^{*}\right)$. As indicated in figure 4.1 , the specific design points ( $R_{1}$, $C_{1}$ ) and $\left(R_{5}, C_{5}\right)$ represent an increase in the component noise insulation and a decrease in component cost relative to ( $\left.R^{*}, C^{*}\right)$. Using these design points, the architect would increase the roise insulation of the total design and decrease the total construction cost. The design point ( $\left.R_{3}, C_{3}\right)$ represents a design that has decreased noise insulation and increased cost relative to ( $R^{*}$, $\mathrm{C*}^{*}$ ). The result is that the architect can either make a decision based on one of the available designs or create a new design using ( $\mathrm{R}^{*}, \mathrm{C}^{*}$ ) as the design objective.

A limitation of the design method described here is that the user must always check the results to insure that the optimum noise insulation value, $\mathrm{R}^{*}$, for each component is within the range of values for which the component cost equation is defined. For the two examples presented in section 4.2.3, the calculated optimum STC values for each component are all included in the STC range for the component's cost equation. Using the method, it is possible for the noise control code provision, $R_{C}$, to be such a magnitude that the optimum component STC value is outside the range of the cost equation. In this case, the optimum design is found by following the procedure described in Appendix C.3.4. 

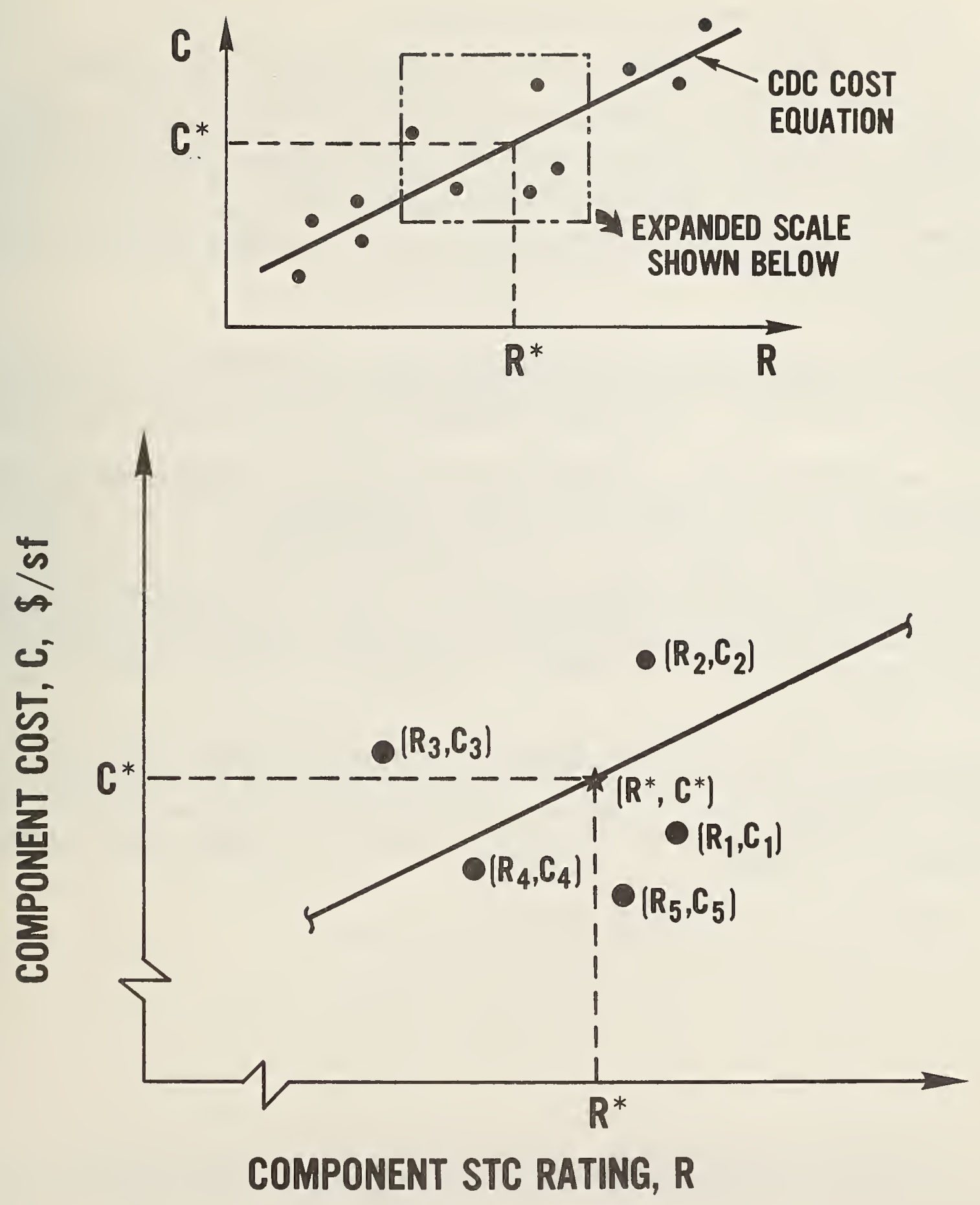

Figure 4.1 Selection of Specific Designs Relative to the Optimum Design Point $\left(\mathrm{R}^{*}, \mathrm{C}^{*}\right)$. 


\section{ENERGY SAVINGS AND NON-CONSTRUCTION COSTS}

This section deals with three types of economic impacts other than the construction-related expenditures. The first subsection treats the energy savings that may result from increasing the acoustical performance of exterior glazing. The second subsection deals with the code administration costs likely to result from a noise control code. The experience of the City of San Diego is reviewed as a basis for the latter discussion. The final subsection concerns the costs of acoustical testing required by a noise control code for building occupancy certification.

\subsection{ENERGY SAVINGS}

One special economic effect of improved acoustical performance of the exterior envelope concerns possible energy savings. This subsection provides an illustration of how energy savings for one building component might be calculated.

The windows used in this illustration are originally designed to be $1 / 4$ inch plate glass in fixed aluminum frames with a coefficient of thermal transmission (U value) of $1.09 \mathrm{Btu} / \mathrm{hr} / \mathrm{sf} / \Delta^{\circ} \mathrm{F}$. 1 The total window area is $80 \mathrm{sf}$, and the STC rating of this window is 31 . The windows being analyzed are part of a building which consumes natural gas fuel at a cost of $\$ 0.64 /$ therm with a heating efficiency of 75 percent. The building is located in a climate with 4000 heating degree days per year; for this illustration the savings are based only on heating requirements. The possible savings from a reduced cooling load are not included.

Consider the effect of a noise control requirement that calls for an STC rating of 36 . It is assumed that this requirement is met by changing the glass in the windows to 1 inch insulating glass, which has a U value of 0.57 .2 In order to calculate life-cycle energy savings of such a change, the following assumptions are made:

1. The life of the windows is 25 years.

2. The salvage value of the indows is zero.

1 American Society of Heating, Refrigerating and Air-Conditioning Engineers, Inc. (ASHRAE), ASHRAE Handbook of Fundamentals (New York, 1972), table 8, p. 370 .

2 Ibid. 
3. The real discount rate is 10 percent.

4. The annual fuel price escalation rate is 2 percent. 1

The annual energy savings are calculated as follows:

Energy consumption $=($ Thermal transmittance) $\mathrm{x}$ (hrs/day) $\mathrm{x}$ (degree days/year) $\mathrm{x}$ (window area)/(heating efficiency)

Current energy consumption $=\left(1.09 \mathrm{Btu} / \mathrm{hr} / \mathrm{sf} / \Delta^{\circ} \mathrm{F}\right) \times(24 \mathrm{hr} /$ day $)$ $\mathrm{x}(4000$ degree days/year) $\mathrm{x}(80 \mathrm{sf}) /(.75)$

$=111.6$ Therms/year

Expected energy consumption $=\left(0.57 \mathrm{Btu} / \mathrm{hr} / \mathrm{sf} / \Delta^{\circ} \mathrm{F}\right) \times(24 \mathrm{hr} / \mathrm{day})$ $\mathrm{x}$ (4000 degree days/year) $\mathrm{x}(80 \mathrm{sf}) /(.75)$

$=58.4$ Therms/year

Annual energy savings = (Current energy consumption - Expected energy consumption) $x$ (cost of fuel)

$=(111.6$ Therms/year -58.4 Therms/year $) \times(\$ 0.64 /$ Therm $)$

$=\$ 34.05 /$ year .

Under the given assumptions, the formula for life-cycle energy savings is:

Life-cycle energy savings $=A\left(\frac{1+e}{i-e}\right)\left[1-\left(\frac{1+e}{1+i}\right)^{n}\right]$,

where $A=$ Annual energy savings, $i=$ real discount rate, $e=$ fuel price escalation rate, and $n=$ assumed life of windows. ${ }^{2}$ Using this formula we find:

Life-cycle energy savings $=(\$ 34.05)\left(\frac{1+.02}{.10-.02}\right)\left[1-\left(\frac{1+.02}{1+.10}\right)^{25}\right]$

$=(\$ 34.05)(12.75)(.84858)$

$=\$ 368.40$.

1 This projected fuel price escalation rate for natural gas is taken from Federal Register Department of Energy, Office of Conservation and Solar Energy. Vol. 45, No. 16 (Washington, D.C.: U.S. Government Printing Office, 1980), p. 5646 .

2 Rosaliє T. Ruegg et al., Life-Cycle Costing: A Guide for Selecting Energy Conservation Projects for Public Buildings, National Bureau of Standards, Building Science Series 113 (Washington, D.C.: U.S. Government Printing Office, 1978), p. 9 . 
Thus, the present value of the heating energy savings due to the assumed noise control requirement change would be $\$ 368.40 .1$

\subsection{CODE ADMINISTRATION COSTS}

Generally, a jurisdiction adopting any code can expect to incur operating costs above those presently experienced for bullding code administration. For the MNCC it is difficult to formulate a quantitative estimate of these costs, since many of the specialized requirements of the MNCC may already be met by current activities of the jurisdiction's present code administration. It is appropriate, however, to describe the specialized administrative requirements of the MNCC provisions. Basically, these specialized requirements include personnel skills and documentation necessary to administer the MNCC provisions. Details of the considerations discussed here are described in the Implementation Manual developed by BBN as supporting documentation for the Model Noise Control Code.2 An overview of the experience of the City of San Diego, California is presented to illustrate one jurisdiction's approach to implementing a noise control ordinance. ${ }^{3}$ Code administration costs are not a specific element of this cost assessment method but these costs must be recognized by the local jurisdiction as a potential cost factor.

\subsubsection{Overview of Administrative Requirements}

The MNCC provisions require of a code jurisdiction certain specialized personnel skills and documentation necessary to administer the noise control code. Table 5.1 presents an overview of these MNCC requirements related to administration. Specific tasks are defined by the MNCC for issuing the construction permit and for issuing the occcupancy permit. Table 5.1 indicates these tasks by the sections of the MNCC. Basical1y, these tasks encompass document review and evaluation of analyses and test data submitted by the builder. The necessary skills and documentation required for tasks leading to issue of the construction permit are described in this section. Costs associated with acoustical acceptance testing are discussed in the following section.

\subsubsection{Specialized Ski1ls}

The MNCC provisions require a basic level of skill in environmental noise prediction and noise control in buildings. The noise isolation performance of interior walls and decks (section 3504) and the exterior building shell (section

1 The total energy savings would equal the heating plus cooling energy saving. The cooling energy saving calculation method can be found in ASHRAE, "Cooling and Heating Load Calculation Manual, "New York, New York: American Society of Heating, Refrigerating, and Air-Conditioning Engineers, Inc., 1979, p. 7-11.

2 Bolt, Beranek, and Newman, Inc., Report No. 3837.

3 San Diego, California: Case History of a Municipal Noise Control Program: (Washington, D.C.: U.S. Environmental Protection Agency, Office of Noise Abatement and Control; 1978). 


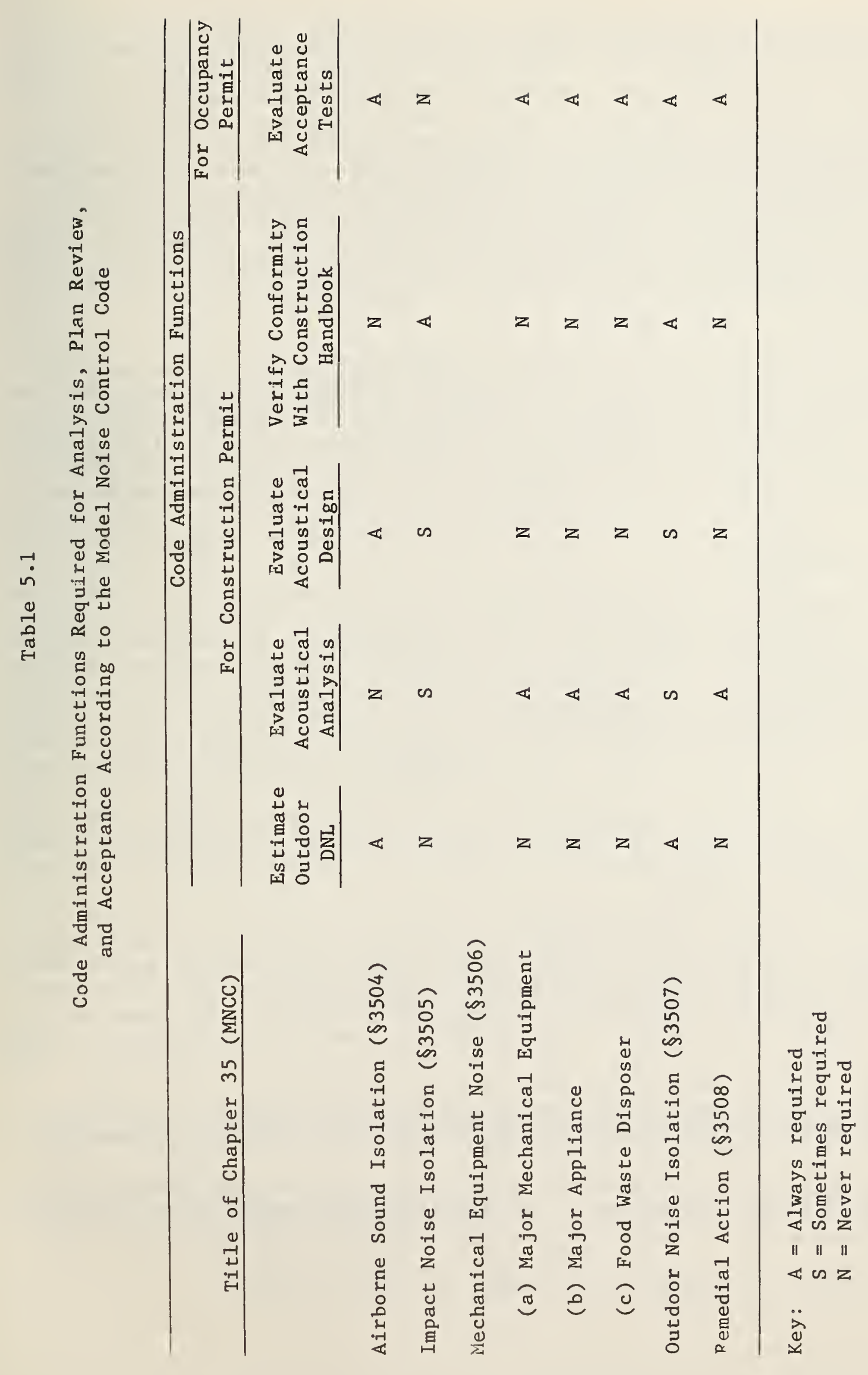


3507 ) is based upon the present and the future outdoor noise environment expected at the building site. Since these performance requirements are based upon predictions of the outdoor day-night sound level, the building code official must verify the designer's prediction when reviewing documents prior to issuing the construction permit. Hence, the building code official reviewing these estimates must possess basic technical skills related to environmental noise prediction. The necessary level of these technical skills will depend upon the documentation available to building code officials concerning environmental noise within their jurisdiction as described below. These skills may be initiated and maintained either by training of existing staff or hiring staff with the required technical background. The specific approach taken can only be assessed at the local level.

Documentation review prior to issuing the construction permit requires the evaluation of acoustical analyses of mechanical equipment noise (section 3506) and airborne noise isolation of the interior walls (section 3504) and the exterior building shel1 (section 3507). These skills may be classified within the technical area of building noise control and are consistent with the technical skills in the area of environmental noise prediction described above. The basic technical skills for building noise control may also be initiated and maintained either by training existing staff or hiring staff with the required technical background.

Prior to occupancy, the MNCC provisions require the building owner to conduct acoustical acceptance tests of the finished building to certify that both the construction and operation of mechanical equipment meet the applicable performance requirements. If the acceptance test report(s) indicate that the performance requirements are not satisfied, the building owner must complete remedial action - including additional testing - to certify compliance. The building code official must possess the skills necessary to review the acceptance test reports, to evaluate their accuracy and to require remedial action as appropriate. These requirements are described in section 3508 of the MNCC. The staff trained in reviewing the documents for issuing building permits can be expected to possess also the necessary skills required for evaluation of the acoustical acceptance test reports.

In summary, the MNCC provisions define technical skills that may not be available within a jurisdiction's current staff. The necessary skills may be realized either by training existing staff or by hiring additional staff with the appropriate technical background. Training may be obtained, for example, by staff attending short courses on environmental noise and building noise control. Once the nucleus of technical skills is established within a jurisdiction the se skills may be maintained and expanded at a level appropriate to the local requirements. This may include instructing building inspectors in common construction defects that result in degradation of noise isolation performance.

The staff size required to administer the MNCC provisions also depends upon the local requirements as described in the Implementation Manual. 1 The resulting

1 Bolt, Beranek, and Newman, Inc., Report No. 3837, p. 24-30. 
administration costs for staff may be defrayed by appropriate adjustments to the building permit fees.

\subsubsection{Specialized Documentation}

The MNCC provisions require the avallability of specialized documentation to support the administration of the various sections of the code. This documentation must be available to the building owner prior to application for the construction permit. First, an accepted technique for predicting the environmental noise expected at the site during the building's useful life must be available. The Implementation Manual includes such a prediction method that encompasses the noise generated by major sources of transportation noise. Second, the impact noise isolation provision (section 3505) is a prescriptive requirement wherein the builder will consruct floor/ceiling assemblies in compliance with a Construction Handbook. Section 3507 of the MNCC also refers to the Construction Handbook for examples of exterior building shell configurations that will satisfy the outdoor noise isolation provisions. Because the Construction Handbook that must accompany the MNCC provisions has not been prepared, the adopting jurisdiction would have to develop and/or provide the equivalent documentation.

Additional specialized documentation is required to ease the administrative work associated with enforcing the MNCC provisions. This documentation is concerned with the prediction of the outdoor day-night sound levels within the jurisdiction and with establishing a portfolio of noise insulation data of building construction configurations. The data necessary to estimate both present and future outdoor day-right sound levels must be based upon local conditions. As described in the Implementation Manual, most of the necessary data may be obtained from other 1ocal, state, and Federal Government agencies. These data may even be available in the form of noise level contours or "noise maps" for areas within the jursidiction.

The effort required to establish a portfolio of noise isolation data for building construction is rather minor because a number of useful sources already exist. For example, the State of California has published an extensive catalog of STC and IIC ratings for wall and floor/ceiling assemblies. 1 Additionally, publications are available that describe practical design methods for implementing building noise control. ${ }^{2}$ Due to the availability of data relative to the the building construction requirements to achieve a design level of noise isolation, a local jurisdiction should readily be able to establish a comprehensive portfolio of acceptable designs. These data, would be used by the

1 Catalog of STC and IIC Ratings for Wall and Floor/Ceiling Assemblies, (Berkeley: California Department of Health Services, Office of Noise Control, 1980).

2 Quieting in the Home: (Washington, D.C.: U.S. Environmental Protection Agency, Office of Noise Abatement and Control, 1978). 
building code official during his review of the building plans prior to issuing the construction permit.

\subsubsection{The Experience of San Diego}

Given the above discussion, it can be appreciated that a quantitative estimate of code administration costs can only be based upon the requirements of the local jurisdiction. However, a brief overview of the experience of the City of San Diego, California, provides some useful insights. This overview is based upon a case history study ${ }^{1}$ of San Diego's municipal noise control program and the implementation of building noise isolation standards within the framework of the San Diego Noise Control Ordinance.

In 1973, the San Diego City Council adopted Article 9.5, Noise Abatement and Control, of the San Diego Municipal Code. This Article does not contain a section covering building noise isolation. However, the San Diego Noise Ordinance does establish the Noise Abatement and Control Administration within the City Building Inspection Department. In 1978, the San Diego Noise Abatement and Control Administration employed five staff members: an administrator, an assistant administrator (professional), a field inspector (nonprofessional), a stenographer (secretary), and a clerk typist. This staff represents 4 to 5 percent of the total department staff and is responsible for the administration of the San Diego Noise Control Ordinance. In addition to these responsibilities, the staff also assists other departments within the City government in administration of California noise control ordinances. For example, the staff assisted the Building Inspection Department in reviewing 600 building plans for compliance with the California Noise Insulation Standards ${ }^{2}$ during 1977.

From an administrative standpoint, the basic tasks performed by the San Diego Noise Abatement and Control staff in assisting the Building Inspection Department parallel the administrative requirements of the MNCC. As part of their responsibilities, the San Diego staff must maintain an official record of noise levels in the city called the "San Diego City Noise Map." This documentation serves as the basis for determining the noise insulation from outdoor sources that is required by the California Noise Insulation Standards. Hence, the

San Diego staff has an estimate of the outdoor noise environment readily available for use in reviewing building plans. The MNCC requires a similar activity

1 San Diego, California: Case History of a Municipal Noise Control Program (Washington, D.C., U.S. Environmental Protection Agency, Office of Noise Contro1, 1978.)

2 "California Noise Insulation Standards", California Administrative Code, Title 25, Chapter 1, Subchapter 1, Article 4, February, 1974. 
to establish the noise insulation requirements for the building. 1 Both the California Noise Insulation Standards and the MNCC require the building code official to verify that the proposed construction satisfies the appropriate noise insulation standards.

The MNCC provisions require the building owner to certify by a defined set of field tests that the finished construction satisfies the design standards. The California Noise Insulation Standards require field testing only if, in the judgment of the building code official, such testing is necessary. This judgment is based upon field inspection to determine whether the construction is in accordance with the approved plans. The approach taken by the City of San Diego in requiring asceptance testing -- and the costs of the testing -are described in the next section.

Hence, as part of the administration of the MNCC provisions, the adopting jurisdiction may decide to incorporate construction inspection for designed noise control features as a duty of the building inspector. As described above, staff administering the MNCC provisions may readily train building inspectors to recognize construction faults that degrade noise insulation of the approved design. Using this approach, the likelihood of expensive remedial construction and testing (section 3508 of $\mathrm{MNCC}$ ) is remote. The Implementation Manual details the recommended inspections as part of the code administration. ${ }^{2}$

\subsection{ACOUSTICAL TESTING COSTS FOR ACCEPTANCE}

A noise control code usually requires acceptance tests, which further increase costs. As indicated in table 5.1 , the MNCC provisions require acceptance testing for airborne noise isolation (sections 3504 and 3507) and for noise generated by the operation of mechanical equipment (section 3506). The costs of conducting the acceptance testing are paid by the building owner. Table 5.2 further illustrates the acceptance testing requirements by indicating the building categories included in each section of the MNCC provisions. As emphasized in the annotation to the Model Noise Control Code, the only certain means by which one can verify that the MNCC provisions are met is a final measurement in the completed building. 3 The MNCC provisions require that the acceptance testing be conducted by a qualified acoustical engineer/consultant as defined in section 3503 .

1 The California Noise Insulation Standard specifies constant noise insulation requirements for interior walls and floor/ceiling assemblies both for airborne noise and impact noise.

2 Bolt, Beranek, and Newman, Inc., Report No. 3837, p. 37.

3 Bolt, Beranek, and Newman, Report No. 3759. 


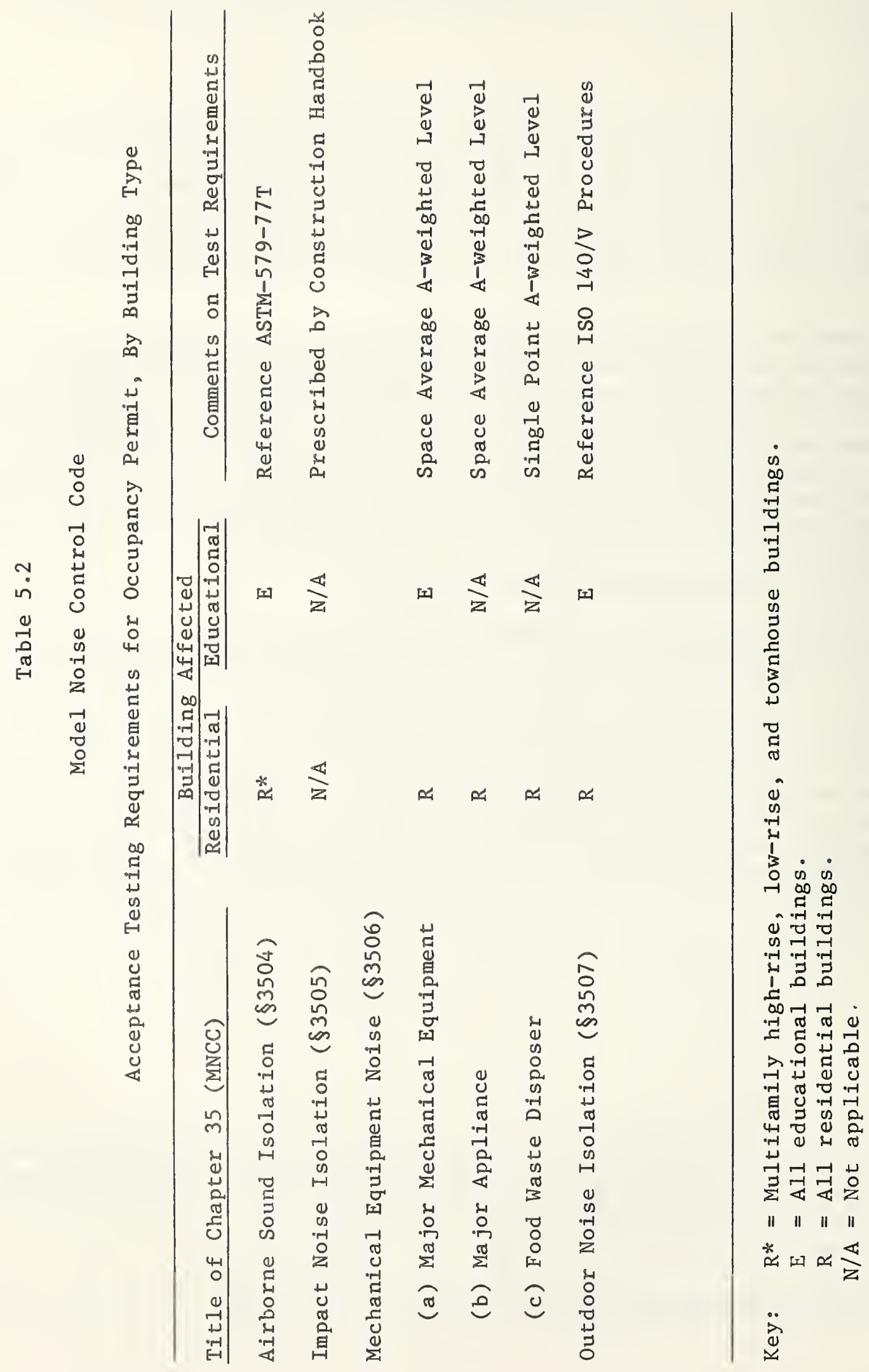


As noted in the comment column of table 5.2, the airborne noise isolation acceptance tests are based upon standard test methods. Section 3504 requires acceptance testing using the ASTM 597-77T recommended practice.1 Section 3507 requires acceptance testing using the procedures of International Standard ISO $140 / \mathrm{V}^{2}$ and A-weighted sound level measurements. The consulting firm of Bolt, Beranek and Newman estimates that the cost in 1978 of conducting the performance testing to be approximately $\$ 25$ to $\$ 40$ per test (one test denotes a building component). 3

The total costs of conducting acceptance testing can be estimated on the basis of a unit or component cost and the number of tests required by the MNCC provisions. Section 3504 (c) of the MNCC provisions specifies the number of tests required for acceptance. This rumber depends upon two categories of space-tospace utilization for walls and floor-celling assemblies and on the possible variation of construction type within the building or project. Hence, the number of tests required and the related testing cost can only be estimated for each specific building design or project. These total costs can be expected to vary significantly from building to building or project to project.

Compared to the airborne noise isolation tests required in section 3504 and 3507, the acceptance testing for mechanical equipment noise under section 3506 is easily conducted. The number of tests required is also dependent upon the specific building design as in the case of airborne noise isolation tests. It is difficult, therefore, to estimate an average total cost per building.

The above discussion focuses on the direct testing cost to certify the final building for occupancy. However, the adopting jurisdiction should be aware of possible additional costs that may arise as a result of the acceptance testing. First, the ASTM 597-77T test standard recommends minimum aging periods for the finished construction before testing can be conducted. These aging periods range from 28 days for masonry to 12 hours for rall board construction using typical joint and finishing compounds. Hence, the aging period represents a fotential time delay between completion of construction and acceptance testing. The costs of this time delay, if any, can only be determined for the specific building construction and would be borne by the building owner. Second, the acceptance testing required under section 3507 of the MNCC provisions applies to all residential and educational buildings and implies that all facades are to be tested using the ISO $140 / \mathrm{V}$ procedure. Two considerations arise concerning these testing costs. The first consideration is the total cost if every

1 American Society for Testing and Materials, Annual Book of ASTM Standards (Philadelphia, PA).

2 Internaticnal Organization for Standardization, Acoustics - Measurement of Sound Insulation in Buildings and of Building Elements - Part V: Field Measurements of Airborne Sound Insulation of Facade Elements and Facades ISO 140/V-1978(E), (Geneva, 1978).

3 Bolt, Beranek, and Newman, Report 3759. 
exterior facade element is included in the test. For example, testing every exterior facade element (vertical wall separating an interior space from the outside) of a single dwelling unit could potentially increase the final sales cost several hundred dollars. Second, the ISO $140 / \mathrm{V}$ procedure requires the positioning of a microphone on the facade exterior. This requirement presents practical difficulties for facade elemments located over two stories above the ground elevation. Hence, the placement of an exterior microphone for conducting an acceptance test may become a technical challenge in itself. As a result, additional test costs can be estimated only on the basis of the specific building design.

An alternate approach to acceptance testing is taken by the San Diego Noise Abatement and Control Administration. As described in section 5.2, the San Diego staff assists the Building Inspection Department in administration of the California Noise Insulation Standards. During construction, building inspectors verify that the approved design is constructed and that common construction faults degrading noise isolation are avoided. The requirement to conduct acoustical performance tests is left to the judgment of the building code official. Additionally, the California Noise Insulation Standard recognizes a complaint by an occupant as one basis for requiring field testing. In this case, the complainant posts a bond or sufficient funds in an escrow account for the cost of the required tests. If the field tests indicate compliance with the standards, the testing costs are chargeable to the complainant. If the tests show noncompliance, the testing costs are borne by the building owner or builder. This approach avoids continuous testing of every building by insuring quality construction per the approved design. Hence, testing costs are incurred only if the building code official either detects faulty construction or receives a complaint from the occupant. 
This research on the cost impacts of noise control requirements for multifamily residential and educational buildings has led to two major accomplishments. First, a general methodology has been developed to estimate the cost impacts of a wide range of noise insulation requirements applied to a single building component. The methodology is composed of five basic steps: identifying the affected building component; (2) selecting the category of designs to be applied to the component (Component Design Category); (3) obtaining reliable construction cost and STC data on a range of specific designs within the selected Component Design Category; (4) applying these data to develop a cost estimating equation that defines construction cost as a function of STC level; and (5) using this equation to estimate the cost of constructing the component both with and without the noise control requirement being analyzed. In this report, the general methodology was applied to 45 commonly used Component Design Categories for five building components: doors, windows, interior walls, exterior walls, and floor/ceiling assemblies.

The second major accomplishment of this research is a special cost minimization method for the acoustical design of a multi-ccmponent wall. When used with appropriate cost estinating equations, this method provides the theoretical leastcost STC values for the constituent components of a wall which satisfy given composite noise control requirements within a reasonable range. The method also determines the minimum construction cost. For a fixed set of Component Design Categories and a fixed area distribution among components, a plot of minimum construction cost versus composite noise control requirement can be derived.

The cost minimization method has several applications. First, the theoretical STC values determined by the method provide a basis for a designer to select the specific values of each component STC. The designer can use the theoretical values to establish detailed component specifications and obtain refined construction cost estimates based on these designs and local economic conditions. Secondly, for a given area distribution of a particular set of Component Design Categories, the designer can use the method to estimate the change in construction cost for different composite noise control requirements. The plot of minimum construction cost versus the composite requirement provides the basis for this application. Thirdly, the method can be used to evaluate the cost implications of alternative designs. For a given composite noise control requirement, one can determine the effect on minimum construction cost of changing the component area distribution for a given set of Component Design Categories. Similarly, the designer can use the method to measure the cost consequences of changing the Component Design Categories for a particular component area distribution and composite nofse control requirement.

The primary focus of this report concerns the estimation of construction-related costs necessary to achieve alternative noise control specifications. The report also discusses other costs related to implementation of a model noise control code. Although a cost estimation model for quantifying these implementation costs is not developed here, the general overview of the relevant cost considerations provided in section 5 serves as an aid to establishing such cost estimates for the specific conditions of a local jurisdiction. 
1. American Soclety of Heating, Refrigerating, and Air-Conditioning Engineers, Inc., ASHRAE Handbook of Fundamentals, New York, 1972.

2. American Society of Testing and Materials, "Standard Classification for Determination of Sound Transmission Class," ASTM Standard No. E413-73, Annual Book of ASTM Standard, Philadelphia, 1973.

3. American Society of Testing and Materials, "Tentative Recommended Practice for Determining a Single-Number Rating of Airborne Sound Isolation in Multiunit Building Specifications," ASTM Standard No. E 597-77T, Annual Book of ASTM Standards, Philadelphia, 1977.

4. Architectural Aluminum Manufacturers Association, Architectural Aluminum Industry Statistical Review: 1980, Chicago, 1981。

5. Beranek, L.L., ed., Noise and Vibration Contro1, New York: McGraw-Hill Book Company, 1971.

6. Berendt, R.D., Winzer, G.E., and Burroughs, C.B., A Guide to Airborne, Impact and Structureborne Noise-Control in Multifamily Dwellings, Federal Housing Administration Publication 750, Washington, D.C., Department of Housing and Urban Development, September 1967.

7. Boeckh, Inc., "Architectural Fees", Boeckh Building Valuation Manual, 2nd ed., Milwaukee, Wisc., 1979.

8. Bolt, Beranek, and Newman, Inc., Development of Noise Control Requirements for Model Building Code, Interim Report No. 3547, Cambridge, Mass., 1977.

9. Bolt, Beranek, and Newman, Inc, Noise Control for Building Codes: Implementation Manual, Report No. 3837, Cambridge, Mass., 1978.

10. Bolt, Beranek, and Newman, Inc., Noise Control for Building Codes: Noise Control Provisions, Report No. 3759, Cambridge, Mass., 1978.

11. U.S. Department of Commerce, Construction Review, Washington, D.C. Published bimonthly.

12. U.S. Department of Energy, Office of Conservation and Solar Energy, Federal Register, Vol.45, No. 16 (1980), p。5644.

13. Fukiniski, T., and Yamamoto, T., "Field Measurement of Sound Insulation of Houses by the Integral of Sound Energy," Proceedings Inter-Noise 75, Sandai, Japan: Inter-Noise 75, 1975, pp.351-354.

14. Gilbert, P., An Investigation of the Protection of Dwellings from External Noise through Facade Walls, Paris: Centre Scientifique et Technique du Batiment, Translated in National Bureau of Standards, Technical Note 710-2, Washington, D.C., March 1972. 
15. Hedeen, R.A., Compendium of Materials for Noise Control, Washington, D.C., Department of Health, Education and Welfare, National Institute of Occupational Safety and Health, Report DHEW (NIOSH) 80-116, May 1980.

16. Hildebrand, F.B., Methods of Applied Mathematics, New York: Prentice-Hall, Inc., 1952 .

17. International Conference of Building Officials, Uniform Building Code, 1979 ed., Whittier, California, 1979.

18. International Organization for Standardization, "Field Measurements of Airborne Sound Insulation of Facade Elements and Facades," International Standard ISO 140/V-1978(E), Acoustics-Measurement of Sound Insulation in Buildings and of Building Elements, 1978-07-15, 1st ed., Geneva, 1978, Part V.

19. Lewis, P.T., "A Method for Fleld Measurement of the Transmission Loss of Building Facades," Journal of Sound and Vibration, Vol. 33, No. 2 (1974), pp. 127-141.

20. L junggren, S., Sound Insulation of Windows with Respect to Traffic Noise, Report No. H-3065-A, Gothenburg, Sweden: Ingemanssons Ingenjörsbyra $A B$, February 1972 .

21. Mange, G.E., Skale, S.R., and Sutherland, L.C., Background Report on Outdoor-Indoor Noise Reduction Calculation Procedures Employing the Exterior Wall Noise Rating (EWNR) Method, Report No. FHWA-TS-77-220, Washington, D.C., U.S. Department of Transportation, Federal Highway Administration, March 1978.

22. McKee-Berger-Mansueto, Inc., Building Cost File: Eastern Edition, New York: Von Nostrand Reinhold Company, 1978.

23. McKee-Berger-Mansueto, Inc., Design Cost File, New York: Von Nostrand Reinhold Company, 1979.

24. Pallett, D.S. et al., Design Guide for Reducing Transportation Noise in and Around Buildings, National Bureau of Standards, Building Science Series 84, Washington, D.C., 1978.

25. Quirt, J.D., Measurement of Sound Transmission Loss of Windows, Building Research Note No. 172, National Research Council of Canada, Ottawa, 1981.

26. Ruegg, R. T. et al., Life-Cycle Costing: A Guide for Selecting Energy Conservation Projects for Public Buildings, National Bureau of Standards, Building Science Series 113, Washington, D.C., September 1978.

27. Sabine, H. J. et al., Acoustical and Thermal Performance of Exterior Walls, Doors, and Windows, Washington, D.C.: U.S. Department of Commerce, National Bureau of Standards, 1975. 
28. Sharp, B.H., Kasper, P.K., and Montrol, M.L., Sound Transmission through Building Structures-Review and Recommendations for Research, National Bureau of Standards, Report No. GCR-80-250, Washington, D.C., July 1980.

29. Ungar, E.E., Structureborne Sound in Buildings: Needed Practical Research in Light of the Current State-of-the-Art, National Bureau of Standards, Report No. GCR-80-250, Washington, D.C., June 1980 . 
This appendix contains cost estimating equations for most commonly used designs in multifamily residential and educational buildings. These equations are to be used in estimating changes in basic construction costs resulting from noise control requirements. The estimated costs are all expressed in $\$ / \mathrm{sf}$. The estimating equations are grouped according to the five major building components likely to be affected by noise control requirements: (1) Doors; (2) Windows and Sliding Glass Doors; (3) Exterior Walls; (4) Interior Walls; and (5) Floor/Ceiling Assemblies. Within each building component group there is an estimating equation for each $C D C$, as explained in section 3 . For each $C D C$ there is a list of specificacions which describe the architectural design for the equation. The cost estimating equation is reported along with the t-statistic indicating the significance of the estimated coefficient of STC. The adjusted $\mathrm{R}^{2}$, the range of STC values, and the number of individual designs used in the regression are also reported for each $\mathrm{CDC}$. The data listed in table 3.2 are obtained by rounding the data presented in this appendix.

\section{NOTE :}

The value of the t-statistic is enclosed in parenthesis below the STC coefficient. The following notation is used:

(Value)* denotes a 95 percent level of confidence; and (Value)** denotes a 99 percent level of confidence. 
APPENDIX A.1。 DOORS

CDC Headings

A.1.1 Wood or Metal Doors

$A-2$ 


\section{A.1.1 Wood or Metal Doors}

$$
\begin{aligned}
\text { Cost }=0.769+ & 0.4616 \mathrm{STC} \\
& (6.6114) * *
\end{aligned}
$$

Ad justed $R^{2}=.84224$

STC Range Covered: 20-51

Number of Designs: 9

Description:

1. 3'x7' Door; Metal or Wood; Unfinished

2. Assumed Constant Frame; Weatherstripped Continuously

3. Hardware Assumed Constant 
APPENDIX A.2. WINDOWS AND SLIDING GLASS DOORS

CDC Headings

A.2.1 Aluminum Frame Fixed Sheet or Plate Glass

A.2.2 Aluminum Frame Fixed Tempered Glass

A.2.3 Steel Frame Fixed Sheet or Plate Glass

A.2.4 Steel Frame Fixed Tempered Glass

A.2.5 Aluminum Frame Pivoting Casement Sheet or Plate Glass

A.2.6 Aluminum Frame Pivoting Casement Tempered Glass

A.2.7 Steel Frame Pivoting Casement Sheet or Plate Glass

A.2.8 Steel Frame Pivoting Casement Tempered Glass

A.2.9 Aluminum Frame Double Hung Sheet or Plate Glass

A.2.10 Aluminum Frame Double Hung Tempered Glass

A.2.1 Steel Frame Double Hung Sheet or Plate Glass

A.2.12 Stee1 Frame Double Hung Tempered Glass

A.2.13 Aluminum Frame Horizontal S1iding Sheet or Plate Glass

A.2.14 Aluminum Frame Horizontal Sliding Tempered Glass

A.2.15 Sliding Glass Door 
A.2.1 Sheet or Plate Glass

Cost $=-13.099+0.9401$ STC $(14.8576) * *$

Ad justed $R^{2}=.956474$

STC Range Covered: 29-47

Number of Designs: 11

\section{Insulating Glass}

$\begin{array}{llll}\text { Thickness(in) } & 1 / 2 & 5 / 8 & 1\end{array}$

$\begin{array}{llll}\text { Cost } & 24.35 & 25.87 & 27.30\end{array}$

$\begin{array}{llll}\text { STC } & 32 & 34 & 36\end{array}$

\section{A.2.2 Tempered Glass \\ Cost $=-6.4391+0.8113$ STC \\ $(5.35736) * *$}

Ad justed $R^{2}=.798279$

STC Range Covered: 31-47

Number of Designs: 8

Laminated Glass

\begin{tabular}{lrrr} 
Thickness(in) & \multicolumn{1}{c}{$5 / 16$} & $1 / 2$ & $3 / 4$ \\
Cost & 21.37 & 23.31 & 28.20 \\
STC & 36 & 40 & 43
\end{tabular}




$$
\begin{array}{r}
\text { A.2.3 Sheet or Plate Glass } \\
\text { Cost }=-13.476+\begin{array}{r}
0.7880 \mathrm{STC} \\
(10.6121) * *
\end{array}
\end{array}
$$

Adjusted $\mathrm{R}^{2}=.917774$

STC Range Covered: 29-47

Number of Designs: 11

\section{Insulating Glass}

$\begin{array}{lrrr}\text { Thickness(in) } & 1 / 2 & 5 / 8 & 1 \\ \text { Cost } & 21.29 & 21.77 & 22.25 \\ \text { STC } & 32 & 34 & 36\end{array}$

$$
\begin{aligned}
& \text { A.2.4 Tempered Glass } \\
& \text { Cost }=-8.128+0.7171 \mathrm{STC} \\
& (9.40619) * *
\end{aligned}
$$

Ad justed $R^{2}=.925907$

STC Range Covered: 31-47

Number of Designs: 8

Laminated Glass

$\begin{array}{lrrr}\text { Thickness(in) } & 5 / 16 & 1 / 2 & 3 / 4 \\ \text { Cost } & 15.27 & 18.21 & 23.10 \\ \text { STC } & 36 & 40 & 43\end{array}$




\section{A.2.5 Sheet or Plate Glass}

Cost $=-12.736+0.9446$ STC $(14.8948) * *$

Ad justed $R^{2}=.956683$

STC Range Covered: 29-47

Number of Designs: 11

\section{Insulating Glass}

$\begin{array}{lrrr}\text { Thickness(in) } & 1 / 2 & 5 / 8 & 1 \\ \text { Cost } & 24.93 & 26.50 & 27.83 \\ \text { STC } & 32 & 34 & 36\end{array}$

\section{A.2.6 Tempered Glass \\ Cost $=-7.966+0.8813$ STC \\ $(11.1561)$ **}

Ad justed $R^{2}=.946343$

STC Range Covered: 31-47

Number of Designs: 8

\section{Laminated Glass}

$\begin{array}{lrrr}\text { Thickness(in) } & 5 / 16 & 1 / 2 & 3 / 4 \\ \text { Cost } & 20.88 & 23.82 & 28.71 \\ \text { STC } & 36 & 40 & 43\end{array}$


A.2.7 Sheet or Plate Glass

Cost $=-13.508+0.7869$ STC

$(10.6103) * *$

Ad justed $R^{2}=.917749$

STC Range Covered: 29-47

Number of Designs: 11

Insulating Glass

$\begin{array}{llll}\text { Thickness(in) } & 1 / 2 & 5 / 8 & 1\end{array}$

$\begin{array}{llll}\text { Cost } & 18.96 \quad 20.95 & 22.15\end{array}$

$\begin{array}{llll}\text { STC } & 32 & 34 & 36\end{array}$

A.2.8 Tempered Glass

Cost $=-12.340+0.8483 \mathrm{STC}$

$(5.07651) * *$

Ad justed $\mathrm{R}^{2}=.779673$

STC Range Covered: 31-47

Number of Designs: 8

Laminated Glass

$\begin{array}{llll}\text { Thickness(in) } & 5 / 16 & 1 / 2 & 3 / 4\end{array}$

$\begin{array}{llll}\text { Cost } & 15.20 & 18.14 & 23.03\end{array}$

$\begin{array}{llll}\text { STC } & 36 & 40 & 43\end{array}$ 


\section{A.2.9 Sheet or Plate Glass}

Cost $=-12.659+0.9382$ STC

$(14.8353) * *$

Adjusted $R^{2}=.956348$

STC Range Covered: 29-47

Number of Designs: 11

\section{$\underline{\text { Insulating Glass }}$}

$\begin{array}{lrrr}\text { Thickness(in) } & 1 / 2 & 5 / 8 & 1 \\ \text { Cost } & 24.53 & 26.33 & 27.70 \\ \text { STC } & 32 & 34 & 36\end{array}$

\section{A.2.10 Tempered Glass}

Cost $=-7.850+0.8741$ STC

$(11.1259) * *$

Ad justed $R^{2}=.946065$

STC Range Covered: 31-47

Number of Designs: 8

Laminated Glass

$\begin{array}{lrrr}\text { Thickness(in) } & 5 / 16 & 1 / 2 & 3 / 4 \\ \text { Cost } & 20.75 & 23.69 & 28.58 \\ \text { STC } & 36 & 40 & 43\end{array}$




\author{
A.2.11 Sheet or Plate Glass \\ Cost $=-13.743+0.8043$ STC \\ $(10.6796) * *$ \\ Ad justed $R^{2}=.918735$ \\ STC Range Covered: 29-47 \\ Number of Designs: 11
}

\title{
Insulating Glass
}

$\begin{array}{llll}\text { Thickness(in) } & 1 / 2 & 5 / 8 & 1\end{array}$

$\begin{array}{llll}\text { Cost } & 19.32 & 26.06 & 22.15\end{array}$

$\begin{array}{llll}\text { STC } & 32 & 34 & 36\end{array}$

A.2.12 Tempered Glass

Cost $=-8.183+0.7244$ STC

$(7.89161) * *$

Ad justed $\mathrm{R}^{2}=.897477$

STC Range Covered: 31-47

Number of Designs: 8

\section{Laminated Glass}

$\begin{array}{llll}\text { Thickness(in) } & 5 / 16 & 1 / 2 & 3 / 4\end{array}$

$\begin{array}{llll}\text { Cost } & 15.54 & 18.48 & 23.37\end{array}$

$\begin{array}{llll}\text { STC } & 36 & 40 & 43\end{array}$

A-10 
A.2.13 Sheet or Plate Glass

Cost $=-12.458+0.8781$ STC

$(13.643) * *$

Adjusted $\mathrm{R}^{2}=.948752$

STC Range Covered: 29-47

Number of Designs: 11

\section{Insulating Glass}

$\begin{array}{llll}\text { Thickness(in) } & 1 / 2 & 5 / 8 & 1\end{array}$

$\begin{array}{llll}\text { Cost } & 22.80 & 23.52 & 23.97\end{array}$

$\begin{array}{llll}\text { STC } & 32 & 34 & 36\end{array}$

$$
\begin{aligned}
\text { A.2.14 Tempered Glass } & \text { Tost }=-7.087+\begin{array}{l}
0.8024 \text { STC } \\
(9.9424) * *
\end{array}
\end{aligned}
$$

Ad justed $R^{2}=.933239$

STC Range Covered: 31-47

Number of Designs: 8

Laminated Glass

$\begin{array}{lrrr}\text { Thickness(in) } & 5 / 16 & 1 / 2 & 3 / 4 \\ \text { Cost } & 19.02 & 21.96 & 26.85 \\ \text { STC } & 36 & 40 & 43\end{array}$




\section{A.2.15 Sliding Glass Doors}

Glass Type

Thickness(in)

Cost

STC
Plate

$1 / 4$

22.89

31
Insulating

$5 / 8$

27.47

34
Insulating

1

30.19

36 


\section{APPENDIX A.3. EXTERIOR WALLS}

CDC Headings

A.3.1 Stud Frame Wall with Wood Siding Exterior

A.3.2 Stud Frame Wall with Stucco Exterior

A.3.3 Stud Frame Wall with Aluminum Siding Exterior

A.3.4 Stud Frame Wall with Metal Siding $22 \mathrm{Ga}$. Exterior

A.3.5 Stud Frame Wall with Brick Veneer

A.3.6 Cast In Place Concrete Wal1

A.3.7 Concrete Wall with Brick Veneer

A.3.8 Concrete Block Wall

A.3.9 Concrete Block Wal1: Without Parge Coat, With Brick Veneer

A.3.10 Concrete Block Wall: With Parge Coat and Brick Veneer

A.3.11 Granite Veneer

A.3.12 Marble Veneer

A.3.13 Limestone Veneer

A.3.14 Precast Concrete Walls 
A.3.1 Stud Frame Walls with Wood Siding Exterior

$$
\begin{aligned}
\text { Cost }=1.144+ & 0.0715 \text { STC } \\
& (3.74847) *
\end{aligned}
$$

Adjusted $\mathrm{R}^{2}=.723008$

STC Range Covered: 37-48

Number of Designs: 6

Description:

1. Steel or Wood Frame; Thickness $31 / 4 "-6 "$

2. 1/2" Firecode Drywall; Taped and Spackled

3. $21 / 2 "$ Fiberglass Insulation

4. 5/8" Gypsum Sheathing; Felt and Foil Backed

5. Stained Siding: Textured Plywood, Clapboard, Redwood, or Hardwood

\section{A.3.2 Stud Frame Walls with Stucco Exterior}

Cost $=2.001+0.0516$ STC

$(3.24024) *$

Ad justed $R^{2}=.655153$

STC Range Covered: 37-47

Number of Designs: 6

Description:

1. Steel or Wood Frame; Thickness $31 / 4 "-6$ "

2. 1/2" Firecode Drywa11; Taped and Spackled

3. $21 / 2^{\prime \prime}$ Fiberglass Insulation

4. 5/8" Gypsum Sheathing; Felt and Foil Backed

5. 3/4" Stucco on Self Firr Lath 


\section{A.3.3 Stud Frame Walls with Aluminum Siding Exterior}

$$
\begin{aligned}
\text { Cost }=-0.628+ & 0.1103 \text { STC } \\
& (3.34714) *
\end{aligned}
$$

Ad justed $R^{2}=.629706$

STC Range Covered: $37-50$

Number of Designs: 7

Description:

1. Steel or Wood Frame; Thickness $31 / 4^{\prime \prime}-6 "$

2. 1/2" Firecode Drywal1; Taped and Spackled

3. $21 / 2$ " Fiberglass Insulation

4. 5/8" Gypsum Sheathing; Felt and Foil Backed

5. Siding; Insulated and Non-Insulated Aluminum

A.3.4 Stud Frame Walls with Metal Siding $22 \mathrm{Ga}$. Exterior

$\begin{aligned} \text { Cost }=4.454+ & 0.0715 \text { STC } \\ & (3.74847) *\end{aligned}$

Adjusted $\mathrm{R}^{2}=.723008$

STC Range Covered: 37-48

Number of Designs: 6

Description:

1. Steel or Wood Frame; Thickness $31 / 4 "-6$ "

2. 1/2" Firecode Drywa11; Taped and Spackled

3. $21 / 2 "$ Fiberglass Insulation

4. 5/8" Gypsum Sheathing; Felt and Foil Backed

5. Siding; 22 Ga. Metal; Porcelain Enameled 


\section{A.3.5 Stud Frame Wall with Brick Veneer}

$\begin{aligned} \text { Cost }=2.068+ & 0.0791 \mathrm{STC} \\ & (6.83657) * *\end{aligned}$

Adjusted $\mathrm{R}^{2}=.91958$

STC Range Covered: 48-65

Number of Designs: 5

Description:

1. Wood and Metal Framing

2. Standard Face Brick; Tooled Finish

3. Wall Ties

4. Varied With and Without 4" Batt Insulation

5. Flashed and Dampproofed 


\section{A.3.6 Cast In Place Concrete Wall}

$\begin{aligned} \text { Cost }=0.218+ & 0.177 \mathrm{STC} \\ & (8.27719) * *\end{aligned}$

Adjusted $\mathrm{R}^{2}=.882371$

STC Range Covered: 47-60

Number of Designs: 10

Description:

1. Concrete; 3000 psi, Rebars; Thickness 6"-15"

2. Varied With and Without 1" Rigid Insulation

3. Dampproofed

\section{A.3.7 Concrete Wal1 with Brick Veneer}

$\begin{aligned} \text { Cost }=-44.463 & +1.0940 \mathrm{STC} \\ & (30.0886) * *\end{aligned}$

Ad justed $\mathrm{R}^{2}=.996694$

STC Range Covered: 53-56

Number of Designs: 4

Description:

1. Cast In Place Concrete; 3000 psi; Thickness 6" $-12^{\prime \prime}$

2. Standard Face Brick; Tooled Finish

3. Wall Ties and Shelf Angles

4. Varied With and Without 1" Rigid Insulation

5. Flashed and Dampproofed 


$$
\begin{array}{r}
\text { A.3.8 Concrete Block Wall } \\
\begin{aligned}
\text { Cost }=-6.133+ & 0.2452 \mathrm{STC} \\
& (17.2591)^{* *}
\end{aligned}
\end{array}
$$

Adjusted $\mathrm{R}^{2}=.899962$

STC Range Covered: 44-80

Number of Designs: 34

Description:

1. Concrete Block; Heavyweight; Split and Smooth Face; Tooled Finish; 2 Coats of Silicone Dampproofing

2. Durowa11 Every 2nd Course

3. Flashed and Asphalt Dampproofing

4. Varied With and Without 1" Rigid Insulation

5. The upper STC limit is based upon an estimate for a double wall of solid concrete block separated by an airspace.

\section{A.3.9 Concrete Block Wall: Without Parge Coat, With Brick Veneer}

Cost $=-23.250+0.609$ STC

$$
(83.3679) * *
$$

Ad justed $\mathrm{R}^{2}=.999281$

STC Range Covered: 50-55

Number of Designs: 6

Description:

1. Standard Face Brick; Tooled Finish

2. Concrete Block; Light and Heavyweight; 3000 psi; Joints Struck Smooth; Reinforced; Thickness 4"-8"

3. Wa11 Ties

4. Varied With and Without 1" Rigid Insulation

5. Flashed and Dampproofed 


\section{A.3.10 Concrete Block Wall: With Parge Coat and Brick Veneer}

$\begin{aligned} \text { Cost }=-8.504+ & 0.2734 \text { STC } \\ & (7.25868) * *\end{aligned}$

Adjusted $\mathrm{R}^{2}=.911799$

STC Range Covered: 58-63

Number of Designs: 6

Description:

1. Concrete Block; Light and Heavyweight; Joints Struck Smooth; Thickness 4"-8"

2. Standard Face Brick; Tool Finish

3. Wall Ties

4. Varied With and Without 1" Rigid Insulation

5. Flashed and Dampproofed

\section{A.3.11 Granite Veneer}

Cost $=3.464+0.4079$ STC

$(11.3246) * *$

Ad justed $R^{2}=.947857$

STC Range Covered: 50-61

Number of Designs: 8

Description:

1. Finished Granite; Median Quality; Thickness 2" or 3"

2. Concrete Block; Heavyweight; Joints Struck Smooth; 6"-12"

3. Varied With and Without 1 " Rigid Insulation

4. Steel Shelf Angle and Stone Anchor

5. Flashed and Dampproofed 


\section{A.3.12 Marble Veneer}

$\begin{aligned} \text { Cost }=4.010+ & 0.3864 \text { STC } \\ & (6.7044) * *\end{aligned}$

Ad justed $R^{2}=.862608$

STC Range Covered: 50-61

Number of Designs: 8

Description:

1. Finished Marble, Median Quality $11 / 2^{\circ}-21 / 4^{*}$

2. Concrete Block; Heavyweight; Joints Struck Smooth; 6" -12 "

3. Varied With and Without $1^{\prime \prime}$ Rigid Insulation

4. Steel Shelf Angle and Stone Anchor

5. Flashed and Dampproofed

$$
\begin{aligned}
\text { A.3.13 } & \text { Limestone Veneer } \\
\text { Cost }=1.536+ & \begin{array}{r}
0.2989 \mathrm{STC} \\
(11.7394) * *
\end{array}
\end{aligned}
$$

Ad justed $\mathrm{R}^{2}=.951326$

STC Range Covered: 50-61

Number of Designs: 8

Description:

1. Limestone Panels; Light Texture 2"-4"

2. Concrete Block; Joints Struck Smooth; 6"-12"

3. Varied With and Without 1" Rigid Insulation

4. Steel Shelf Angle and Stone Anchor

5. Flashed and Dampproofed 


\section{A.3.14 Precast Concrete Walls}

Cost $=1.997+0.2683$ STC

$(21.6376) * *$

Ad justed $R^{2}=.970905$

STC Range Covered: 40-61

Number of Designs: 15

Description:

1. Precast Concrete; Self Anchored and Masonry Anchored; Thickness 4"-6"

2. Varied Rigid Insulation $1 ", 11 / 2 "$, and None

3. Masonry Block; Joints Struck Smooth; Thickness 8"-12"

4. Stone Anchor

5. Dampproofed 


\section{APPENDIX A.4. INTERIOR WALLS}

CDC Headings
A.4.1 Wood Stud Frame Plaster Partition
A.4.2 Metal Stud Frame Plaster Partition With Gypsum Lath
A.4.3 Shaft Stud Frame Drywal1 Partition
A.4.4 Wood Stud Frame Drywall Partition
A.4.5 Metal Stud Frame Drywall Partition
A.4.6 Concrete Partition Cast In Place
A.4.7 Brick Partition
A.4.8 Block Partition Lightweight Concrete Block
A.4.9 Heavyweight Concrete Block Partition
A.4.10 Structural Clay Tile Partition 
A.4.1 Wood Stud Frame Plaster Partition

Cost $=0.904+0.0633 \mathrm{STC}$

$(3.48883) * *$

Adjusted $\mathrm{R}^{2}=.503878$

STC Range Covered: 32-45

Number of Designs: 12

Description:

1. Wood Studs With Blocking; Thickness 3"-6" Nomina1

2. Gypsum Plaster; Varied 1-3 Coats; Sanded

3. Varied; Gypsum Lath $3 / 8 "-1 / 2 "$; Metal Lath 3.41 b.; Drywal1 1/2"-1 1/4"; With and Without $11 / 2$ " Soundproof Glass Fiber Insulation

\section{A.4.2 Metal Stud Frame Plaster Partition With Gypsum Lath}

Cost $=-0.048+0.0755 \mathrm{STC}$

$(3.91263) * *$

Ad justed $\mathrm{R}^{2}=.565366$

STC Range Covered: 38-52

Number of Designs: 12

Description:

1. Meta1 Studs With Runners and Bracing; Thickness $15 / 8^{\prime \prime}-31 / 4^{\prime \prime}$

2. Gypsum Lath; Perforated; Thickness $3 / 8^{\prime \prime}$ and $1 / 2$ "

3. Gypsum Plaster; 2 Coats; Sanded; Thickness $3 / 8^{\prime \prime}$ and $1 / 2 "$

4. Varied With and Without Resilient Clips

5. Varied With and Without $11 / 2$ " Soundproof Glass Fiber Insulation 


\section{A.4.3 Metal Shaft Frame Drywall Partition}

$$
\begin{aligned}
\text { Cost }=1.619+ & 0.0475 \text { STC } \\
& (8.08837) * *
\end{aligned}
$$

Ad justed $\mathrm{R}^{2}=.697041$

STC Range Covered: 25-59

Number of Designs: 29

Description:

1. Shaft Studs $11 / 2^{\prime \prime}-4 "$

2. Firecode Drywa11; Taped and Spackled; Thickness $1 / 2^{\prime \prime}-11 / 4^{\prime \prime}$

3. Coreboard; Thickness $1^{\prime \prime}$ or $2^{\prime \prime}$

4. Varied With and Without Resilient Channels

5. Varied With and Without 1 1/2" Soundproof Glass Fiber Insulation

\section{A.4.4 Wood Stud Frame Drywall Partition}

Cost $=-1.363+0.1080 \mathrm{STC}$

$(4.19982) * *$

Ad justed $\mathrm{R}^{2}=.648965$

STC Range Covered: 32-47

Number of Designs: 10

Description:

1. Wood Stud With Blocking; Thickness 3"-6" Nominal

2. Firecode Drywal1; Taped and Spackled; Thickness 1/2" and 5/8"

3. Varied With and Without Resilient Clips

4. Varied With and Without 1 1/2" Soundproof Glass Fiber Insulation 


\title{
A.4.5 Metal Stud Frame Drywall Partition
}

$$
\begin{aligned}
\text { Cost }=-0.692+ & 0.0740 \mathrm{STC} \\
& (10.5884) * *
\end{aligned}
$$

Adjusted $\mathrm{R}^{2}=.874129$

STC Range Covered: 38-55

Number of Designs: 17

Description:

1. Metal Studs With Runners and Bracing; Thickness $15 / 8^{\prime \prime}-31 / 4^{\prime \prime}$

2. Firecode Drywall; Taped and Spackled; Thickness $1 / 2^{\prime \prime}$ and 5/8"

3. Varied With and Without Resilient Clips

4. Varied With and Without 1 1/2" Soundproof Glass Fiber Insulation

\author{
A.4.6 Concrete Partition Cast In Place \\ Cost $=1.323+0.1440 \mathrm{STC}$ \\ $(13.9371) * *$ \\ Ad justed $R^{2}=.96024$ \\ STC Range Covered: 46-62 \\ Number of Designs: 9 \\ Description:
}

1. Concrete: Lightweight and Regular; 3000 psi

2. Spaded Clean

3. Rebars

4. Partition Thickness 6"-16" 


$$
\begin{aligned}
& \text { A.4.7 Brick Partition } \\
& \text { Cost }=-22.660+0.5538 \text { STC } \\
& (19.8403) * *
\end{aligned}
$$

Ad justed $R^{2}=.987426$

STC Range Covered: 47-67

Number of Designs: 6

Description:

1. Common Face Brick

2. Common Brick

3. Tooled Joints

\section{A.4.8 Block Partition Lightweight Concrete Block}

$$
\begin{aligned}
\text { Cost }=-1.608+ & 0.0983 \text { STC } \\
& (11.384) * *
\end{aligned}
$$

Adjusted $\mathrm{R}^{2}=.89554$

STC Range Covered: 32-53

Number of Designs: 16

Description:

1. Lightweight Concrete Block: Solid and Hollow Core

2. Joints Struck Smooth

3. Durowall Reinforcing Every 2nd Course

4. Partition Thickness $3 "-12 "$ 


\section{A.4.9 Heavyweight Concrete Block Partition}

Cost $=0.804+0.0792$ STC

$(6.89108) * *$

Ad justed $R^{2}=.756046$

STC Range Covered: 35-58

Number of Designs: 16

Description:

1. Heavyweight Concrete Block; Joints Struck Smooth

2. Durowall Reinforcing Every 2nd Concrete

\section{A.4.10 Structural Clay Tile Partition}

Cost $=-5.238+0.1899$ STC

$(7.10287) * *$

Ad justed $R^{2}=.722428$

STC Range Covered: 35-43

Number of Designs: 20

Description:

1. Structural Clay Tile; Hollow Core; Joints Struck Smooth; Rough and Smooth Surface

2. Durowal1 Reinforced Every 2nd Course 


\section{APPENDIX A.5. FLOOR/CEILING ASSEMBLIES}

CDC Headings

A.5.1 Wood Joists With Drywall Ceiling

A.5.2 Wood Joists With Plaster Ceiling on Gypsum Lath

A.5.3 Wood Joists With Plaster Ceiling on Metal Lath

A.5.4 Drop Ceiling Panels Added to Floor Structural System

A.5.5 Drywall Ceiling Added to Concrete Slab

A.5.6 Steel Joists \& Drywall Ceiling Added to Floor Structural System 


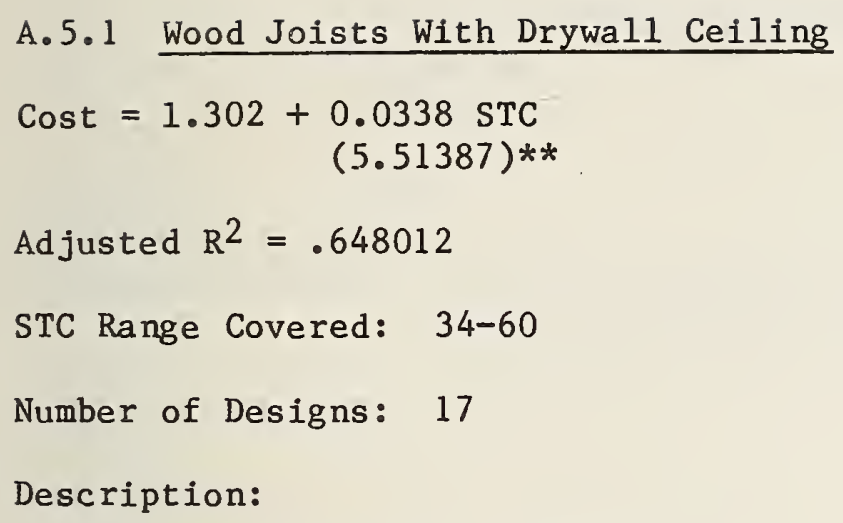

Adjusted $\mathrm{R}^{2}=.648012$

STC Range Covered: $34-60$

Number of Designs: 17

Description:

1. 2" $\mathrm{x} 8$ " Wood F1oor Joists

2. Bridging

3. 5/8" T\&G Plywood

4. 3/8"-1 1/4" Drywall; Taped and Spackled

5. Varied With, Without and In Combination: Various Backing and Core Boards; Resilient Clips; and 1"-4" Insulation

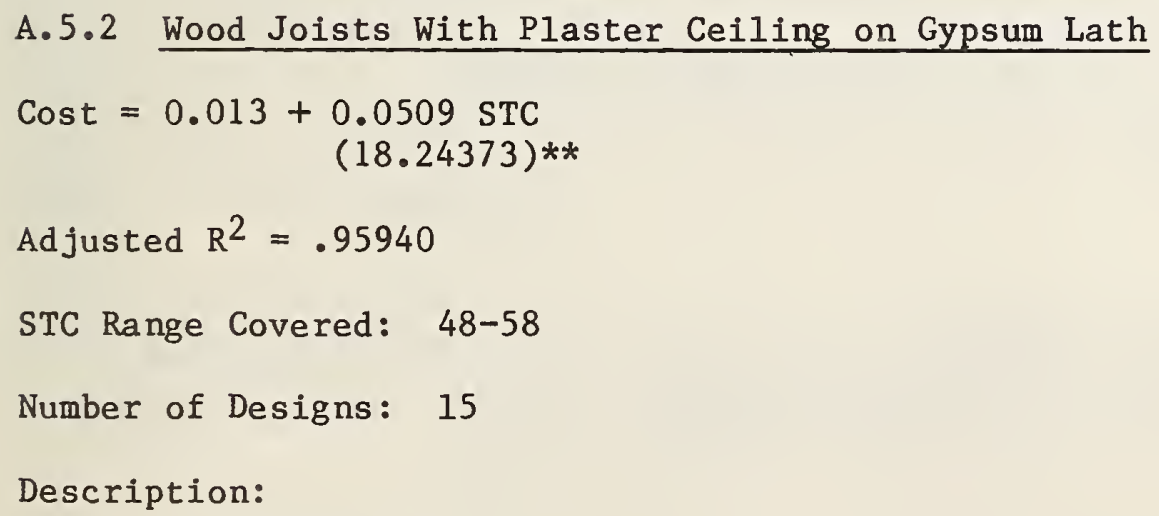

1. 2" 88 " Wood Floor Joists

2. Bridging

3. 5/8" T\&G Plywoood

4. Gypsum Lath $3 / 8^{\prime \prime}-1 / 2 "$ and Two Coats of Gypsum Plaster

5. Varied With, Without and In Combinations: $2 "-4$ " of Insulation; $1 / 4^{\prime \prime}-5 / 8^{\prime \prime}$ Gypsum Backing Board; and Resilient Clips 


\section{A.5.3 Wood Joists With Plaster Ceiling on Metal Lath}

$$
\begin{aligned}
\text { Cost }=0.684+ & 0.0557 \text { STC } \\
& (11.9017)^{*}
\end{aligned}
$$

Ad justed $\mathrm{R}^{2}=.88641$

STC Range Covered: 41-58

Number of Designs: 19

Description:

1. $2 " \times 8$ " Wood Floor Joists

2. Bridging

3. 5/8" T\&G Plywood

4. Metal Lath With Plaster or special acoustical plaster

5. Varied With, Without, and In Combination: Various Backing and Core Boards; 1"-4" Insulation

\section{A.5.4 Drop Ceiling Panels Added to Floor Structural System}

$$
\begin{aligned}
\text { Cost }=-0.075+ & 0.0443 \text { STC } \\
& (2.81656) *
\end{aligned}
$$

Ad justed $R^{2}=.464273$

STC Range Covered: 25-40 Not Including STC for the Floor Structural System of the Floor/Ceiling Assembly

Number of Designs: 9

Description:

1. Various Ceiling Tiles With Appropriate Mounting Material

Note: The cost and STC values for the floor structural system of the floor/ ceiling assembly are not included in this estimating equation. Before the floor/ceiling assembly's complete Total Cost and STC values can be applied in this methodology, the Total Cost and STC values of the floor structural system must be determined independently and then combined with the corresponding values derived from the estimating equation. 


\section{A.5.5 Deck Drywall Ceiling Added to Concrete Slab}

Cost $=0.588+0.0388$ STC

$(6.32012) * *$

Ad justed $R^{2}=.829584$

STC Range Covered: 8-22 Not Including STC for the Floor Structural System of the Floor/Ceiling Assembly

Number of Designs: 9

Description:

1. $1 " \times 2 "$ Furring

2. $3 / 8 "-5 / 8 "$ Gypsum Drywall; Tape and Spackle

3. Varied With and Without 1" Mineral Fiber Insulation; and Also With and Without Resilient Clips

Note: The cost and STC values for the floor structural system of the floor/ ceiling assembly are not included in this estimating equation. Before the floor/ceiling assembly's complete Total Cost and STC values can be applied in this methodology, the Total Cost and STC values of the floor structural system must be determined independently and then combined with the corresponding values derived from the estimating equation. In this case, a concrete slab is the only type of floor structural system compatible with the design specifications used to develop this CDC estimating equation.

\section{A.5.6 Steel Joists With Drywall Ceiling Floor Structural System}

$$
\begin{aligned}
\text { Cost }=0.536+ & 0.0446 \text { STC } \\
& (14.5924) * *
\end{aligned}
$$

Ad justed $\mathrm{R}^{2}=.950659$

STC Range Covered: 8-27 Not Including STC for the Floor Structural System of the Floor/Ceiling Assembly

Number of Designs: 12

Description:

1. 1 "x2" Furring

2. 3/8"-5/8" Gypsum Drywall; Taped and Spackled 
3. Varied With, Without, and In Combinations: Various Backing and Core Boards; 1" -3 " Insulation; and Resilient Clips

Note: The cost and STC values for the floor structural system of the floor/ ceiling assembly are not included in this estimating equation. Before the floor/ceiling assembly's complete Total Cost and STC values can be applied in this methodology, the Total Cost and STC values of the floor structural system must be determined independently and then combined with the corresponding values derived from the estimating equation. 
The cost equations presented in Appendix $A$ are based on cost information from the Eastern Edition of the Building Cost File. That edition uses Philadelphia as the source of its basic cost information. In order to account for price diffferences between cities, it is necessary to multiply the result of any cost equation from Appendix A by a Regional Cost Adjustment Factor (RCAF). Table B.1 presents RCAFs for most major cities. The RCAF for a particular city is the ratio of the acoustical treatment cost index for that city divided by the acoustical treatment cost index for Philadelphia.

As an example of how to use the RCAF, suppose a building were to be constructed in Bismarck, North Dakota and one had calculated the increase in construction cost for doors to be $\$ 45.00$ per door including the contractor markup and the A\&E design fee. To calculate the increase in construction cost appropriate for Bismarck, one would do the following:

$$
\begin{aligned}
\text { Bismarck increase in cost } & =\text { Bismarck RCAF } \times \text { Base increase in cost } \\
& =(0.824) \times \$ 45.00 \\
& =\$ 37.08
\end{aligned}
$$

Thus the estimated increase in construction cost for the door in Bismarck, North Dakota would be $\$ 37.08$ per door. 
Table B.1. Regional Cost Adjustment Factors (RCAF) for Major U.S. Cities

\begin{tabular}{|c|c|c|}
\hline CITY & STATE & $\mathrm{RCAF}$ \\
\hline Abilene & $\mathrm{TX}$ & 0.843 \\
\hline Albany & NY & 0.942 \\
\hline Albuquerque & NM & 0.958 \\
\hline Amarillo & $\mathrm{TX}$ & 0.890 \\
\hline Anchorage & $\mathrm{AK}$ & 1.398 \\
\hline Atlanta & GA & 0.860 \\
\hline Baltimore & MD & 0.900 \\
\hline Bangor & $\mathrm{ME}$ & 0.904 \\
\hline 20 City Base & & 0.997 \\
\hline Baton Rouge & LA & 0.877 \\
\hline Billings & MT & 0.832 \\
\hline Binghamton & $\mathrm{NY}$ & 0.882 \\
\hline Birmingham & AL & 0.803 \\
\hline Bismarck & ND & 0.824 \\
\hline Boise & ID & 0.909 \\
\hline Boston & MA & 1.032 \\
\hline Buffalo & NY & 1.125 \\
\hline Burlington & $\mathrm{VT}$ & 0.948 \\
\hline Camden & $\mathrm{NJ}$ & 1.007 \\
\hline Centralia & IL & 0.921 \\
\hline Charleston & WV & 0.909 \\
\hline Charleston & SC & 0.761 \\
\hline Charlotte & NC & 0.778 \\
\hline
\end{tabular}


Table B.1. Regional Cost Adjustment Factors (RCAF) for Major U.S. Cities (Continue)

\begin{tabular}{|c|c|c|}
\hline CITY & STATE & $\underline{\mathrm{RCAF}}$ \\
\hline Cheyenne & WY & 0.924 \\
\hline Chicago & IL & 0.982 \\
\hline Cincinnati & $\mathrm{OH}$ & 1.200 \\
\hline Cleveland & $\mathrm{OH}$ & 1.138 \\
\hline Columbus & GA & 0.788 \\
\hline Columbus & $\mathrm{OH}$ & 1.131 \\
\hline Corpus Christi & $\mathrm{TX}$ & 0.844 \\
\hline Council Bluffs & IA & 0.824 \\
\hline Dallas & $\mathrm{TX}$ & 0.921 \\
\hline Denver & CO & 0.962 \\
\hline Des Moines & IA & 0.862 \\
\hline Detroit & MI & 1.229 \\
\hline Dover & $\mathrm{DE}$ & 0.931 \\
\hline Dubuque & IA & 0.888 \\
\hline Duluth & $\mathrm{MN}$ & 0.901 \\
\hline E1 Paso & $\mathrm{TX}$ & 0.849 \\
\hline Evansville & IN & 0.887 \\
\hline Fargo & ND & 0.847 \\
\hline Fort Worth & TX & 0.921 \\
\hline Fresno & $\mathrm{CA}$ & 1.108 \\
\hline Grand Rapids & MI & 1.104 \\
\hline Great Falls & MT & 0.872 \\
\hline Harrisburg & $\mathrm{PA}$ & 0.882 \\
\hline
\end{tabular}


Table B.1. Regional Cost Adjustment Factors (RCAF) for Major U.S. Cities (Continue)

CITY

Hartford

Honolulu

Houston

Indianapolis

Jackson

Jacksonville

Kansas City

Knoxville

Lansing

Las Vegas

Lexington

Little Rock

Los Angeles

Louisville

Madison

Manchester

Memphis

Miami

Milwaukee

Minneapolis

Mobile

Moline
STATE

CT

HI

TX

IN

MS

FL

MO

TN

MI

NV

KY

AR

CA

KY

WI

$\mathrm{NH}$

TN

FL

WI

MN

AL

IL

\section{RCAF}

0.950

0.946

0.942

1.192

0.864

0.873

0.886

0.801

1.152

1.024

1.129

0.799

1.044

1.129

0.890

0.915

0.881

0.886

0.959

0.918

0.911

0.865 
Table B.1. Regional Cost Adjustment Factors (RCAF) for Major U.S. Cities (Continue)

\begin{tabular}{|c|c|c|}
\hline CITY & STATE & $\underline{\mathrm{RCAF}}$ \\
\hline Nashville & $\mathrm{TN}$ & 0.824 \\
\hline Nassau- & & \\
\hline Suffolk County & NY & 1.052 \\
\hline New Haven & CT & 0.956 \\
\hline New Orleans & LA & 0.925 \\
\hline New York City & NY & 1.068 \\
\hline Newark & NJ & 0.981 \\
\hline Norfolk & VA & 0.815 \\
\hline North Platte & $\mathrm{NE}$ & 0.942 \\
\hline Oklahoma City & OK & 0.903 \\
\hline Omaha & $\mathrm{NE}$ & 0.878 \\
\hline Paduka & $\mathrm{KY}$ & 0.851 \\
\hline Peoria & IL & 0.954 \\
\hline Philadelphia & PA & 1.000 \\
\hline Phoenix & $\mathrm{AZ}$ & 0.983 \\
\hline Pittsburgh & PA & 1.010 \\
\hline Portland & OR & 1.073 \\
\hline Portland & $\mathrm{ME}$ & 0.904 \\
\hline Providence & $\mathrm{RI}$ & 1.004 \\
\hline Pueblo & $\mathrm{CO}$ & 0.933 \\
\hline Raleigh & NC & 0.778 \\
\hline Redding & $\mathrm{CA}$ & 1.106 \\
\hline Reno & $\mathrm{NE}$ & 0.980 \\
\hline \multicolumn{3}{|c|}{$B-5$} \\
\hline
\end{tabular}


Table B.1. Regional Cost Adjustment Factors (RCAF) for Major U.S. Cities (Continue)

\begin{tabular}{|c|c|c|}
\hline CITY & STATE & $\underline{\mathrm{RCAF}}$ \\
\hline Richmond & VA & 0.815 \\
\hline Roanoke & VA & 0.797 \\
\hline Sacramento & $\mathrm{CA}$ & 1.106 \\
\hline Salt Lake City & VT & 0.970 \\
\hline San Antonio & $\mathrm{TX}$ & 0.889 \\
\hline San Diego & $\mathrm{CA}$ & 1.004 \\
\hline San Francisco & $\mathrm{CA}$ & 1.106 \\
\hline San Juan & Puerto Rico & 0.709 \\
\hline Savannah & GA & 0.812 \\
\hline Scranton & PA & 0.899 \\
\hline Seattle & WA & 1.047 \\
\hline Shreveport & LA & 0.902 \\
\hline Sioux Falls & $\mathrm{SD}$ & 0.852 \\
\hline South Bend & IN & 0.915 \\
\hline Spokane & WA & 1.046 \\
\hline Springfield & MO & 0.860 \\
\hline Springfield & MA & 0.989 \\
\hline Springfield & IL & 0.921 \\
\hline St. Louis & MO & 0.919 \\
\hline Syracuse & NY & 1.077 \\
\hline Tallahassee & FL & 0.760 \\
\hline Tampa & FL & 0.865 \\
\hline Toledo & $\mathrm{OH}$ & 1.129 \\
\hline \multicolumn{3}{|c|}{$B-6$} \\
\hline
\end{tabular}


Table B.1. Regional Cost Adjustment Factors (RCAF) for Major U.S. Cities (Continue)

\begin{tabular}{lcc} 
CITY & STATE & $\underline{\text { RCAF }}$ \\
\cline { 2 - 3 } Topeka & KS & 0.835 \\
Trenton & NJ & 0.971 \\
Tulsa & OK & 0.906 \\
Tuscon & AZ & 0.983 \\
Washington & DC & 0.912 \\
$\begin{array}{l}\text { Westchester } \\
\text { County }\end{array}$ & NY & 0.992 \\
Wichita & KS & 0.848 \\
Wilmington & DE & 0.931 \\
Winston-Salem & NC & 0.778 \\
Yakima & WA & 1.047
\end{tabular}





\section{APPENDIX C \\ DESIGN OF MINIMUM COST MULTI-COMPONENT WALLS TO ACHIEVE A SPECIFIED LEVEL OF NOISE INSULATION}

This appendix describes a method for selecting the noise insulation values of each component of a multi-component wall so that the noise insulation property of the total structure meets a specified value and the total construction cost is minimized. The method uses the cost equations presented in Appendix A. The user selects the particular Component Design Categories corresponding to each component of the multi-component wall. Using a pocket calculator, the minimum cost design is obtained with a few minutes effort. Examples are presented in this appendix illustrating several uses of the method.

\section{C.1 NOISE INSULATION OF MULTI-COMPONENT WALLS}

A multi-component wall is a composite structure consisting of two or more different components. For example, a basic wall structure with doors and windows is a multi-component wal1. Each component may exhibit a different noise insulation property such as an STC rating. For the multi-component wall, it is then necessary to determine the noise insulation value of the multicomponent wall from the noise insulation properties of each of the components.

Assuming that the acoustic power is uniformly distributed over the surface of the multi-component wal1, the noise insulation of the wall is expressed in terms of the noise insulation properties of the $\mathrm{N}$ components by the relationship: 1

$$
R_{c}=-10 \log \left\{\sum_{i=1}^{N} k_{i} \cdot 10^{-R_{i} / 10}\right\} \quad, d B
$$

whe re

$$
\begin{aligned}
& \mathrm{R}_{\mathrm{C}}=\text { the "composite" noise insulation property of the multi-component } \\
& \text { wall; } \\
& \mathrm{R}_{\mathrm{I}}=\text { the noise insulation property of the ith component; } \\
& \mathrm{k}_{1}=\mathrm{S}_{\mathrm{i}} / \mathrm{S} \text { is the fraction of the total wall area, } S \text {, of the } i \text { th } \\
& \text { component; and } \\
& \mathrm{S}_{1}=\text { the wall area of the } i \text { th component. }
\end{aligned}
$$

Hence, to calculate the noise insulation property of the composite wall it is necessary to know both the noise insulation properties of the components and the fraction (or percentage) of the total wall area comprising each component.

Concerning the "noise insulation property" of both the component and the composite or multi-component wall, the relationship indicated by equation (C.1)

1 See L. L. Beranek, ed., Noise and Vibration Control (New York: McGraw-Hill Book Company, 1971) pp. 311-312. 
is applicable for sound transmission loss at a given frequency and for single number noise insulation ratings such as the Sound Transmission Class or STC rating. Since the cost equations presented in Appendix A are developed using the STC rating for noise insulation, the STC rating will be used for the noise insulation property of components in the remaining discussion of this appendix. That is, $R_{i}$ will denote the STC rating of the ith component of a multi-component wall and $R_{c}$ will denote the composite "STC rating" (i.e., the composite sound insulation property) of the multi-component wall.

For a majority of configurations encountered in practice, a multi-component wall comprising two or three elements is sufficient to characterize the structure. For example, common configurations of two component walls are a basic wall structure such as described by the Component Design Categories presented in Appendix A.3 an A.4 and either a door (Appendix A.1) or a glazing component (Appendix A.2). A three component wall may comprise a basic wall structure, doors, and a single type of glazing. Hence, it is convenient to present the general form of equation $(C .1)$ as specialized results for both the two component wall and the three component wall.

\section{C.1.1 Noise Insulation of a Two Component Wall}

For a two component wall, one sets $\mathrm{N}=2$ in equation ( $\mathrm{C} .1$ ) to obtain:

$$
R_{c}=-10 \log \left\{k_{1} 10^{-R_{1} / 10}+k_{2} 10^{-R_{2} / 10}\right\}
$$

Noting that $k_{1}+k_{2}=1$, this result may be further simplified to obtain:

$$
R_{c}=R_{1}-10 \log \left\{1+k_{2}\left[10^{\left(R_{1}-R_{2}\right) / 10}-1\right]\right\} \text {. }
$$

For example, if component 1 is a wall structure with an STC rating of 40 and component 2 is a door with an STC rating of 30 and the door comprises 15 percent of the total wall area, then $R_{1}=40, R_{2}=30$ and $k_{2}=0.15$ and $R_{c}=36.3$. The multi-component wall then is estimated to have an STC rating of 36 . (One should, in general, round fractions of a dB or STC ratings to the nearest whole integer.)

\section{C.1.2 Noise Insulation of a Three Component Wall}

For a three component wall, one sets $\mathrm{N}=3$ in equation ( $\mathrm{C} .1$ ) to obtain:

$$
R_{c}=-10 \log \left\{k_{1} 10^{-R_{1} / 10}+k_{2} 10^{-R_{2} / 10}+k_{3} 10^{-R_{3} / 10}\right\},
$$

where

$$
k_{1}+k_{2}+k_{3}=1 .
$$


For example, suppose that the door in the two component wall described in section C.1.1 is installed so that a perimeter crack exists around the door and the perimeter crack represents 0.5 percent of the total wall area. Denoting the crack as "component 3 " with an STC rating of zero, the composite STC rating is obtained using equation ( $C .3$ ) with the data: $R_{1}=40, k_{1}=0.85, R_{2}=30$, $\mathrm{k}_{2}=0.145$; and $\mathrm{R}_{3}=0, \mathrm{k}_{3}=0.005$. The composite STC rating with the door and the crack is $R_{C}=22.8$ or the composite STC rating is 23 . Hence, the 0.5 percent opening around the door results in a degradation of the noise insulation performance of 13 STC units. This example illustrates the importance of using gaskets and seals around doors and windows to maintain the design integrity of multi-component wall noise insulation.

\section{C.2 NOISE ISOLATION OF MULTI-COMPONENT WALLS}

The discussion of section C.l addresses the topic of noise insulation of multi-component walls. For the model described in this report, the single number noise insulation rating selected for use is the Sound Transmission Class or STC rating. 1 Noise insulation is a property of the structure that is determined from latoratory tests. Noise isolation is a measure of the overall noise attenuation achieved by a bullding structural component or components as realized in the specific bullt environment. This section discusses and presents relationships between noise insulation performance of a design and noise isolation performance of the constructed building. This relationship is necessary in order to understand the performance requirements for building structure noise isolation as used in noise control codes. 2

Basically, the noise isolation of a building component is measured as the difference between the sound level on the source side of the component and the sound level on the receiver side of the component. The noise insulation of the building component is defined in terms of the acoustic sound power incident upon the component on the source side and the sound power transmitted by the component to the receiving space. Hence, the rationship between the noise insulation property of the building component and the noise isolation performance of the component in the built environment involves the relationship between sound power and sound pressure on both the source side and the receiver side of the component. As might be expected, the relationship is different for components separating interior building spaces and for components separating an

1 See American Society of Testing and Materials, "Standard Classification for Determination of Sound Transmission Class," ASTM E413-73, Annual Book of ASTM Standards, 1973.

2 The discussion here will not attempt to consider flanking sound transmission. The interested reader should see B. H. Sharp, P. K. Kasper, and M. L. Montrol, Sound Transmission through Building Structures-Review and Recommendations for Research, National Bureau of Standards Report No. GCR-80-250 (Washington, D.C.: U.S. Department of Commerce, 1980) and E. E. Ungar, Structureborne Sound in Buildings: Needed Practical Research in Light of the Current State-of-the-Art, National Bureau of Standards Report No. GCR-80-248 (Washington, D.C.: U.S. Department of Commerce, 1980). 
interior space from intruding exterior noise. The performance requirements of the MNCC recognize these differences. The noise isolation requirements for interior walls are a distinct consideration from the noise isolation requirements for exterior walls.

\section{C.2.1 Noise Isolation of Interior Walls}

The airborne noise isolation requirements of interior walls are presented in tables 35-A and 35-B of the Model Noise Control Code. The requirements are specified in terms of the normalized sound level difference between adjacent interior spaces within the building. This quantity is determined by conducting field tests using the procedures of ASTM E597-77T, "Tentative Recommended Practice for Determining a Single-Number Rating of Airborne Sound Isolation in Multiunit Building Specifications." The definition used in that report for the normalized sound level difference is:

$$
D_{n}=\bar{L}_{S}-\bar{L}_{\mathrm{r}}+10 \log \left(S_{\mathrm{fl}} / A_{\mathrm{r}}\right) \text {, }
$$

where

$D_{n}$ is the normalized sound level difference

$\overrightarrow{\mathrm{L}}_{\mathrm{S}}$ is the average (A-weighted) sound level in the source room

$\overrightarrow{\mathrm{L}}_{\mathrm{r}}$ is the average (A-weighted) sound level in the receiving room

$\mathrm{S}_{\mathrm{fl}}$ is the floor area in the receiving room

$\mathrm{A}_{\mathrm{r}}$ is the amount of sound absorption in the receiving room.

The relationship indicated in equation (C.4) is the form used to present test results based upon ASTM E597-77T. The MNCC provisions in table 35-A indicate that the design value for the interior partition, in terms of the STC rating, should be selected 5 units above the required normalized sound level difference. This 5 unit adjustment is a design margin recommended by the MNCC provisions. The cost model developed in this appendix allows the designer to estimate the cost of incorporating this design margin so that a value may be placed upon this particular design approach。

\section{C.2.2 Noise Isolation of Exterior Walls}

The airborne noise isolation requirements of exterior walls are presented in table 35-C of the Model Noise Control Code. The requirements are specified as the "sound level reduction provided by the exterior shell。" As defined by the MNCC, the sound level reduction is the difference, in decibels, between the outdoor equivalent A-weighted sound level, $\mathrm{L}_{e q}$, and the corresponding equivalent Aweighted sound level inside the building. The exterior level is to be measured at a distance of 2 meters from the outside surface of the wall. In order to utilize the cost minimization model described in the next section of this appendix, it is necessary to develop a relationship between the A-weighted sound level reduction required by the MNCC provisions (table 35-C) and the composite STC rating, $R_{C}$, of the exterior wall as given by equation (C.1). The form of the relationship developed in this section is as follows:

$$
\mathrm{R}_{\mathrm{C}}=\Delta \mathrm{L}_{\mathrm{A}}+10 \log (\mathrm{S} / \mathrm{A})+\text { constant }
$$


where

$\mathrm{R}_{\mathrm{C}}$ is the composite STC rating for the multi-component exterior wall given by equation (C.1)

$\Delta \mathrm{L}_{\mathrm{A}}=\left(\mathrm{L}_{\mathrm{eq}}\right)_{2 \mathrm{~m}}-\left(\mathrm{L}_{\mathrm{eq}}\right)_{\text {interior }}$ is the A-weighted sound level reduction required by the MNCC provisions of table 35-C

$S$ is the total surface area of the exterior wall transmitting exterior sound into the interior receiving space

$A$ is the total sound absorption in the receiving space (average for the $500 \mathrm{~Hz}$ to $1 \mathrm{kHz}$ bands).

In equation ( $C .5$ ), the parameters 3 and $A$ must be expressed in consistent units (i.e., both in $\mathrm{m}^{2}$ or $\mathrm{sf}$ ). The following discussion focuses upon the determination of the "constant" appearing in equation (C.5).

Any relationship between a single number noise insulation rating, such as STC, of a composite exterior wall and the sound reduction achieved in the built environment is an approximation. For the purpose of formulating a building code provision and providing design guidance, differences between noise sources used in laboratory measurements and the environmental noise sources to which the building is exposed must be recognized. Specifically, the relationship must include the following considerations:

- Reflection of sound from the building exterior wall surface

- Non-diffuse sound fields generated by environmental noise sources

- Spectral characteristics of environmental noise sources.

The MNCC provisions require that the field noise isolation performance of the structure be verified using the procedures of ISO 140/V (1978), "AcousticsMeasurement of Sound Insulation in Buildings and of Building Elements, Part $V$. Field Measurements of Airborne Sound Insulation of Facade Elements and Facades." The testing, however, is to be performed using only A-weighted sound level data with the exterior measurement location being 2 meters from the facade exterior surface. This location is specified to relate field measured noise source sound levels to the corresponding source room sound level measured in the laboratory since in either case the measured levels are approximately $3 \mathrm{~dB}$ less than levels measured at the surface of the wall.

This observation would suggest that a measurement location on the exterior wall surface could be as easily justified as a location 2 meters from the exterior surface. There are practical considerations that favor either location ${ }^{1}$;

1 For discussion of these considerations, see P. T. Lewis, "A Method for Field Measurement of the Transmission Loss of Building Facades," Journal of Sound and Vibration, 33(2), 1974, pp. 127-141. 
however, the 2 meter location is used as the basis for the development in this appendix since it is the location required for the MNCC provisions.

First, it is necessary to quantify the effect of reflections of the incident sound from the exterior surface. To do this, a few terms must be defined. The sound level at a location on the exterior surface of the facade is denoted as $\left(\mathrm{L}_{e q}\right)$ surface. The sound level at a location 2 meters from this exterior surface location is denoted as $\left(\mathrm{L}_{\mathrm{eq}}\right) 2 \mathrm{~m}$. Both of these sound levels include the incident and the reflected components of the sound pressure. The sound level at this location on the exterior surface but in the physical absence of the surface is denoted as $\left(\mathrm{L}_{e q}\right)$ free. The $\left(\mathrm{L}_{\text {eq }}\right)_{\text {free }}$ sound level is a measure of only the incident sound pressure at the location of the facade since there is no physical surface present from which the incident sound can be reflected. For example, ( $L_{e q}$ ) free might be measured at a site before the building is constructed or might be predicted for locations on the exterior building surface.1 All of these sound levels will vary with location over the building surface.

Assuming perfect reflection of incident sound waves from the building exterior surface, the sound levels ( $\left.\mathrm{L}_{\text {eq }}\right)_{\text {surface, }}\left(\mathrm{L}_{\mathrm{eq}}\right)_{2 \mathrm{~m}}$, and $\left(\mathrm{L}_{\text {eq }}\right)_{\text {free }}$ are related as follows:

$$
\begin{array}{llll}
\left(\mathrm{L}_{e q}\right)_{2 m} & =\left(\mathrm{L}_{\text {eq }}\right) \text { surface } & -3 & \mathrm{~dB} \\
\left(\mathrm{~L}_{e q}\right)_{2 m} & =\left(\mathrm{L}_{\text {eq }}\right) \text { free } & +3 & \mathrm{~dB} \\
\left(\mathrm{~L}_{e q}\right) \text { surface } & =\left(\mathrm{L}_{\text {eq }}\right) \text { free } & +6 & \mathrm{~dB} .
\end{array}
$$

The assumption of perfect reflection of the incident sound waves applies to a smooth and acoustically hard exterior surface. It is recognized that this condition is rarely encountered in practice. However, experimental data describing effects of both irregular exterior surfaces and absorptive exterior surfaces are available for more refined estimates. 2

The MNCC provisions require a specified A-weighted Sound Level Difference, $\triangle_{\mathrm{L}} \mathrm{A}$, depending upon the predicted outdoor day-night sound level at the building site. Expressed in terms of the equivalent sound levels defined above, the required sound level reduction is expressed as:

$$
\Delta \mathrm{L}_{\mathrm{A}} \equiv\left(\mathrm{L}_{\mathrm{eq}}\right)_{2 \mathrm{~m}}-\left(\mathrm{L}_{\text {eq }}\right)_{\text {interior, }}
$$

where the term (Leq) interior is measured in the interior receiving space of the building according to the test provisions in ISO 140/V (1978).

1 The measurement and/or predictions in the free environment must include any shielding of the facade by the building.

2 One source of this data is P. Gilbert, An Investigation of the Protection of Dwellings from External Noise through Facade Walls, Centre Scientifique et Technique du Batiment, Paris, France, translated in NBS Technical Note 710-2, (Washington, D.C.: U.S. Department of Commerce, 1978). 
The result of equation ( $C .7$ ) bases the sound level reduction on an exterior mesurement at the 2 meter location including both incident and reflected components of the sound pressure. For subsequent use in the development of equation (C.5), it is necessary to express the sound level reduction in terms of $\left(\mathrm{L}_{\mathrm{eq}}\right)_{\text {free }}$ rather than $\left(\mathrm{L}_{\mathrm{eq}}\right)_{2 \mathrm{~m}}$. Substituting equation (C.6b) into equation (C.7), the sound level difference required by the MNCC provisions is expressed as:

$$
\Delta \mathrm{I}_{\mathrm{A}}=\left(\mathrm{L}_{\mathrm{eq}}\right)_{\text {free }}-\left(\mathrm{L}_{\mathrm{eq}}\right)_{\text {interior }}+3=\mathrm{SLR}+3
$$

This expression for the sound level reduction represents the effect of sound pressure reflections from the exterior surface of the structure as used in this development.

To incorporate the effect of non-diffuse exterior sound fields, it is necessary only to state that the requirement to use and equivalent or time-averaged sound level metric, such as $\mathrm{L}_{e q}$, also accounts directly for this effect. Research on noise isolation of buildings from exterior environmental noise sources generally supports this statement. 1 Hence, no additional adjustment is required, in this developement, to account non-diffuse exterior sound fields for typical environmental noise sources.

It is, however, necessary to incorporate the effect of noise source spectra for different basic environmental noise sources such as highways, railways, and aircraft. Fortunately, extensive numerical studies have been conducted to determine empirically this type of adjustment. 2 The form of these empirical results relates the A-weighted sound level difference, as given by equation (C.8), to the sound level reduction calculated using the STC ratings of each component of the mutli-component exterior wall. This result is:

$$
\mathrm{SLR}_{\mathrm{STC}}=\mathrm{SLR}+\mathrm{C}=\Delta \mathrm{L}_{\mathrm{A}}+\mathrm{C}-3
$$

The term SLRSTC is the sound level reduction calculated using the STC ratings of each component of the multi-component wall. The term $C$ is an empirical parameter dependent upon the type of environmental noise source.

1 For descriptions of some research, see S. Ljunggren, Sound Insulation of Windows with Respect to Traffic Noises, Report No. H-3065-A, (Gothenburg, Sweden: Ingemanssons Ingenjorsbyra $\mathrm{AB}, 1972$ ) and T. Fukinski and T. Yamamoto, "Field Measurement of Sound Insulation of Houses by the Integral of Sound Energy," Proceedings Inter-noise 75 (Sandai, Japan: 1975).

2 For descriptions of some studies, see D. S. Pallett, et al., Design Guide for Reducing Transportation Noises in and Around Buildings, National Bureau of Standards Building Science Series 84 (Washington, D.C.: U.S. Department of Commerce, 1978) and G. E. Mange, S. R. Skale, and L. C. Sutherland, Background Report on Outdoor-Indoor (EWNR) Method, Federal Highway Administration Report No. TS-77-220 (Washington, D.C.: Department of Transportation, 1978). 
The sound level reduction calculation based upon the component STC rating is:

$$
\operatorname{SLR} R_{S T C}=R_{C}-10 \log (S / A)-6
$$

where

$R_{C}$ is given by equation (C.1)

$\mathrm{S} \& \mathrm{~A}$ are defined in equation (C.5).

Based upon the numerical studies the following average values of the parameter $C$ may be used for design guidance: 1

$$
\begin{array}{ll}
C=+2( \pm 2.8) d B & \begin{array}{l}
\text { For either highway or railway } \\
\text { environmental noise spectra }
\end{array} \\
C=+4(t 3.9) d B & \begin{array}{l}
\text { For alrcraft noise spectra } \\
C=+3(t 3.6) d B
\end{array} \\
& \begin{array}{l}
\text { For a composite of highway, railway, and } \\
\text { alrcraft noise spectra. }
\end{array}
\end{array}
$$

The numercial values in parentheses are the 90 percent confidence limits for each of the mean values of the parameter $C$.

The final relationship between the A-weighted sound level difference, $\Delta \mathrm{L}_{A}$, of the MNCC provisions and the composite STC rating, $\mathbb{R}_{C}$, of the multi-component exterior wall is obtained by substituting equation (C.9) into equation (C.10) and solving for $R_{C}$.

The final result, to be used for design guidance, is

$$
R_{C}=\Delta I_{A}+10 \log (S / A)+3+C, S T C,
$$

where

$\Delta \mathrm{L}_{\mathrm{A}}$ is the A-weighted sound level reduction required for the MNCC
provisions

$S$ is the surface area of the exterior wall transmitting exterior sound into the interior receiving space

$A$ is the total sound absorption in the receiving space (average value for $500 \mathrm{~Hz}$ to $1 \mathrm{kHz}$ bands)

$C$ is the adjustment for the environmental noise source spectra (see equation (C.11))。

For average outdoor environmental noise conditions, the value $C=+3 \mathrm{~dB}$ may be used to simplify the above result. A further simplication may also be made by

1 See G. E. Mange, S. R. Skale, and L. C. Sutherland, Report No. TS-77-220.

$$
\text { C-8 }
$$


noting that an average value of the $+10 \log (\mathrm{S} / \mathrm{A})$ term is $-3 \mathrm{~dB} \cdot 1$ Hence, the adjustment for noise source spectrum is on the order of, but opposite to, the adjustment for interior space sound absorption. With these approximations, the multi-component wall STC rating is related to the A-weighted sound level reduction required by $\mathbb{M N C C}$ as:

$$
\mathrm{R}_{\mathrm{C}}=\Delta \mathrm{L}_{\mathrm{A}}+3, \mathrm{STC} \text {. }
$$

It is emphasized that the results of either equation (C.12) or equation (C.13) do not include a design margin for either flanking sound transmission or faulty construction. These considerations are judgments that must be made by the architect or acoustical consultant. For exterior walls, flanking sound transmission should not be a major problem for we 11 designed structures.1 Further, the numerical studies used to determine the empirical constant, $C$, exhibit significant variation. For example, the data of D. S. Pallett, et. al., Report No. BSS-84 (table B-1, page 153) would lead one to the conclusion that -1 is an appropriate adjustment for equation (C.13) rather than the +3 adjustment quoted.

The lengthy discussion of this subsection is presented so that the reader may understand the considerations required to relate an STC rating to an A-weighted sound level reduction. The next section uses the results of this section to determine the minimum construction cost of a multi-component wall that will achieve the MNCC provisions.

\section{C.3 DESIGN OF MINIMUM COST MULTI-COMPONENT WALLS}

The design method described in this section provides for an explicit calculation of the noise insulation required of each component of a multi-component wall such that the multi-component wall achieves a specified noise insulation value and the total construction cost of the wall is a minimum. The minimization (or optimization) technique used to achieve the final result is the Lagrange multiplier method.2 First, the total construction cost is expressed in terms of the component areas and the average cost per unit area (as a function of the noise insulation) of the components. The component cost functions used are the CDC cost equations described in Appendix A. The noise insulation required of each component is determined by minimizing the total construction cost subject to the constraint that the complete assembly of components must achieve the specified value of noise insulation.

The final results obtained are explicit expressions for the required component noise insulation. To use these results, one requires only the CDC cost equations of appendix A. It is not necessary to solve a system of equations to determine the solution, and calculations may be performed using a pocket calculator.

1 See B. H. Sharp, P. K. Kasper, and M. L. Montro1, Report No. GCR-80-250.

2 See F. H. Hildebrand, Methods of Applied Mathematics (Prentice Ha11, Inc., 1952). 


\section{C.3.1 Component Cost Equations and the Total Construction Cost}

Appendix A presents the cost equations developed for several Component Design Categories (CDC) typical of U.S. building construction practice. Each of the CDC cost equations expresses the average cost per unit area of the component ${ }^{1}$ as a linear function of the component's STC rating. Denoting the parameters related to each component by a subscript " $i$ ", the average cost per unit area for the ith component is:

$$
C_{1}=A_{1}+B_{1} R_{i} \quad \text { cost per unit area, }
$$

where

$A_{i}$ is the intercept and $B_{i}$ is the slope of a least squares curves fit of cost estimates and STC rating points for the ith component ( $B_{i}$ is always positive),

$R_{i}$ is the STC rating for the component.

As noted in Appendix $A$, each $C D C$ cost equation is defined for a limited range of STC ratings such that

$$
R_{i L} \leq R_{i} \leq \mathbb{R}_{i U}
$$

where

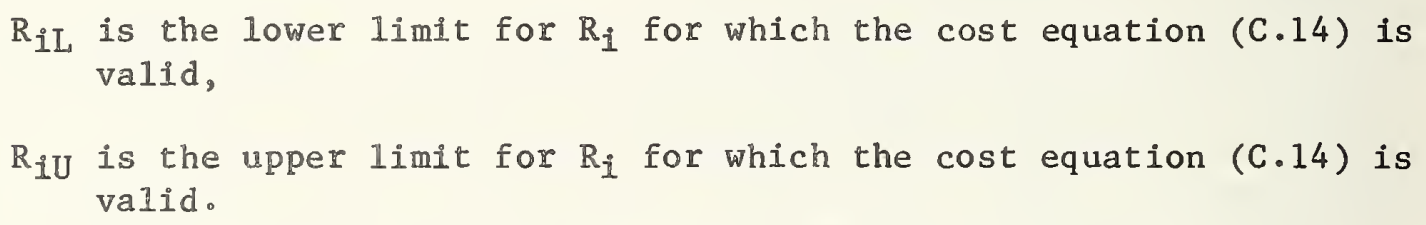

The inequality ( $C .15$ ) simply states that it is physically possible to select only values of the component STC rating, $R_{i}$, within the range of values for which the component cost equation is defined. The practical importance of this restriction is discussed in section C.3.3.

The multi-component wall comprises $\mathrm{N}$ district components each defined by a CDC cost equation. It is assumed that the total construction cost is the sum of the construction costs for each of the components. Denoting the average construction cost per unit area of the multi-component wall by $C$, the total construction cost is given by the expression ${ }^{2}$

$$
S . C=\sum_{i=1}^{N} S_{i} C_{i}=\sum S_{i}\left(A_{i}+B_{i} R_{i}\right) \text {, cost units. }
$$

1 The term "component" refers to one of the CDCs 1isted in Appendix A.

2 Unless otherwise noted all sums, $\Sigma$, are over the range $i=1, \ldots, N$.

$$
\mathrm{C}-10
$$


Solving for the average construction cost per unit area, C, one obtains:

$$
C=\sum k_{i}\left(A_{i}+B_{i} R_{i}\right) \text { cost per unit area, }
$$

where

$\mathrm{S}$ is the total wall area: $\mathrm{S}=\sum \mathrm{S}_{\mathbf{i}}$

$S_{i}$ is the wall area of the $i$ th component

$k_{i}=s_{i} / S$ is the fraction of the total wall area of the ith component.

It is important to note that the parameter $k_{i}$ satisfies the following relationships:

$$
0<k_{i}<1 \text { and } \Sigma k_{i}=1 \text {. }
$$

Equation (C.16) expresses the total construction cost in terms of the component construction costs. Equation (C.17) expresses the average construction cost per unit area in terms of the average component construction cost per unit area weighted by the fractional area of each component. Since the component STC ratings, $R_{i}$, are the only variables in equations (C.16) and (C.17), a minimum total construction cost is also a minimum average construction cost per unit area.

\section{C.3.2 Noise Insulation for Minimum Cost}

The noise insulation of a multi-component wall is determined using equation (C.1) and the average construction cost of the wall is determined using equation (C.17). Using these two results, the problem of estimating the minimum construction cost to achieve a specified noise insulation rating is completely defined. However, it is convenient first to transform the equations so that the variable is the sound transmission coefficient, $\tau_{i}$, rather than the component STC rating, $\mathrm{R}_{\mathfrak{I}}$.

The component STC rating, $R_{i}$, and the component sound transmission coefficient, $\tau_{i}$, are related by the definition

$$
R_{i} \equiv-10 \log \left(\tau_{i}\right)=-10 \log (e) \ln \left(\tau_{i}\right)
$$

where

$$
\begin{aligned}
\log () & =\log _{10}() \\
\ln () & =\log _{e}() \quad e=2.718282 .
\end{aligned}
$$

Using the definition of equation (C.19), the average construction cost per unit area given by equation (C.17) becomes: ${ }^{2}$

1 Unless otherwise noted all sums, $\Sigma$, are over the range $i=1, \ldots N$.

$$
\mathrm{C}-11
$$




$$
C=\sum k_{i}\left[A_{i}-b_{1} \text { \&n }\left(\tau_{i}\right)\right]
$$

and the composite noise insulation of the multi-component wall given by equation (C.1) becomes:

$$
\tau_{c}=\Sigma k_{i} \tau_{i}
$$

where

$A_{i}$ and $B_{i}$ are the intercept and slope of the CDC cost equation for the ith component (see equation (C.14))

$\mathrm{b}_{1}=10 \log (\mathrm{e}) \mathrm{B}_{\mathrm{i}}=4.34295 \mathrm{~B}_{\mathrm{i}}$

$k_{i}=s_{i} / S($ see equation $(C .1)$ or $(C .17)$ )

$\tau_{c}=10^{-R_{c} / 10}$ is the composite sound transmission coefficient.

The problem is to determine the sound transmission coefficients, $\tau_{i}$ ( $i=1, \ldots$, $N)$, so that the average construction cost is minimized and the composite sound transmission coefficient, $\tau_{c}$, has a specified value.

The Lagrange multiplier method is used to obtain the equations in the variable $\tau_{i}$ that must be solved to define the minimum cost design. Using the Lagrange multiplier method, one forms of the objective function, $F\left(\tau_{i}, \lambda\right)$, and the constraint function, $\phi\left(\tau_{i}\right)$, using equations (C.20). The parameter $\lambda$ is called the Lagrange multiplier.

The objective function is:

$$
F\left(\tau_{i}, \lambda\right)=\Sigma k_{i}\left[A_{i}-b_{i} \ln \left(\tau_{i}\right)\right]+\lambda \phi\left(\tau_{i}\right) \text {. }
$$

The objective function is subject to the constraint:

$$
\phi\left(\tau_{i}\right)=\sum k_{i} \tau_{i}-\tau_{c}=0 \text { 。 }
$$

The possible extrema in construction cost (maximum cost or minimum cost) are given by equations (C.16) and (C.17) for the set of numbers $\tau_{i}(i=1, \ldots, N)$ obtained by solving the system of equations:

$$
\begin{aligned}
& \frac{\partial F}{\partial \tau_{i}}=-k_{i} b_{i} / \tau_{i}+k_{i} \lambda=0 \quad i=1, \ldots N \\
& \phi\left(\tau_{i}\right)=\sum k_{i} \tau_{i}-\tau_{c}=0 .
\end{aligned}
$$

A more convenient form of the equations is obtained by expressing the Lagrange multiplier, $\lambda$, in terms of $b_{1}$ and $\tau_{1}$ and substituting this result into each of the $\mathbb{N}$ equations ( $C .22 a$ ). Doing this, one obtains the system of linear equations: 


$$
\left[\begin{array}{ccccc}
k_{1} & k_{2} & k_{3} & \cdots & k_{N} \\
-b_{2} & b_{1} & 0 & \ldots & 0 \\
-b_{3} & 0 & b_{1} & \cdots & 0 \\
\vdots & \vdots & \vdots & \vdots \\
-b_{N} & 0 & 0 & \ldots & b_{1}
\end{array}\right]\left\{\begin{array}{c}
\tau_{1} \\
\tau_{2} \\
\tau_{3} \\
\vdots \\
\tau_{N}
\end{array}\right\}=\left\{\begin{array}{c}
\tau_{c} \\
0 \\
0 \\
\vdots \\
0
\end{array}\right\} .
$$

The solution to this system of equations is ${ }^{1}$ :

$$
\tau_{i}=b_{i} \tau_{c} /\left(\sum k_{r} b_{r}\right) \quad i=1, \ldots, N \text {. }
$$

In terms of the component STC rating, $R_{i}$, one uses the relationship of equation (C.19) to obtain:

$$
R_{i}=R_{c}-10 \log \left[B_{i} /\left(\sum k_{r} B_{r}\right)\right] \quad i=1, \ldots, N
$$

Equation ( $C .25$ ) is the final result. The required component STC rating, $R_{i}$, is expressed in terms of the specified composite STC rating, $R_{c}$, of the multicomponent wall; the marginal cost of each component, $B_{i}$; and the fraction of the total area for each component, $k_{i}$. By substituting the $N$ values of the component STC ratings, $R_{i}$, given by equation (C.25) into equation (C.1), it is seen that the composite STC rating for the wal1, $R_{C}$, is obtained.

The estimated minimum construction cost is obtained by substituting the $N$ values of $R_{i}$ from equation (C.25) into the cost equations (C.16) or (C.17).

\section{C.3.3 Range of Application and Discussion of Assumptions}

The assumptions used to develop the component STC ratings given in equation (C.25) are as follows:

(1) Each component comprises on constant percentage of the total surface area of the multi-component wall,

(2) Each component is defined by its cost equation which is a linear function of the component noise insulation (STC) rating, ${ }^{2}$

(3) The total construction cost of the multi-component wall is the sum of the construction costs of each component.

1 The sum, $\Sigma$, in equations $(C .24)$ and (C.25) is for the subscript $r=1, \ldots, N$.

2 See section 4.2.4 in the main text of this report for a discussion of the practical implications of this assumption to design. 
Assumptions (1) and (2) above define the "design configuration" so that the only variables are the component noise insulation ratings, $R_{1}$. Changing either the fractional areas, $k_{1}$, or the components as defined by their cost equations, defines a new "design configuration".

Assumption (2) also requires that the component cost equation must be a linear function of the component noise insulation as described by equation (C.14). This assumption allows the problem to be formulated so that linear equations result from the use of the Lagrange multiplier method. These linear equations are solved explicitly so that numerical results can be obtained using a pocket calculator.

Assumption (3) requires that each component cost equation must be independent of the other component cost equations. For example, this assumption implies that the cost of installing a door does not depend upon the type of wall construction used. Hence, the CDC cost equations for doors and glazing include an average installation cost that is constant for all wall designs.

Physically, a restriction must be placed upon the range of composite noise insulation values, $R_{c}$, for which a minimum cost design can be realized. The method used to obtain, at the building design stage, the component noise insulation ratings, $\mathbb{R}_{\mathfrak{l}}$, given in equations (C.25) assumes that all component cost equations are defined for any required value of $R_{1}$ relative to the composite noise insulation rating, $R_{c}$. However, each component cost equation is defined over a limited range of noise insulation values as indicated by equation (C.15). Hence, the minimum cost design is obtained only for a limited range of composite noise insulation ratings, $R_{c}$, that depends upon the particular components selected for the design.

This restriction may be quantified by combining the results of equations (C.15) and (C.25). First, the component noise insulation rating, $R_{i}$, is expressed in terms of the composite noise insulation rating, $R_{c}$, as:

$$
R_{i}=R_{c}+\Delta_{i}
$$

where

$$
\Delta_{1}=-10 \log \left[B_{1} /\left(\Sigma k_{\mathbb{I}} B_{\mathbb{I}}\right)\right] \text {. }
$$

This is a restatement of equation (C.25). Substituting for $R_{i}$ from equation (C.26) into equation (C.15) one obtains:

or

$$
R_{i L} \leq R_{c}+\Delta_{i} \leq R_{i U} \quad i=1, \ldots, N
$$

$$
R_{1 L}-\Delta_{1} \leq R_{c} \leq R_{i U}-\Delta_{1} \quad i=1, \ldots, N
$$

For a design to achieve the composite noise insulation rating, $\mathrm{R}_{\mathrm{C}}$, and each component exhibit a noise insulation rating within the range $R_{i L} \leq R_{i} \leq R_{i U}$, the value of $R_{C}$ must be within the range:

$$
\begin{aligned}
& \left\{R_{i L}-\Delta_{i}\right\}_{\max } \leq R_{c} \leq\left\{R_{1 U}-\Delta_{i}\right\}_{\text {min }}, \\
& \text { C-14 }
\end{aligned}
$$


where

$$
\begin{aligned}
& \left\{R_{i L}-\Delta_{i}\right\}_{\max } \begin{array}{r}
\text { is the largest value of the set of numbers } \\
\left\{R_{i L}-\Delta_{i}\right\}, i=1, \ldots, N
\end{array} \\
& \left\{R_{i U}-\Delta_{i}\right\}_{\min } \text { is the smallest value of the set of numbers } \\
& \left\{R_{i U}-\Delta_{i}\right\}, i=1, \ldots, N .
\end{aligned}
$$

The result of equation ( $C .28$ ) indicates the range of composite noise insulation, $R_{C}$, for which equation (C.25) applies. This range of noise insulation values is the range over which a minimum cost design may be achieved given the freedom to vary the noise insulation of each component. The next section presents the methodology applicable to situations for which the noise insulation value is specified for one or more components of the multi-component wall.

\section{C.3.4 Noise Insulation with Specified Components}

In the design of a multi-component wall to meet a specified level of noise insulation, sigtuations may arise for which one or several of the components are specified based upon criteria other than the component's noise insulation. These components will exhibit a constant value of noise insulation at a constant cost. If the design includes two or more elements for which the noise insulation may be selected based upon cost, the methodology used to obtain equation (C.25) is used to obtain the minimum cost solution. An example of such a situation is an exterior wall containing doors and glazing with the basic wall structure selected for architectural features and thermal insulation performance. The minimum cost design, in this case, is determined by varying only the door and glazing noise insulation.

Suppose that an $\mathrm{N}$ component wall is composed of $\mathrm{n} \geq 2$ components for which the noise insulation may be selected based upon cost and $(N-n)$ components for which the noise insulation values and costs are constant. The multi-component wall is required to meet a composite noise insulation of $R_{c}$. The minimum cost design is the design for which the noise insulation of the $n$ variable components is given by:

$R_{i}=R_{c}-10 \log \left[1-\sum_{r=n+1}^{N} k_{r} \cdot 10^{-\left(R_{r}-R_{c}\right) / 10}\right]-10 \log \left[B_{i} / \sum_{r=1}^{n} k_{r} B_{r}\right]$,

$i=1, \ldots, n \leq N$,

where

$R_{i}$ is the noise insulation for the $i t h$ component of the minimum cost design: $i=1, \ldots, n \leq N$

$R_{i}$ is the constant value of the noise insulation for the $i$ th component: $i=n+1, n+2, \ldots, N$

$\mathrm{R}_{\mathrm{C}}$ is the composite noise insulation rating of the multi-component wal1 
$k_{i}=S_{i} / S$ is the fraction of the total area for the ith component: $i=1, \ldots, N$

$B_{i}$ is the marginal cost for the ith component cost as a function of the component ${ }^{2}$ s noise insulation, $R_{1}: C_{i}=A_{1}+B_{i} R_{i} ; i=1, \ldots, N$

$\left(B_{i} \equiv 0\right.$ for $\left.i=n+1, \ldots, N\right)$ 。

In the above result, the components with variable noise insulation are denoted by the subscripts, $i=1, \ldots, n$. The components with constant noise insulation are denoted by the subscripts $i=n+1, \ldots, N$. Equation (C.29) is analogus to equation (C.25).

As discussed in section C.3.3, a minimum cost design is defined over a limited range of composite noise insulation, $R_{c}$, defined by the limits of noise insulation $R_{i L}$ and $R_{i U}$ for each of the components $(i=1, \ldots, n)$. For the present discussion, the range of $R_{c}$ for which the minimum cost design is defined is obtained by solving equation ( $C .29$ ) for $R_{c}$ in terms of $R_{i}(i=1, \ldots, n)$. The result is:

$R_{c}=-10 \log \left\{\left[B_{1} / \sum_{r=1}^{n} k_{r} B_{r}\right]^{-1} \cdot 10^{-R_{i} / 10}+\sum_{r=n+1}^{N} k_{r} 10^{-R_{r} / 10}\right\}$,

where

$R_{i}$ is a variable for $i=1, \ldots, n$

$R_{r}$ is a constant for $r=n+1, \ldots, N$.

The limiting values of $R_{c}$ are determined by substituting the limiting values of $R_{i}=R_{i L}$ and $R_{i}=R_{I U}$ for $i=1, \ldots, n$ and selecting the largest value of the set of numbers $\left\{R_{c}\left(R_{i L}\right)\right\}$ and the smallest value of the set of numbers $\left\{R_{c}\left(R_{i U}\right)\right\}$. This is identical to procedure described in section C.3.3.

The estimated minimum average construction cost per unit area for the design is given by:

$$
C=\sum_{i=1}^{n} k_{i}\left[A_{1}+B_{i} R_{i}\right]+\sum_{i=n+1}^{N} k_{i} A_{i}
$$

The values of $R_{1}$ in equation (C.31) are given by equation (C.29). The last sum in equation ( $C .31$ ) is, of course, a constant. The next section presents examples illustrating the use of these results.

\section{C.4 EXAMPLES ILLUSTRATING THE USE OF THE EQUATIONS}

Two example problems are presented to illustrate the use of the design equations presented in section C.3. In particular, the reader should note 
that the method may be easily used in two ways. First, the method may be used to determine the noise insulation required of each component to achieve a specified composite noise insulation. Second, the method may be used to determine the total noise insulation performance range for the composite wall and the corresponding minimum construction cost range for the composite wall. The latter use of the method quantifles the range of noise insulation for which the design may be used and the cost of achieving any value of noise insulation within this range. In either case, the method is easily used and requires only a pocket calculator.

\section{C.4.1 Effect on Construction Cost of Varying Glazing Area}

This example considers a three component wall comprised of a basic structure, a door, and glazing. Each Component Design Category (CDC) is held constant. Three designs are defined using these CDCs by varying only the percentage of glazing. The example illustrates the calculation of the range of composite noise insulation, $R_{c}$, over which a minimum cost design is defined and also illustrates the effect on construction cost of varying the percentage of glazing for the Component Design Categories selected.

The three CDCs selected for this example are a frame wall with aluminum siding (component 1), a door (component 2), and glazing (component 3 ). The glazing is an aluminum frame with fixed sheet and plate glass. From table 3.2 , the data for the components are:

\section{Cost Coefficients}

Component

No. 1, Wall

No. 2, Door

No. 3, Glazing $\quad-13 \cdot 10$
$A_{i}$

0.77
$-0.63$

\section{Coeficients}

$B_{i}$

0.110

0.462

0.940
STC Limits

$R_{i L} \quad R_{i U}$

$37 \quad 50$

$20 \quad 51$

$29 \quad 47$.

For the example problem, the glazing area is varied with the total area held constant so that the three designs are defined as follows:

Component

\section{Wal1 Door Glazing}

$\begin{array}{llll}\text { Design 1 } & \mathrm{k}_{1}=0.725 & \mathrm{k}_{2}=0.175 & \mathrm{k}_{3}=0.100 \\ \text { Design 2 } & \mathrm{k}_{1}=0.675 & \mathrm{k}_{2}=0.175 & \mathrm{k}_{3}=0.150 \\ \text { Design 3 } & \mathrm{k}_{1}=0.625 & \mathrm{k}_{2}=0.175 & \mathrm{k}_{3}=0.200 .\end{array}$


The problem is to determine, for each of the above designs, the variation of the minimum construction cost over the range of composite noise insulation performance, $R_{C}$, of each design. Details of the calculations are presented for design 1 so that the reader may follow the procedures. The results for designs 2 and 3 are presented and the complete results are summarized in a plot of minimum construction cost versus noise insulation, $R_{c}$.

Equation ( $C .25)$ is the basis for the calculations and is, for this example:

$$
R_{i}=R_{C}-10 \log \left[B_{i} / \Sigma k_{r} B_{r}\right], i=1,2,3 .
$$

Using the above data for design 1, the following results are obtained:

$$
\begin{aligned}
\sum k_{r} B_{r} & =(0.725)(0.110)+(0.175)(0.462) \\
& +(0.100)(0.940)=0.2546 .
\end{aligned}
$$

For equation (C.25), the component STC ratings are:

$$
\begin{aligned}
& R_{1}=R_{c}-10 \log [0.110 / 0.2546]=R_{c}+3.6 \\
& R_{2}=R_{c}-10 \log [0.462 / 0.2546]=R_{c}-2.6 \\
& R_{3}=R_{c}-10 \log [0.940 / 0.2546]=R_{c}-5.7 .
\end{aligned}
$$

From equation ( $C .26$ ), one obtains: $\Delta_{1}=3.6, \Delta_{2}=-2.6$, and $\Delta_{3}=-5.7$.

The next step is to determine the range of $R_{c}$ over which the minimum cost design may be achieved. From equation (C.27b) and the STC limits for the components one obtains:

$$
\begin{aligned}
& \text { Component } 1: 37-3.6 \leq \mathrm{R}_{c} \leq 50-3.6 \text { or } 33.4 \leq \mathrm{R}_{\mathrm{c}} \leq 46.4 \\
& \text { Component } 2: 20+2.6 \leq \mathrm{R}_{\mathrm{c}} \leq 51+2.6 \text { or } 22.6 \leq \mathrm{R}_{\mathrm{c}} \leq 53.6 \\
& \text { Component } 3: 29+5.7 \leq \mathrm{R}_{\mathrm{c}} \leq 47+5.7 \text { or } 34.7 \leq \mathrm{R}_{\mathrm{c}} \leq 52.7 .
\end{aligned}
$$

Selecting the largest value of the lower limit and the smallest value of the upper limit, the composite noise insulation range for which the minimum cost design is defined is $34.7 \leq R_{C} \leq 46.4$. This result is rounded to $35 \leq R_{c}$ $\leq 46$.

For the composite noise insulation range $35 \leq R_{c} \leq 46$, the noise insulation values of each component, $R_{i}$, required to achieve the composite noise insulation, $R_{C}$, are obtained from equations ( $C .32$ ). The minimum construction cost for each level, $R_{C}$, of composite noise insulation is obtained using the corresponding values of $R_{i}$, the cost coefficients of the components (given above) and equation (C.17). The results of these calculations are presented in table C.1 to illustrate the relative changes in the component noise insulation. The minimum construction cost is, of course, a linear function of the composite noise insulation, $R_{C}$ 。 
Table C.1. Detailed Calculation Results for Design No. 1

\begin{tabular}{|c|c|c|c|c|c|c|c|}
\hline \multicolumn{4}{|c|}{ STC Ratings } & \multicolumn{3}{|c|}{ Construction Costs, } & \multirow{2}{*}{$\frac{\$ / s f}{C=\sum k_{i} C_{i}}$} \\
\hline$\overline{\mathrm{R}_{\mathrm{c}}}$ & $\mathrm{R}_{1}$ & $\mathrm{R}_{2}$ & $\mathrm{R}_{3}$ & $\mathrm{C}_{1}{ }^{\mathrm{a}}$ & $\mathrm{C}_{2}$ & $\mathrm{C}_{3}$ & \\
\hline 35 & 38.6 & 32.4 & 29.3 & 3.62 & 15.74 & 14.44 & 6.82 \\
\hline 36 & 39.6 & 33.4 & 30.3 & 3.73 & 16.21 & 15.38 & 7.08 \\
\hline 38 & 41.6 & 35.4 & $32 \cdot 3$ & 3.95 & 17.13 & 17.26 & 7.59 \\
\hline 40 & 43.6 & 37.4 & 34.3 & 4.17 & 18.05 & 19.14 & 8.10 \\
\hline 42 & 45.6 & 39.4 & 36.3 & 4.39 & 18.97 & 21.02 & 8.61 \\
\hline 44 & 47.6 & 41.4 & 38.3 & 4.61 & 19.90 & 22.90 & 9.12 \\
\hline 46 & 49.6 & 43.4 & $40 \cdot 3$ & 4.83 & 20.82 & 24.78 & 9.62 \\
\hline
\end{tabular}

a Component 1 is the wall, Component 2 is the door, Component 3 is the glass, $k_{1}=0.725, k_{2}=0.175$, and $k_{3}=0.100$. 
Following the same steps, the results for design 2 are:

$$
\begin{array}{lll}
\text { Component 1 } & \mathrm{R}_{1}=\mathrm{R}_{\mathrm{C}}+4.3 ; 32.7 \leq \mathrm{R}_{\mathrm{c}} \leq 45.7 \\
\text { Component } 2 & \mathrm{R}_{2}=\mathrm{R}_{\mathrm{c}}-1.9 ; 21.9 \leq \mathrm{R}_{\mathrm{C}} \leq 52.9 \\
\text { Component } 3 & \mathrm{R}_{3}=\mathrm{R}_{\mathrm{c}}-5.0 ; 34.0 \leq \mathrm{R}_{\mathrm{C}} \leq 52.0
\end{array}
$$

and the minimum cost design is defined for the range of composite STC ratings: $34 \leq R_{c} \leq 46$.

The results for design 3 are:

$$
\begin{array}{lll}
\text { Component 1 } & \mathrm{R}_{1}=\mathrm{R}_{\mathrm{c}}+4.9 ; 32.1 \leq \mathrm{R}_{\mathrm{c}} \leq 45.1 \\
\text { Component } 2 & \mathrm{R}_{2}=\mathrm{R}_{\mathrm{c}}-1.4 ; 21.4 \leq \mathrm{R}_{\mathrm{C}} \leq 52.4 \\
\text { Component } 3 & \mathrm{R}_{3}=\mathrm{R}_{\mathrm{c}}-4.5 ; 33.5 \leq \mathrm{R}_{\mathrm{c}} \leq 51.5
\end{array}
$$

and the minimum cost design is defined for the range of composite STC ratings: $33 \leq R_{c} \leq 45$.

The above results, define the minimum construction cost for the three component wall as a linear function of the composite STC rating of the wall over a range of the STC rating. For each design, the cost-STC functions are:

$$
\begin{array}{cc}
\text { Design } 1 \text { (10 percent glazing) } \mathrm{C}=-1.92+0.250 \mathrm{R}_{\mathrm{C}} \\
& 35 \leq \mathrm{R}_{\mathrm{C}} \leq 46 \\
& \\
\text { Design } 2 \text { (15 percent glazing) } \mathrm{C}= & -2.80+0.296 \mathrm{R}_{\mathrm{C}} \\
& 34 \leq \mathrm{R}_{\mathrm{C}} \leq 46 \\
& \\
\text { Design 3(20 percent glazing) } \mathrm{C}= & -3.49+0.338 \mathrm{R}_{\mathrm{C}} \\
& 33 \leq \mathrm{R}_{\mathrm{C}} \leq 45 .
\end{array}
$$

The minimum cost-STC functions given above are represented in figure C.1. For this example, increasing the percentage of glazing increases both the cost per unit area at a constant value of $R_{C}$ and the marginal cost per unit area (the coefficient of $R_{C}$ in the above results). Further, based upon the noise insulation range of the components, each of the above designs are limited on the upper end of the $R_{C}$ range by the wall component and on the lower end of the $R_{C}$ range by the glazing component. Using the method described in section C.3.4, the minimum cost design can be extended to values of $R_{c}$ both above and below the $R_{C}$ limits indicated for each design. To extend the cost-STC functions above the $R_{c}$ limit for a design, the wall component is held constant at $R_{1}=50$ and the door and glazing STC ratings are determined using equation (C.29). To extend the cost-STC functions below the $R_{c}$ limit for a design, the glazing is held constant at $\mathrm{R}_{3}=29$ and the door and wall STC ratings are determined using equation ( $\mathrm{C} .29$ ). Hence, the methods presented in section C.4 allow the designer to estimate the cost-STC function over the entire range of composite STC ratings 


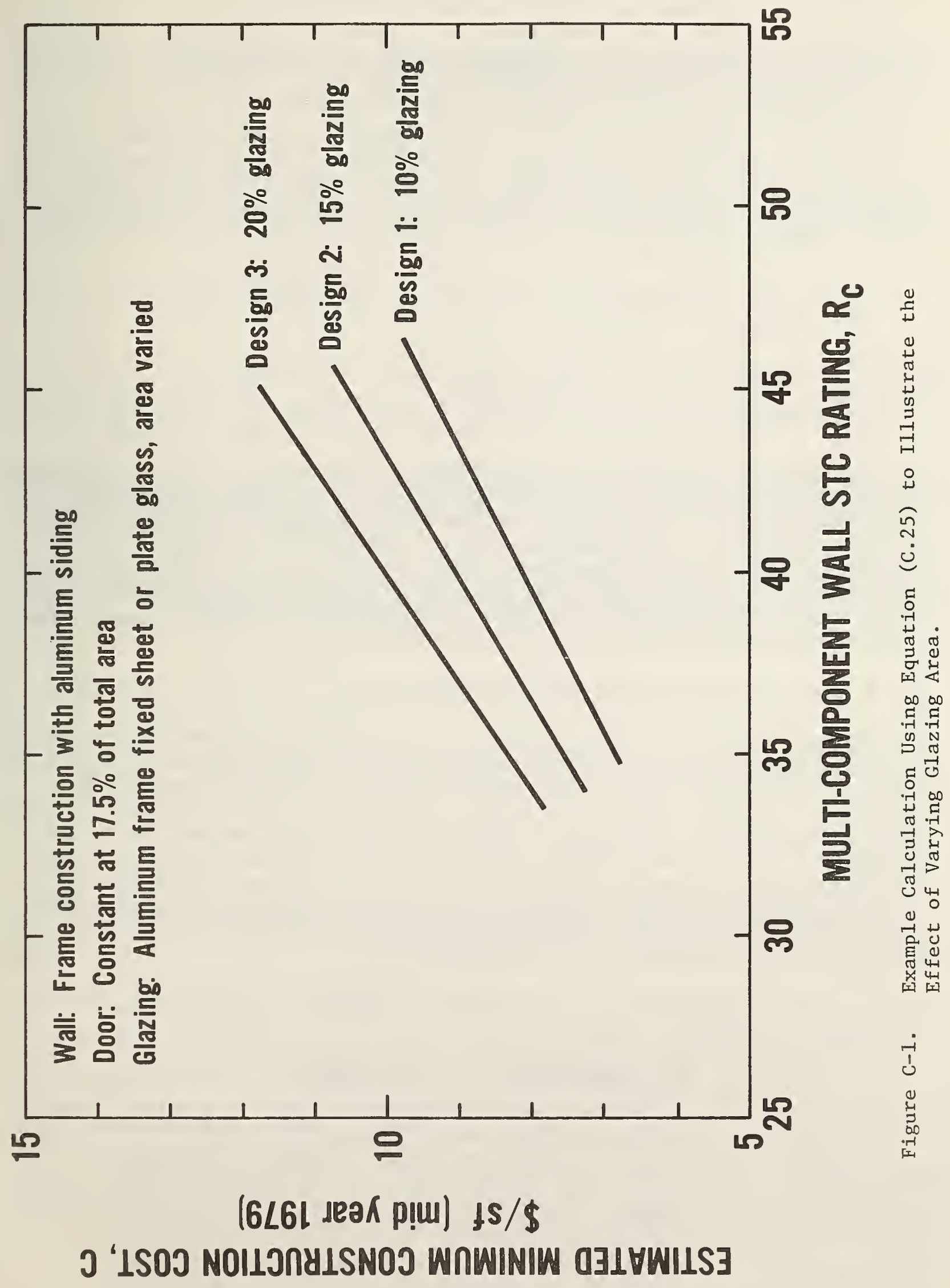


representing the complete STC performance range of all components. This type of problem is illustrated in the next example.

Finally, it is important to note that for a constant value of $R_{c}$ each of the above designs represent a different combination of component STC ratings required to achieve the value of $R_{c}$. For this example and setting $R_{c}=40$, the required component STC ratings for each design are (rounded to the nearest integer value):

$\begin{array}{llll} & \text { Wall } & \text { Door } & \text { Glazing } \\ \text { Design 1 } & \mathrm{R}_{1}=44 & \mathrm{R}_{2}=37 & \mathrm{R}_{3}=34 \\ \text { Design 2 } & \mathrm{R}_{1}=44 & \mathrm{R}_{2}=38 & \mathrm{R}_{3}=35 \\ \text { Design 3 } & \mathrm{R}_{1}=45 & \mathrm{R}_{2}=39 & \mathrm{R}_{3}=36\end{array}$

For this example, the differences in component STC ratings are not too dramatic in that the total variation in component STC is less than 3 units between any two of the designs. However, the marginal costs of each component, $B_{i}$, are rather significant. For example, each unit change in the glazing STC rating represents a cost of $\$ 0.94$ per square foot of glazing. The method does give the architect a technique for initially selecting the component noise insulation performance requirements so that the design may be refined to meet the total requirements of the applicable building code.

\section{C.4.2 Noise Insulation with Specified Components}

This example illustrates the calculation procedure used if the noise insulation of one or more components is held constant and the noise insulation ratings of the remaining components (two or more) may be selected using the method described in section $\mathrm{C} .3 .4$. The example considers a three component wall. The basic wall structure comprises 80 percent of the total area and has an STC rating of 39 with a construction cost of $\$ 3.42$ per square foot. The doors and the glazing each comprise 10 percent of the total wall area. The glazing is aluminum frame double hung windows with sheet and plate glass. The problem is to determine the estimated minimum construction cost per unit area as a function of the composite wall STC rating, $\mathbb{R}_{C}$.

From the above information and the CDC cost equations in Appendix $A$, the data for this example are:

\section{Cost Coefficients}

\begin{tabular}{lrc} 
Component & \multicolumn{1}{c}{$\mathrm{A}_{i}$} & \multicolumn{1}{c}{$\mathrm{B}_{i}$} \\
No. 1, Door & 0.77 & 0.462 \\
No. 2, Glazing & -12.66 & 0.938 \\
No. 3, Wal1 & 3.42 & $* * * *$
\end{tabular}

\section{STC Limits}

$\begin{array}{ccc}\mathrm{R}_{\mathrm{iL}} & \mathrm{R}_{\mathrm{iU}} & \mathrm{k}_{\mathrm{i}}=\mathrm{s}_{\mathrm{i}} / \mathrm{s} \\ 20 & 51 & 0.1 \\ 29 & 47 & 0.1\end{array}$

$\mathrm{R}_{3}=39$

0.80 
The first step in the calculation is to determine the range of $R_{c}$ for which equation (C.29) applies. To do this, equation (C.30) is used to determine the relationship between a component's STC rating, $R_{i}$, and the composite wall STC rating, $R_{C}$. For the door (component 1 ) and the above data, equation (C.30) is:

$$
R_{c}=-10 \log \left[0.303 \cdot 10^{-R_{1} / 10}+0.8 \cdot 10^{-3.9}\right] \cdot
$$

Substituting the STC limits $R_{1 L}=20$ and $R_{1 U}=51$ for $R_{1}$ in the above result, the range for composite wall STC ratings is $25 \leq R_{c} \leq 39.9$.

For the glazing (component 2) and the above data equation (C-30) is:

$$
\mathrm{R}_{c}=-10 \log \left[0.8 \cdot 10^{-3.9}+0.149 \cdot 10^{-\mathrm{R}_{2} / 10}\right] .
$$

Substituting the STC 1 imits $R_{2 L}=29$ and $R_{2 U}=47$ for $R_{2}$ in the above result, the range for composite wall STC ratings is $35.4 \leq R_{c} \leq 39.8$.

The above results define the STC range $35 \leq \mathrm{R}_{\mathrm{c}} \leq 40$ as the range over which one may determine a minimum cost design. This range is established by the STC limits of glazing (component 2).

The STC ratings for the door and the glazing are next determined using equation (C.29). Performing the calculations indicated in equation (C.29) using the data for this example, one obtains:

$$
\begin{aligned}
& R_{1}=R_{c}-10 \log \left[1-0.8 \cdot 10^{-\left(39-R_{c}\right) / 10}\right]-5.2 \\
& R_{2}=R_{c}-10 \log \left[1-0.8 \cdot 10^{-\left(39-R_{c}\right) / 10}\right]-8.3,
\end{aligned}
$$

where

$$
35 \leq R_{c} \leq 40
$$

The STC ratings, $R_{1}$ and $R_{2}$, given above represent the minimum cost design for the range $35 \leq R_{C} \leq 40$. The results of these calculations are presented in table C.2.

At the upper limit of the design range $\left(R_{C}=40\right)$, the minimum cost design is defined by the component STC ratings: $R_{1}=50, R_{2}=47$, and $R_{3}=39$. At the lower limit of the design range $\left(R_{c}=35\right)$, the minimum cost design is defined by the component STC ratings: $R_{1}=32, R_{2}=29$, and $R_{3}=39$. Whereas the minimum cost design utilizes the entire performance range of the glazing $\left(29 \leq R_{2} \leq 47\right)$, the minimum cost design utilizes door components over the range of $3 \overline{2} \leq \mathrm{R}_{1} \leq 50$. Since the performance range of door components is $20 \leq R_{1} \leq 51$, the composite noise insulation range for the design may be increased beyond the minimum cost design range by varying the door STC rating. For values of $R_{c} \leq 35$, the door STC rating would be selected in the range $20 \leq R_{1} \leq 32$. For values of $R_{c} \geq 40$,

$$
\mathrm{C}-23
$$


the door STC rating would be selected in the range $50 \leq R_{1} \leq 51$. Obviously, the variation of the door STC rating between STC 50 and STC 51 is an academic point. However, one must generally consider the extension of the STC range both above and below the minimum cost design range.

To develop the cost-STC values for $R_{C} \leq 35$, the door STC ratings are varied over the range $20 \leq R_{1} \leq 32$ with the glazing STC rating held constant at 29 and the wall STC rating held constant at 39. The composite STC rating is calculated using equation (C.1). For this example, the composite STC rating is:

$$
R_{c}=-10 \log \left[0.1 \cdot 10^{-R_{1} / 10}+0.1 \cdot 10^{-2.9}+0.8 \cdot 10^{-3.9}\right]
$$

or

$$
R_{c}=-10 \log \left[0.1 \cdot 10^{-R_{1} / 10}+2.266 \cdot 10^{-4}\right]
$$

where

$$
20 \leq R_{1} \leq 32
$$

The cost-STC curve for $R_{c} \leq 35$ is developed by substituting values of $R_{1}$ into the above result to calculate $R_{C}$. The construction cost is calculated using these values of $R_{1}$ and the constant costs for the glazing and the wall as indicated by equation ( $C .17$ ). The results of these calculations for this example problem are presented in table C.3.

The resules may also be plotted as construction cost versus the composite STC rating $R_{C}$. Figure $C .2$ represents such a plot. The solid line in figure C.2 represents the minimum cost or optimum design and corresponds to the results in table C.2. The dashed line represents the extension of the optimum design obtained by decreasing the door STC rating as described above. The points defining the dashed curve are presented in table C.3. For completeness, one point is indicated at the upper limit of the optimum design curve that corresponds to the design utilizing the component STC ratings $R_{1}=51, R_{2}=47$, and $\mathrm{R}_{3}=39$.

Another curve is presented in figure C.2 illustrating an additional example using a wall component with an STC rating of 51 at a construction cost of 5.85 dollars per square foot instead of the STC 39 wall described above. All other data are identical to the example problem discussed above. In both examples, the minimum cost or optimum design utilizes the entire noise insulation performance range of the glazing component. However, it is evident that the general shape of the cost-STC curve is quite different for the two examples. Also, it is evident that the minimum cost or optimum design STC range is different for the two examples. The comparison illustrates the significance of component or CDC selection since any component will exhibit a different contribution to the tota1 noise insulation depending upon the performance of a11 other components. The methodology described here, however, allows the architect to evaluate different designs and improve the productivity of the building design process. 
Table C.2. Calculations for Example Problem for Minimum Cost STC Design Range

\begin{tabular}{|c|c|c|c|c|c|c|c|}
\hline \multicolumn{4}{|c|}{ STC Ratings } & \multicolumn{4}{|c|}{ Construction Costs, $\$ / s f$} \\
\hline $\mathrm{R}_{\mathrm{c}}$ & $\mathrm{R}_{1}$ & $\mathrm{R}_{2}$ & $\mathrm{R}_{3}$ & $\mathrm{C}_{1}^{\mathrm{a}}$ & $\mathrm{C}_{2}$ & $\mathrm{C}_{3}$ & $c=k_{i} C_{i}$ \\
\hline 35.4 & 32.1 & 29.0 & 39 & 15.62 & 14.55 & 3.42 & 5.75 \\
\hline 36 & 33.0 & 29.9 & 39 & 16.06 & 15.44 & 3.42 & 5.89 \\
\hline 37 & 34.9 & 31.8 & 39 & 16.90 & 17.15 & 3.42 & 6.14 \\
\hline 38 & 37.2 & 34.1 & 39 & 17.98 & 19.34 & 3.42 & 6.47 \\
\hline 39 & 40.8 & 37.7 & 39 & 19.64 & 22.72 & 3.42 & 6.97 \\
\hline 39.8 & 50.1 & 46.9 & 39 & 23.88 & 31.34 & 3.42 & 8.28 \\
\hline
\end{tabular}

a Component 1 is the door, Component 2 is the glass, Component 3 is the wall, $k_{1}=0.1, k_{2}=0.1$, and $k_{3}=0.8$.

Table C.3. Calculations for Example Problem for Varying Door STC Rating

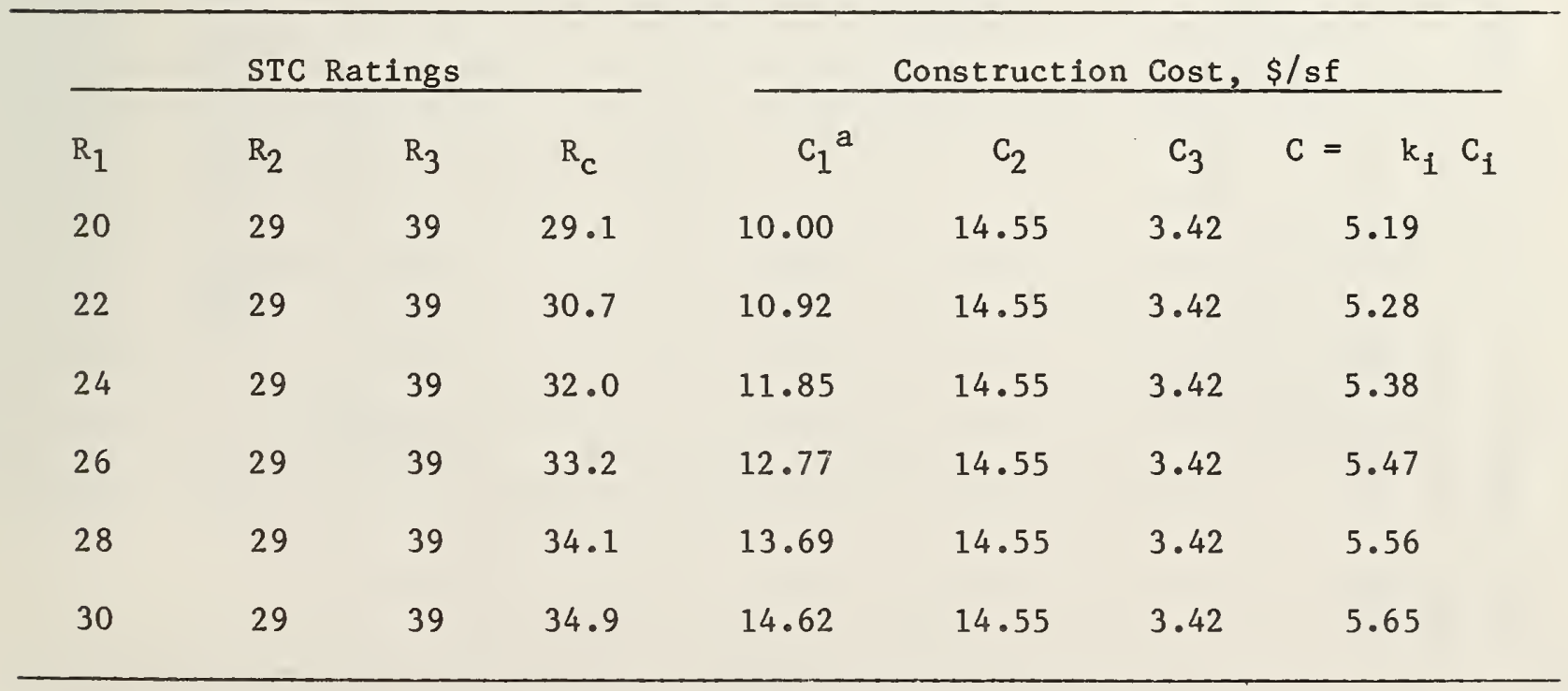

a Component 1 is the door, Component 2 is the glass, Component 3 is the wall, $\mathrm{k}_{1}=0.1, \mathrm{k}_{2}=0.1$, and $\mathrm{k}_{3}=0.8$. 


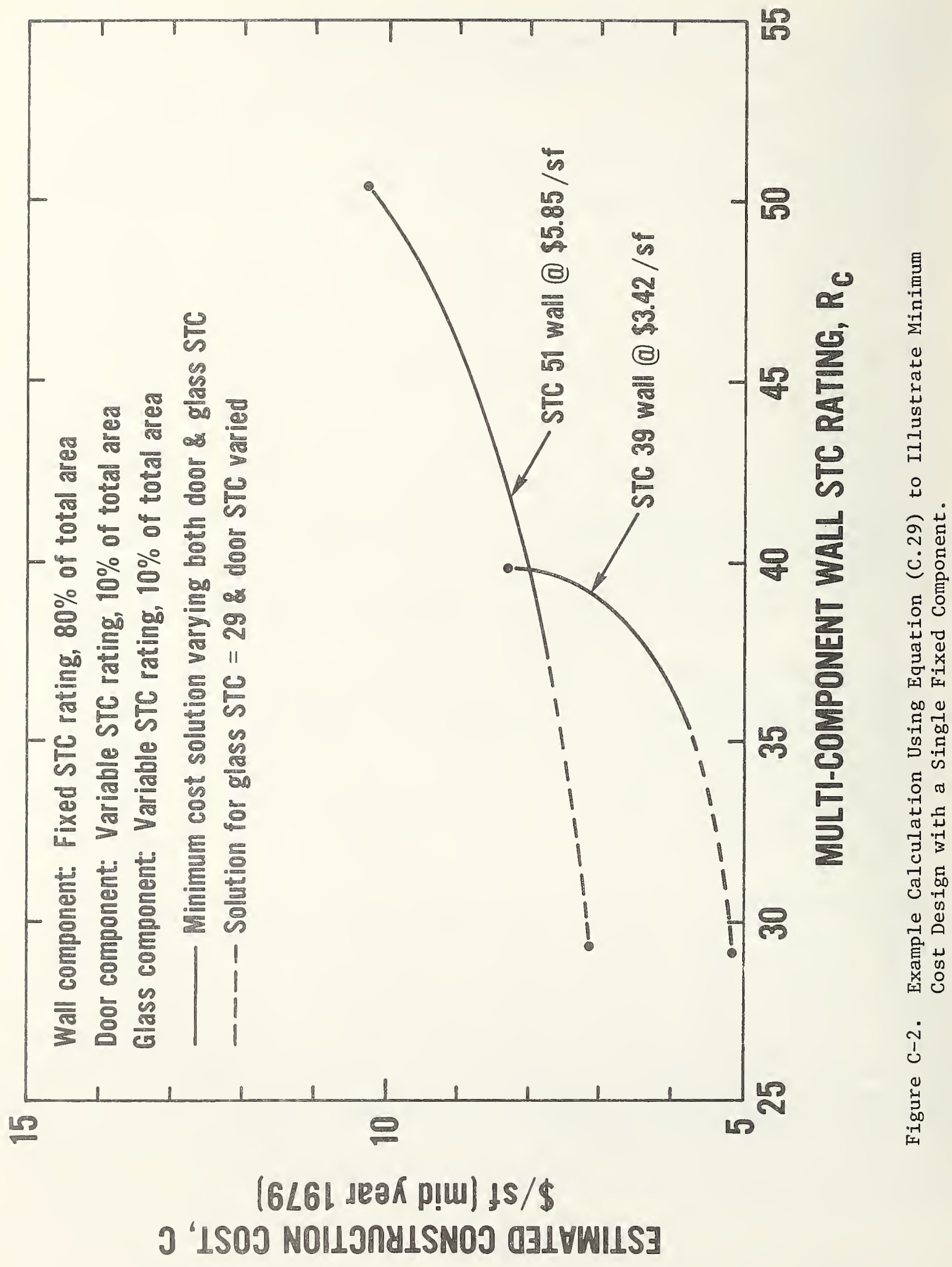


4. TITLE AND SUBTITLE

METHOD FOR ASSESSING COSTS OF NOISE CONTROL REQUIREMENTS IN MULTIFAMILY RESIDENTIAL AND EDUCATIONAL BUILDINGS

\section{AUTHOR(S)}

Stephen F. Weber, Fred F. Rudder, Jr., and Michael J. Boehm
6. PERFORMING ORGANIZATION (If joint or other than NBS, see instructions)
7. Contract/Grant No.
MATIONAL BUREAU OF STAMDARDS
DEPARTMENT OF COMMERCE
WASHINGTON, D.C. 20234
8. Type of Report \& Period Covered Final

9. SPONSORING ORGANIZATION NAME AND COMPLETE ADDRESS (Street, City, State, ZIP)

Environmental Protection Agency

Office of Noise Abatement and Control

Washington, D.C. 20460

\section{SUPPLEMENTARY NOTES}

$\square$ Document describes a computer program; SF-185, FIPS Software Summary, is attached.

11. ABSTRACT (A 200-word or less factual summary of most significant information. If document includes a significant bibliography or literature survey. mention it here)

This report presents a methodology developed to measure the cost impacts of acoustical performance requirements for new buildings. The methodology can be applied to a wide range of noise control requirements. The cost items addressed by this methodology are expected changes in construction costs, the cost of acoustical testing to certify levels of performance, code administration costs, and energy savings due to modifications of the building envelope. The building components considered, which are those most commonly affected by noise control requirements, are doors, windows, interior walls, exterior walls, and floor/ ceiling assemblies. The basic cost assessment method consists of linear cost estimation equations for most component designs commonly used in educational and multifamily residential buildings. Each equation relates the acoustical performance of the design to its construction cost so that construction costs associated with alternate levels of acoustical performance can be compared. The methodology also includes a cost minimization model useful for selecting the least-cost design for a particular level of acoustical performance.

12. KEY WORDS (SIX to twelve entries; alphabetical order; capitalize only proper names; and separate key words by semicolons) acoustical design; acoustics; architectural design; building codes; building economics; construction costs; cost minimization; economic impact; economics; energy: model code; noise control

13. AVAILABILITY

[X] Unlimited

$\square$ For Official Distribution. Do Not Release to NTIS [.] Order From Superintendent of Documents, U.S. Government Printing Office, Washington, D.C.
20402 .

[X] Order From National Technical Information Service (NTIS), Springfield, VA. 2216I

14. NO. OF PRINTED PAGES

\section{7}

15. Price

$\$ 11.00$ 

